Caleidociclos

Reginaldo Alexandre Da Silva 

Data de Depósito:

Assinatura:

\section{Reginaldo Alexandre Da Silva}

\section{Caleidociclos}

Dissertação apresentada ao Instituto de Ciências Matemáticas e de Computação - ICMC-USP, como parte dos requisitos para obtenção do título de Mestre em Ciências - Programa de Mestrado Profissional em Matemática. VERSÃO REVISADA

Área de Concentração: Matemática

Orientador: Prof. Dr. Sérgio Luís Zani

USP - São Carlos

Março de 2017 
Ficha catalográ Eca elaborada pela Biblioteca Prof. Achille Bassi e Seção Técnica de Informática, ICMC/ USP, com os dados fornecidos pelo(a) autor(a)

D229c Silva, Reginaldo Alexandre
Caleidociclos / Reginaldo Alexandre Da Silva;
orientador Sérgio Luís Zani. - São Carlos - SP,
2017.
113 p.
Dissertação (Mestrado - Programa de Pós-graduação
em Mestrado Profissional em Matemática em Rede
Nacional) - Instituto de Ciências Matemáticas e de
Computação, Universidade de São Paulo, 2017.
1. Caleidociclo. 2. Simetria axial. 3. Simetria
rotacional. 4. Polígonos. 5. Poliedros. 6. Teorema
de Pitágoras. 7 . Aplicação da lei dos cossenos.
8. Aplicação da relação fundamental da trigonometria.
I. Zani, Sérgio Luís, orient. II. Título.




\section{Reginaldo Alexandre Da Silva}

\section{Kaleidocycles}

Master dissertation submitted to the Instituto de Ciências Matemáticas e de Computação - ICMCUSP, in partial fulfillment of the requirements for the degree of Mathematics Professional Master's Program. FINAL VERSION

Concentration Area: Mathematics

Advisor: Prof. Dr. Sérgio Luís Zani

USP - São Carlos

March 2017 

Dedico este trabalho à todos os meus professores, desde o meu primeiro ano escolar até os atuais, sem eles muito do que conqui stei não seria possível. 

Agradeço primei ramente à minha esposa Ana Maria, que me deu muito apoio, principalmente nos deveres da casa, me dando mais tempo para os estudos; e minha fil ha Sofia que muitas vezes teve que entender que a pouca atenção que teve nesse período foi para que eu pudesse me empenhar mais nesse trabal ho.

Também agradeço aos meus amigos de turma do PROFMAT, afinal foram muitas horas estudando juntos nas aulas regulares, nas dúvidas via internet, nas semanas intensivas de estudo na USP, nos debates acal orados, até mesmo sem sal as de estudos.

Por fim, agradeço ao ICMC pel apossibilidade de concluir este trabal ho da rede PROFMAT nesta unidade. 

" Viver e não ter a vergonha de ser feliz, Cantar (e cantar e cantar), A beleza de ser um eterno aprendiz" (Gonzaguinha) 



\section{RESUMO}

DA SILVA, R. A.. Caleidociclos. 2017. 113 f. Dissertação (Mestrado em Ciências-Programa de Mestrado Profissional em Matemática) - Instituto de Ciências Matemáticas e de Computação (ICMC/USP), São Carlos-SP.

Os cal eidociclos têm sido utilizados como forma artística de apresentação de imagens, pinturas ou como parte de trabal hos artísticos, principal mente de imagens com simetrias; talvez os mais conhecidos sejam os trabal hos de M. C. Escher. As poucas publicações encontradas da teoria matemática envolvida nos cal eidociclos dão base para imaginar e criar aplicações no desenvolvimento de habilidades e competências trabal hadas na escola. Para aumentar as possi bilidades de aplicações de concei tos, teoremas e rel ações matemáticas estudadas no ensino básico, o presente trabal ho apresenta al gumas propostas de atividades utilizando os cal ei dociclos. As propostas foram elaboradas de acordo com o nível de ensino, ou seja, simetrias para o $7^{\circ}$ ano, teorema de Pitágoras para os $8^{\circ}$ e $9^{\circ}$ anos do Ensino Fundamental, lei dos cossenos e relação fundamental da trigonometria para a $1^{a}$ série e volume e área de superfície de sólidos geométricos para $2^{\mathrm{a}}$ série do Ensino Médio; al gumas das propostas apresentam variações para se adequar ao nível de desenvolvimento em que a turma se encontra. Todos os moldes utilizados e outras possi bilidades de cal eidociclos, incluindo sólidos encai xantes aos cal eidociclos, foram organizados ao final deste trabal ho em um dos apêndices. Há também um apêndice com outros tipos de sólidos geométricos com movimentos, que podem ser usados no mesmo intuito de aplicação diferenciada da geometria espacial .

Palavr as-chave: Cal eidociclo, Simetria axial, Simetria rotacional, Polígonos, Poliedros, Teorema de Pitágoras, Aplicação da lei dos cossenos, A plicação da relação fundamental da trigonometria 



\section{ABSTRACT}

DA SILVA, R. A.. Caleidociclos. 2017. 113 f. Dissertação (Mestrado em Ciências-Programa de Mestrado Profissional em Matemática) - Instituto de Ciências Matemáticas e de Computação (ICMC/USP), São Carlos-SP.

Kal eidocycles have been used as an artistic form of presentation of pictures, paintings or a part of artworks, especially images with symmetries; perhaps the best known works are M. C. Escher's. The few finded publications of the mathematical theory related to these threedimensional rings give rise to imagine and create applications for developing skills to be worked in classroom. In order to increase the possibility of applications of concepts, theorems and mathematical relations, the present work proposes some activities deal ing with kal eidocycles. The proposals were prepared in accordance with the student's level of education, i.e., symmetries for the 7th grade, the Pythagorean theorem for the 8th and 9th grades, law of cosines and the fundamental relation of trigonometry, volume and surface area of geometric solids for high school students; some of the proposals have variations to suit the level of development in which the class is at. All the molds used and other possibilities of kal eidocycles, including solids which fit into kal eidocycles, were organized at the end of this dissertation in one of the appendices. There is also an appendix with other types of mobile geometric solids that can be used in the same purpose in different applications of spatial geometry.

Key-words: Kal eidocycles, Symmetry of reflection, Rotational symmetry, Polygon, Polyhedron, Pythagorean theorem, Application of the law of cosines, Application of the fundamental relation of trigonometry. 



\section{LISTA DE ILUSTRAÇÕES}

Figura 1 - Si metrias na Natureza e nas Construções . . . . . . . . . . . . . . 27

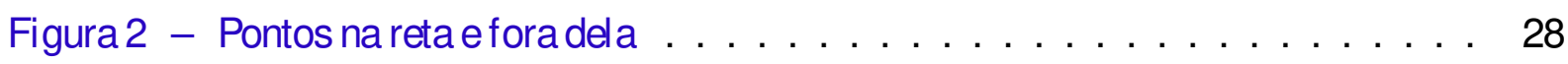

Figura 3 - Eixo de Simetria Axial e Espel hamento . . . . . . . . . . . . . . . . . 29

Figura 4 - Rotação $\theta$ de $\mathrm{P}$ a partir de $\mathrm{O} \ldots \ldots \ldots$. . . . . . . . . . . 29

Figura 5 - Si metrias Rotacionais do ponto $\mathrm{P}$ a partir de $\mathrm{O}$ com ângulo $\theta$. . . . . . 30

Figura 6 - Simetria Rotacional de $60^{\circ} \ldots \ldots \ldots \ldots$. . . . . . . . 30

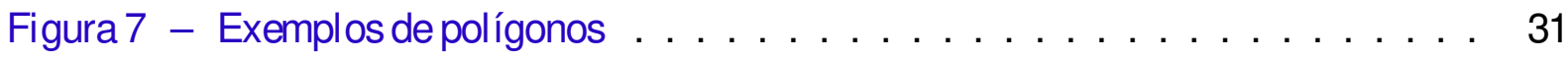

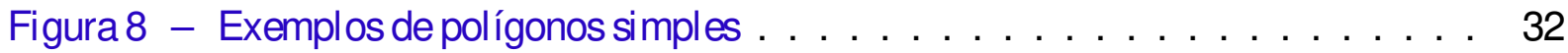

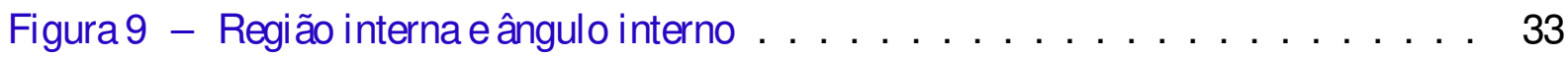

Figura 10 - Polígonos Regulares . . . . . . . . . . . . . . . . . . . . 33

Figura 11 - Polígono Convexo e Não-Convexo . . . . . . . . . . . . . . . . 34

Figura 12 - Região Poligonal . . . . . . . . . . . . . . . . . . . . . 34

Figura 13 - Exemplos de Poliedros . . . . . . . . . . . . . . . . . . 35

Figura 14 - Poliedros convexo e não-convexo . . . . . . . . . . . . . . . . 35

Figura 15 - Poliedros Regulares . . . . . . . . . . . . . . . . . . 36

Figura 16 - Cal eidociclo . . . . . . . . . . . . . . . . . . . . . . 37

Figura 17 - Caleidociclosfechados variados com imagens axial erotacionalmente simétricas 38

Figura 18 - Exemplo de cal ei dociclo com seis tetraedros não-regulares . . . . . . . . . 38

Figura 19 - Cal eidociclo regular de oito tetraedros regulares e cal eidociclo não-regular de oito tetraedros . . . . . . . . . . . . . . . . . 39

Figura 20 - Cal eidociclo regul ar de dez tetraedros regul ares localizado no espaço . . . . 39

Figura 21 - Cal eidociclo de oito tetraedros regulares . . . . . . . . . . . . . . 41

Figura 22 - Oito tetraedros regulares . . . . . . . . . . . . . . . . . . 41

Figura 23 - Secção transversal do cal eidociclo de oito tetraedros regulares . . . . . . . . 42

Figura 24 - Tentativa de cal eidociclo fechado com tetraedros regul ares . . . . . . . . 42

Figura 25 - Corte transversal da tentativa . . . . . . . . . . . . . . . 43

Figura 26 - Hexágono do Corte Transversal . . . . . . . . . . . . . . . . . . 44

Figura 27 - Cal eidociclo fechado com oito tetraedros não-regulares . . . . . . . . . . 44

Figura 28 - Cal eidociclo fechado com dez tetraedros não-regulares . . . . . . . . . 45

Figura 29 - Sequência da construção da reflexão . . . . . . . . . . . . . . . . . 48

Figura 30 - Trabal hos de Simetria Axial em papel A3 real izados por al unos de $7^{\circ}$ ano . 49

Figura 31 - Exemplos para criar simetria rotacional . . . . . . . . . . . . . . 52

Figura 32 - Simetria Rotacional com e sem Simetria Axial . . . . . . . . . . . . . 52 
Figura 33 - Exemplo de como montar o cal eidociclo - parte $1 \ldots \ldots$. . . . . 53

Figura 34 - Exemplo de como montar o cal eidociclo - parte $2 \ldots \ldots \ldots 6$

Figura 35 - Planificação com oito tetraedros regulares . . . . . . . . . . . 60

Figura 36 - Triângulo isósceles de base a e altural/ $2 \ldots \ldots \ldots$. . . . . . . . 62

Figura 37 - Planificação do cal eidocicl o fechado com 12 tetraedros (base hexagonal) . . 64

Figura 38 - Sequência da construção da mal ha . . . . . . . . . . . . . . 66

Figura 39 - Notações para o triângulo isósceles . . . . . . . . . . . . . . . . 67

Figura 40 - Metade do triângulo isósceles da Figura $39 \ldots \ldots$. . . . . . . . . . . . . . . . 68

Figura 41 - Triângulo Isósceles da Mal ha . . . . . . . . . . . . . . . 69

Figura 42 - Triângulo Isósceles base para mal ha . . . . . . . . . . . . . . 69

Figura 43 - Milagre Shinsei e seus caleidociclos . . . . . . . . . . . . . 71

Figura 44 - Medidas do tetraedro a partir do cubo . . . . . . . . . . . . . 72

Figura 45 - Planificação de dois tetraedros do Milagre Shinsei $\ldots \ldots \ldots$. . . . . 72

Figura 46 - Planificação de metade do cal eidociclo . . . . . . . . . . . . 73

Figura 47 - Cubo invertível . . . . . . . . . . . . . . . 73

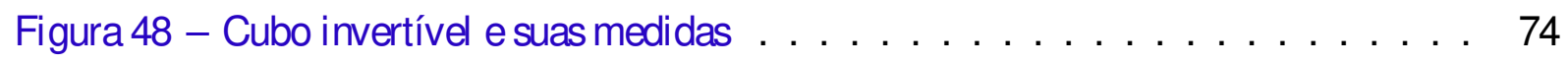

Figura 49 - Planificação de metade do Cubo Invertível . . . . . . . . . . . . . 76

Figura 50 - Os dois cal eidociclos do Milagre Shinsei . . . . . . . . . . . . . 77

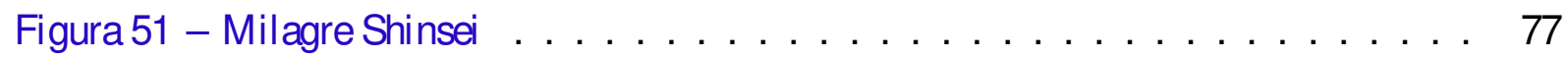

Figura 52 - Milagre Shinsei Modificado . . . . . . . . . . . . . . . . . 78

Figura 53 - Poliedro com "buraco" interno . . . . . . . . . . . . . . . . . . 79

Figura 54 - Quatro posições com forma de triângulo equiláteros . . . . . . . . . 80

Figura 55 - O cal eidociclo lembrando um cubo . . . . . . . . . . . . . . 80

Figura 56 - Cal eidociclo de Seis Tetraedros com Desenhos . . . . . . . . . . . . . 88

Figura 57 - Cal eidociclo de Seis Tetraedros sem Desenhos . . . . . . . . . . . . . 89

Figura 58 - Caleidociclo Fechado com 12 Tetraedros . . . . . . . . . . . . . 90

Figura 59 - Caleidociclo Cubo Invertível . . . . . . . . . . . . . . 91

Figura 60 - Raio Do Cubo Invertível . . . . . . . . . . . . . . . . . . . . 92

Figura 61 - Terça Parte do Cal eidociclo Cubo Invertível . . . . . . . . . . . . . 93

Figura 62 - Terça Parte do Raio do Cubo Invertível . . . . . . . . . . . . . . . . 94

Figura 63 - Caleidociclo Milagre de Shinsei - Metade do Molde . . . . . . . . . . . 95

Figura 64 - Cal eidociclo Milagre de Shinsei - Molde com dois tetraedros . . . . . . . 96

Figura 65 - Caleidociclo Milagre de Shinsei - 4 Moldes com dois tetraedros . . . . . . 97

Figura 66 - Cal eidociclo de 8 Tetraedros Regulares . . . . . . . . . . . . . . . . 98

Figura 67 - Metade do Cal eidociclo de 8 Tetraedros Regulares - Parte $1 \ldots$. . . . . 99

Figura 68 - Metade do Cal ei dociclo de 8 Tetraedros Regulares- Parte 2 . . . . . . . 100

Figura 69 - Caleidociclo Fechado de 8 Tetraedros . . . . . . . . . . . . . . . 101

Figura 70 - Cal eidociclo Fechado de 10 Tetraedros . . . . . . . . . . . . . . 102

Figura 71 - Cilindro alto . . . . . . . . . . . . . . . . . . . . 104 
Figura 72 - Molde do cilindro al to . . . . . . . . . . . . . . . . . . 105

Figura 73 - Cilindro baixo . . . . . . . . . . . . . . . . . . . . 107

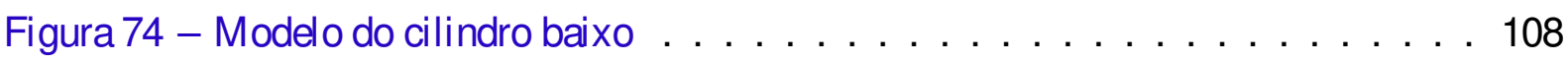

Figura 75 - HyperQBS . . . . . . . . . . . . . . . . . . . . . . 110

Figura 76 - Molde pequeno do HyperQBS . . . . . . . . . . . . . . . 112

Figura 77 - Molde grande do HyperQBS . . . . . . . . . . . . . . . 113 

CONCEITOS INTRODUTÓRIOS: SIMETRIAS E OBJETOS GEOMÉTRICOS 27

Simetria .

Simetria Axial 28

3.1 Caleidociclos com Tetraedros Regulares . . . . . . . . . . . 40

3.2 Caleidociclos Fechados (Tetraedros Não-Regulares) . . . . . . . . . 42

4 ENSINO DE SIMETRIAS POR MEIO DOS CALEIDOCICLOS . . . 47

$4.1 \quad$ Pré-requisitos . . . . . . . . . . . . . . 47

4.1.1 Simetria axial: proposta de atividade . . . . . . . . . . . . 48

4.1.2 Simetria rotacional: proposta de atividade . . . . . . . . . . . . 51

$4.2 \quad$ Proposta de Atividade: simetria com o caleidociclo . . . . . . . . . 53

5 TEOREMA DE PITÁGORAS, LEI DOS COSSENOS E RELAÇÃO FUNDAMENTAL DA TRIGONOMETRIA: APLICAÇÕES NA CONSTRUÇÃO DO CALEIDOCICLO . . . . . . . . . . . . . . . . 59

$5.1 \quad$ Caleidociclo com Tetraedro Regular: altura de face . . . . . . . . . 59

$5.2 \quad$ Caleidociclo fechado e as relações das medidas . . . . . . . . . . . 61

$5.3 \quad$ Propostas de Atividades . . . . . . . . . . . . . . . . . . 64

5.3.1 Ensino Fundamental: $8^{\circ}$ e $9^{\circ}$ anos . . . . . . . . . . . . . 64

5.3.2 Ensino Médio: $1^{\mathrm{a}}$ série . . . . . . . . . . . . . 66

6 CALEIDOCICLO: VOLUME E ÁREA DE SUPERFÍCIE . . . . . . 71

$6.1 \quad$ O Milagre Shinsei . . . . . . . . . . . . . . . . . . 71

$6.2 \quad$ Cubo Invertível . . . . . . . . . . . . . . . . 73

$6.3 \quad$ Propostas de Atividades . . . . . . . . . . . . . 76

6.3.1 O Milagre Shinsei . . . . . . . . . . . . . 76 
6.3.2 Cubo Invertível . . . . . . . . . . . . . . . . . . . . . . 79

7 CONCLUSÃO E CONSIDERAÇÕES FINAIS . . . . . . . . 83

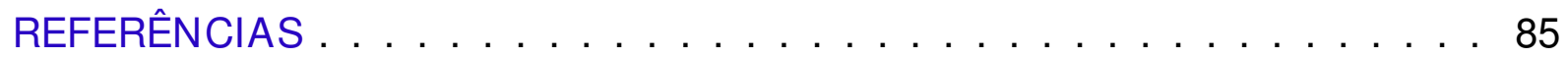

APÊNDICE A MOLDES DOS CALEIDOCICLOS ...... 87

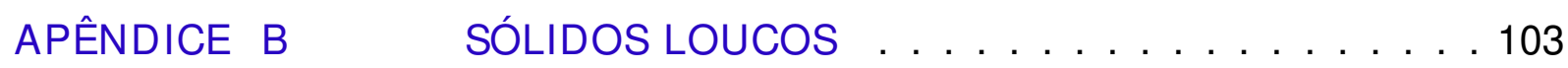

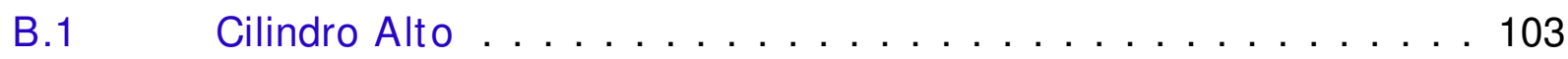

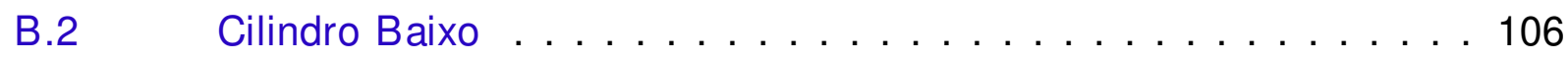

B.3 HyperQBS . . . . . . . . . . . . . . . . . 109 
CAPÍTULO

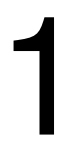

1

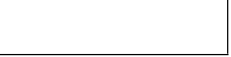

INTRODUÇÃO

Nos últimos anos tem-se fal ado muito no fracasso do ensino da matemática. No último relatório divul gado do PISA (Programa para Avaliação Internacional de Estudantes) de 2012, o Brasil atingiu uma pontuação média de 391,5 em matemática, ficando classificado em nível 1, o mais bai xo da escala de proficiência que vai até nível 6 .

Vitti (1999, p. 19) afirma que:

O fracasso do ensino de matemática e as dificul dades que os al unos apresentam em rel ação a essa disciplina não são um fato novo, pois vários educadores já el encaram el ementos que contribuem para que o ensino da matemática seja assinal ado mais por fracassos do que por sucessos.

Esse fracasso, tem alimentado muitas pesquisas sobre os motivos e também, sobre possibilidades de mudanças dessa situação. Vitti (1999, p. 32) lembra al guns fatores:

A matemática carrega o estigma de ser considerada uma disciplina chata, difícil e abstrata. Muitos pais procuram consolar seus filhos quando revelam que também tinham dificuldades em aprender matemática, ou até mesmo que escoIheram uma área para sua formação profissional que não utilizasse matemática.

É mui to comum ouvirmos cotidianamente comentários afirmando que a Matemática é chata, inclusive por col egas prof essores de outras áreas. Nas reuniões de pais e mestres, quando fala o professor de matemática, sempre surge comentários sobre como a disciplina é difícil e como os pais sempre tiveram dificuldades nessa área, ou ainda, durante conversas particulares com pai s e al unos, os pais comentam que consolam os fil hos fal ando da dificuldade da disci plina, como se isso fosse uma ajuda para o aluno superar as dificuldades, quando na verdade estão dando motivos para que se conformem com as dificuldades que apresentam.

De acordo com Johnson e Rising (1972 apud VITTI, 1999, p. 32) "muitas pessoas têm orgul ho em manifestar ignorância em matemática. Poucos adul tos admitem que foram fracos 
estudantes de hi stória mas muitos pais de al unos enunciam o fato de que eles nunca entenderam matemática."

Outros fatores que também são citados na literatura a respeito do fracasso na aprendizagem matemática é, em al guns casos, causados pel os professores que utilizam a matemática como al go punitivo. Vitti (1999, p. 19) ilustra com um exemplo:

\begin{abstract}
Muitos al unos trazem consigo lembranças terríveis de fatos ocorridos nas aulas de matemática, como o relatado por uma al una, cujo professor, na tentativa de manter a disciplina na sal a de aula, obrigou-a a fazer 50 cópias da tabuada do 2 ao 9. Quem poderá sentir al gum prazer em aprender al go que é colocado em forma de castigo, de punição, por estar conversando em uma aula?
\end{abstract}

Diante dessa realidade e com a sugestão apresentada pelo PROFMAT, escol hemos trabal har com a elaboração de propostas de atividades que apresentem curiosidades aos al unos e a partir delas, discutam a matemática envolvida de várias formas, seja como arte, descrição, classificação, construção, adaptação, definição, etc.

D’Ambrosio (2001, p. 31), quando fal a sobre a natureza da matemática e seu ensino, afirma:

\footnotetext{
É muito difícil motivar com fatos e situações do mundo atual uma ciência que foi criada e desenvolvida em outros tempos em virtude dos problemas de então, de uma real idade, de percepções, necessi dades e urgências que nos são estranha. Do ponto de vista de motivação contextualizada, a matemática que se ensina hoje nas escolas é morta. Poderia ser tratada como um fato histórico.
}

Entendemos que quando D' Ambrósio diz que a matemática ensi nada nas escola é morta, do ponto de vista de motivação contextual izada, ele se refere ao tipo de estímul o que os al unos são expostos para encontrar significação no estudo. Esse fato pode estar relacionado com metodologias de ensino em que são apresentados apenas os estímulos históricos da época e nenhum estímulo atual.

Utilizando o cal eidociclo, podemos estimular o al uno a utilizar habilidades matemáticas jáinteriorizadas por el es e também desenvolver habilidades e competências novas. Ao se deparar com uma curiosidade, o aluno desperta a vontade de entender o funcionamento da novidade, e essa vontade é urgente, não pode ser para depois. Isso abre a janel a para interiorizar habilidades matemáticas novas.

Deacordo com Moysés (2006, p. 23-24), Vygotsky modi ficou a rel ação estímul o-resposta da época dele, introduzindo um novo el emento que chamou de signo - instrumento psicológico por excelência - que mediatizava a rel ação do estímul o com o estímulo associado.

Moysés (2006, p. 25) ainda exemplifica essa relação citando o hábito de culturas primitivas em fazer marcas nos troncos de árvores e pedras para registrar o número de caças. Nessa situação, as caças são os estímulos, a quantidade de caças é o estímulo associado (resposta ao 
estímulo) e as marcações são os signos, ou seja, o instrumento mediador para se lembrar da associação entre as caças e a quanti dade de caças.

Nesse sentido, ao fal armos que precisamos estimular nossos al unos ao estudo matemático, fal amos de apresentar um estímul o, que no caso desse trabalho, é o cal eidociclo. Entendemos a linguagem matemática como o signo que Vygosty nos apresentou, pois é el a o instrumento de medi atização entre os estímulos vivenciados no cotidiano com o estímul o associado que é a abstração. Assim, entendemos a importância de apresentar um estímulo sempre que possível nas aul as de matemática, para que o signo seja interiorizado e faça sentido na sua real idade.

Borin (2007, p. 9) motiva a introdução de jogos nas aul as de matemática como:

$[\cdots]$ a possibilidade de diminuir os bloqueios apresentados por muitos de nossos al unos que temem a Matemática e sentem-se incapacitados para aprendêla. Dentro da situação de jogo, onde é impossível uma atitude passiva e a motivação é grande, notamos que, ao mesmo tempo em que estes al unos fal am matemática, apresentam também um mel hor desempenho e atitudes mais positivas frente a seus processos de aprendizagem.

Apesar do cal eidociclo não se tratar de um jogo, ele contém a ideia do trabal ho matemático de forma lúdica assi m como no jogo. O cal eidocicl o também tem a chance de desbl oquear a relação do al uno com a matemática e de motivar a interação com ela. Algumas das propostas apresentadas nesse trabal ho também levam em consi deração opções de trabal ho em conjunto, dando a oportunidade de desenvolvimento col etivo/social matemático.

Duval (1972 apud BRASI L, 1977, p. 2) al erta que:

Muitas vezes, invoca-se Piaget para afirmar que o domínio excel ente da linguagem é extrínseco à aprendizagem da matemática. O fato é verdadeiro, na medida em que Piaget mostrou que a lógica se desenvolve a partir da ação e, portanto, que as mani pul ações dos objetos devem ter a prioridade sobre o manejo verbal (das operações). Não se deve cansar de repetir isto sempre. Mas, não se deve esquecer que isso val e, essencial mente, para o estádio das operações concretas (7 a 11 anos).

Assim, é essencial o uso de curiosidades, jogos, brinquedos e objetos nos anos iniciais e na transição para os anos finais do Ensino Fundamental, sempre mediando e estimulando a general ização das ideias e auxiliando em uma possível formal ização. Porém, de acordo com Fraisse e Piaget ([19 - - ?] apud BRASIL, 1977, p. 3):

Lá pelos 11/12 anos, com um patamar de equilíbrio aos 14/15 anos, iniciase uma última fase de construção das operações próprias da infância e da adolescência Seu caráter mais evidente é que o sujeito não fica mais obrigado a raciocinar diretamente, apenas, sobre objetos concretos ou suas manipul ações (operações de classe, de rel ações, de números e operações espácio-temporais), mas de tornar-se capaz de deduzir, operatoriamente, a partir de simples hi póteses enumeradas verbal mente (lógica das proposi ções). Como consequência disto, a forma destas novas estruturas operatórias di ssociam-se de seu conteúdo, donde a possibilidade de um raciocínio hipotético-dedutivo ou formal . 
Com isso, lembramos da importância de, no Ensino Médio, frizarmos a formalização teórica e utilizar questões paral elas com hi póteses para estimular a abstração e não apenas se prenderem a manipulação dos cal eidociclos, como estão presentes nas propostas de atividades para este público. Isso não quer dizer que não háimportância no uso dos objetos, mas que podem ser expl oradas outras situações abstratas a partir deles.

Por tudo isso é que nos motivamos a desenvolver e apresentar sugestões de sequências didáticas com cal ei docicl os para aplicação em al guns dos anos finais do Ensino Fundamental e também da possibilidade do desenvolvimento de atividades para trabal har habilidades e competências desejadas para o Ensino Médio.

A simetria é um dos assuntos previstos no Currículo de Matemática das escol as públicas do Estado de São Paulo para o $7^{\circ}$ ano do Ensino Fundamental com o objetivo de identificar si metrias por meio da leitura; comparar e interpretar imagens si métricas; reconhecer padrões geométricos em diferentes imagens como forma de desenvolver uma melhor apreciação estética das linguagens do desenho, pintura, arquitetura etc.

O teorema de Pitágoras está previsto no Currículo para o final do $8^{\circ}$ ano e retomada no $9^{\circ}$ ano. Nessa retomada no $9^{\circ}$ ano, recomenda-se trabalhar aplicações do teorema para desenvolver a habilidade de reconhecer a utilização do teorema em problemas. Assi m, o trabal ho com caleidocicl os com centro fechado pode ser utilizado para esse fim.

A relação fundamental da trigonometria e a lei dos cossenos estão previstas para a $1^{\mathrm{a}}$ série do Ensino Médio com objetivo de desenvolver habilidades que possibilitem aos alunos enf rentar situações-problema envolvendo as razões trigonométricas em diferentes contextos e generalizar o Teorema de Pitágoras com a Lei dos Cossenos. Nesse contexto, o cálculo das medi das necessárias para uma planificação de um cal eidociclo de centro fechado contribui para perceber a utilização tanto da rel ação fundamental da trigonometria como da lei dos cossenos.

$\mathrm{Na} 2^{\mathrm{a}}$ série do Ensino Médio, o Currículo prevê o desenvolvimento de habilidades relacionadas à geometria espacial como reconhecer e nomear prismas; relacionar el ementos geométricos eal gébricos; sintetizar egeneral izar fatos obtidos de formas concretas. Nesse aspecto os cal eidociclos podem ajudar no que se refere ao cálculo de volumes e áreas de superfícies, inclusive proporcionando demonstrações de razões de vol umes em rel ação a prismas e também de vol umes constantes quando a área de superfície varia.

Desse modo, organizamos a dissertação da seguinte forma:

- Capítulo 1: Introdução com visão gl obal da matemática, embasamento e especificação do problema com a sugestão de possibilidade de sol ução

- Capítulo 2: Conceitos de si metria axial e rotacional e conceitos de polígonos e poliedros.

- Capítul o 3: Definição de caleidocicl os, exemplos e classificação. 
- Capítulo 4: Simetrias axial e rotacional com caleidociclos.

- Capítul o 5: Teorema de Pitágoras, lei dos cossenos e rel ação fundamental da trigonometria com aplicações na construção de cal eidociclos de centro aberto e fechado.

- Capítulo 6: Volume e área de superfície de cal eidocicl os e sua rel ação com prismas.

- Capítulo 7: Conclusão e considerações finais.

Temos também dois Apêndices, o primeiro com mol des de cal eidocicl os citados neste trabal ho e o segundo com apresentação de outros três sól idos móveis que podem contribuir com o desenvolvimento das habilidades e competências matemáticas como os cal eidociclos.

Esperamos assim, que esse trabal ho venha contribuir no estudo geométrico e al gébrico de forma diferenciada, mas relacionada diretamente com os elementos formais do estudo dessas áreas matemáticas.

Por fim, esclarecemos que para a construção de muitas das figuras el aboradas pelo autor foram usados os sof twares livre GeoGebra 5.0 e GIMP e as imagens de cal ei docicl os são fotos tiradas de cal eidociclos construídos e fotografados pelo autor. 

CAPÍTULO

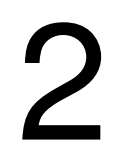

\section{CONCEITOS INTRODUTÓRIOS: SIMETRIAS E OBJETOS GEOMÉTRICOS}

Neste capítul o iremos enunciar conceitos matemáticos que serão util lizados para abordar o assunto principal deste trabal ho. Caso o leitor já esteja familiarizado com tais conceitos, poderá seguir para o capítulo 3 onde iniciaremos a definição e características dos cal eidocicl os.

\subsection{Simetria}

A ideia de simetria geral mente é relacionada com Arte e Natureza mais do que com a Matemática. É natural essa relação já que encontramos simetria facilmente na natureza e de forma agradável aos ol hos.

Figura 1 - Simetrias na Natureza e nas Construções

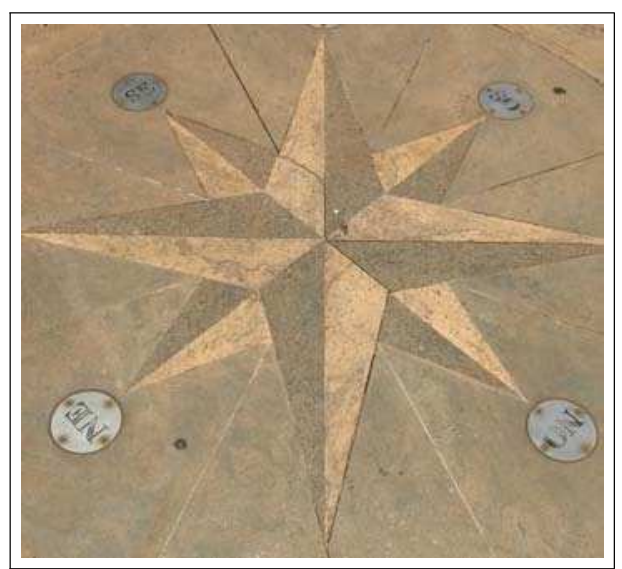

(a) Rosa dos ventos - Observatório USP - São Carlos

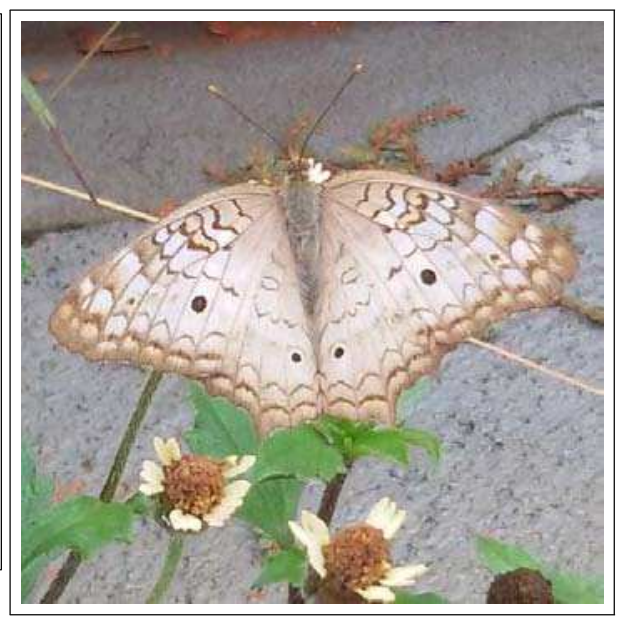

(b) Borboleta 


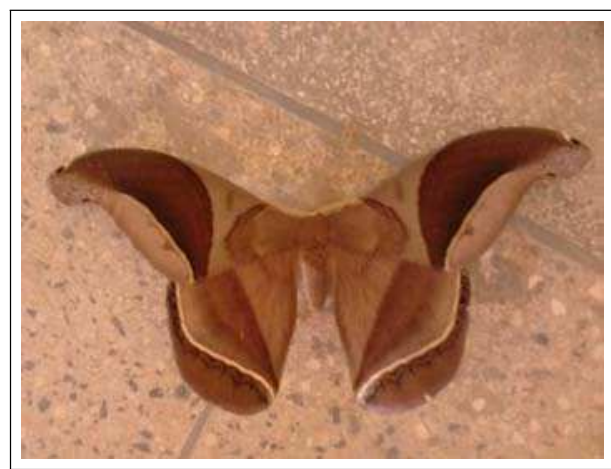

(c) Mariposa

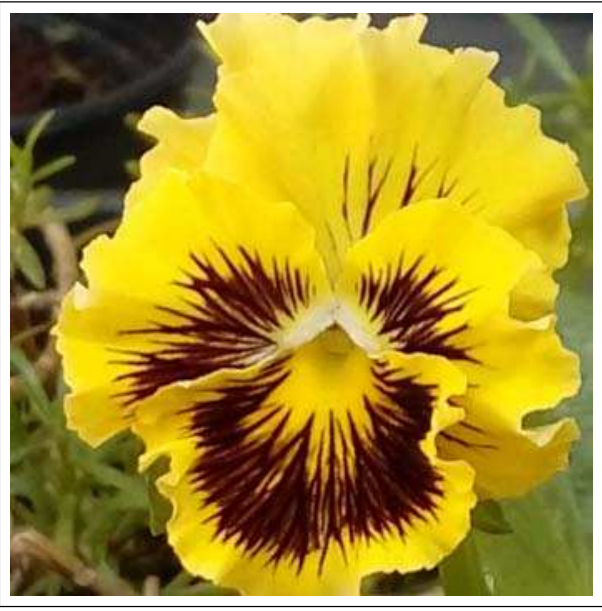

(d) Flor - Amor Perfeito

Fonte: Elaborada pelo autor.

Vamos utilizar dois tipos principais de si metria nesse trabal ho, a si metria axial (ou de Reflexão) e a rotacional. Paraisso, vamos defini-las e também definir al guns outros el ementos importantes para o trabal ho.

\subsubsection{Simetria Axial}

Definição 1. Seja $r$ uma reta no plano $\Pi$. A simetria axial em torno da reta $r$ é a função $R_{r}$ definida por

$$
R_{r}(P)=\begin{aligned}
& P \text { se } P \in r \\
& P^{\prime} \text { se } P \notin r \text { de forma que } r \text { seja a mediatriz de } \overline{P P}
\end{aligned},
$$

para todo ponto $\mathrm{P} \in \Pi$ er échamada eixo de simetria.

\section{Observe as figuras a seguir}

Figura 2 - Pontos na reta e fora dela

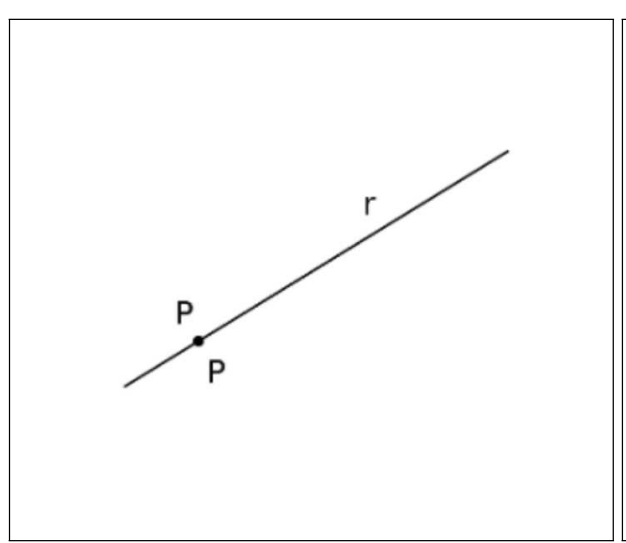

(a) $P \in r$

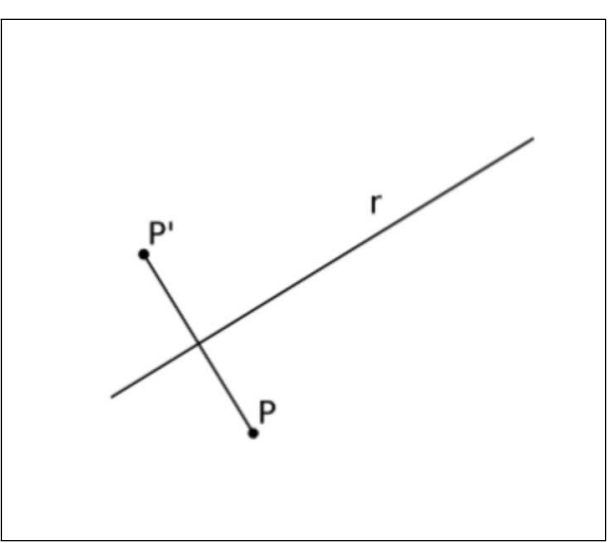

(b) $P \notin r$

Fonte: Elaborada pelo autor. 
Definição 2. Uma figura plana se diz ter simetria axial quando podemos traçar uma reta $r$ dividindo a figura em duas partes de modo que uma das partes é a imagem da outra por uma simetria axial de eixo $r$.

De maneira menos rigorosa, podemos dizer que uma figura possui simetria axial quando podemos traçar uma reta imagi nária (eixo de simetria axial) dividindo a figura em duas partes em que uma dessa partes aparenta ser um espel hamento da outra. Como na figura:

Figura 3 - Eixo de Simetria Axial e Espel hamento

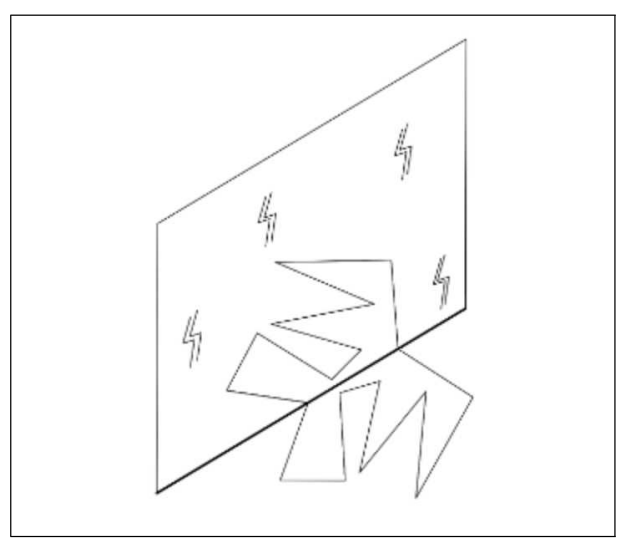

Fonte: Elaborada pelo autor.

\subsubsection{Simetria Rotacional}

Definição 3. Seja $O$ um ponto do plano $\Pi$. Uma rotação a partir de $O$ é uma função $R_{\theta}$ definida por $\mathrm{R}_{\theta}(\mathrm{P})=\mathrm{P}^{\prime}$ com $\mathrm{P}$ um ponto do plano $\Pi, \mathrm{OP}=\mathrm{OP}^{\prime}, \mathrm{ROP}^{\prime}=\theta$. Dizemos então, que o ponto $P$ sofreu uma rotação $\theta$ a partir do ponto $O$.

Figura 4 - Rotação $\theta$ de $\mathrm{P}$ a partir de $\mathrm{O}$

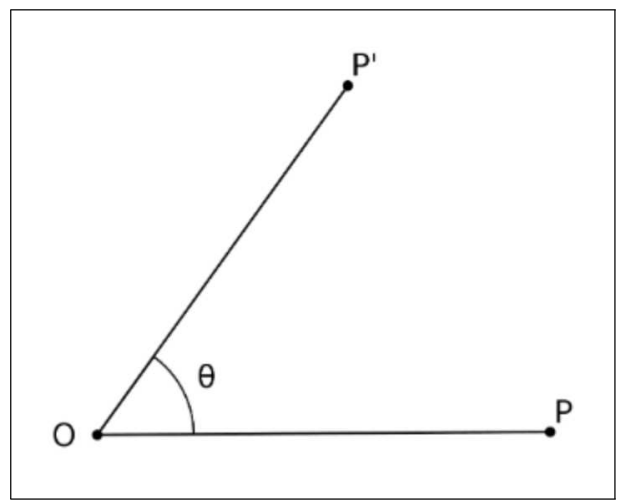

Fonte: Elaborada pelo autor.

Definição 4. Seja $\mathrm{O}$ e $\mathrm{P}$ pontos do plano $\Pi, \theta$ um ângulo divisor de $360^{\circ}$ e $\alpha=\mathrm{k} \cdot \theta$ com $\mathrm{k} \in\{1,2, \cdots, 360 / \theta\}$, chamamos de simetria rotacional de $\mathrm{P}$ a partir de $\mathrm{O}$ com rotação $\theta$ o 
conjunto Sdefinido como

$$
S=\left\{Q \in \Pi \mid R_{\alpha}(P)=Q \text { a partir de } O\right\}
$$

e chamamos $\mathrm{O}$ de centro de si metria rotacional.

Exempl os de Simetria Rotacional :

Figura 5 - Simetrias Rotacionais do ponto $\mathrm{P}$ a partir de $\mathrm{O}$ com ângulo $\theta$

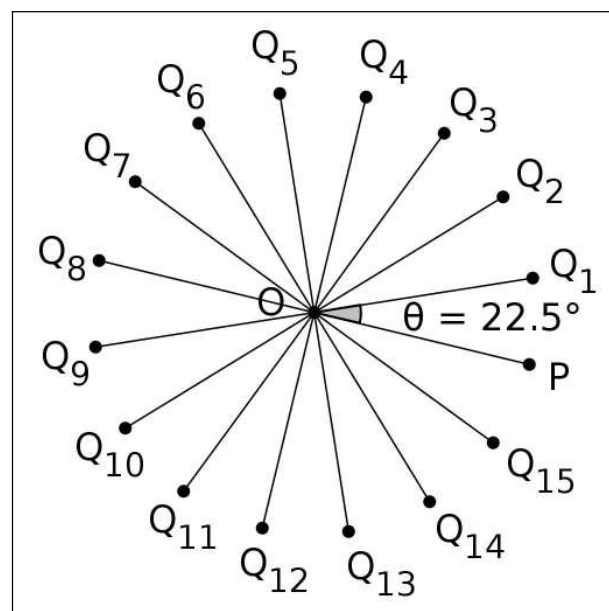

(a) $\theta=22,5^{\circ}$

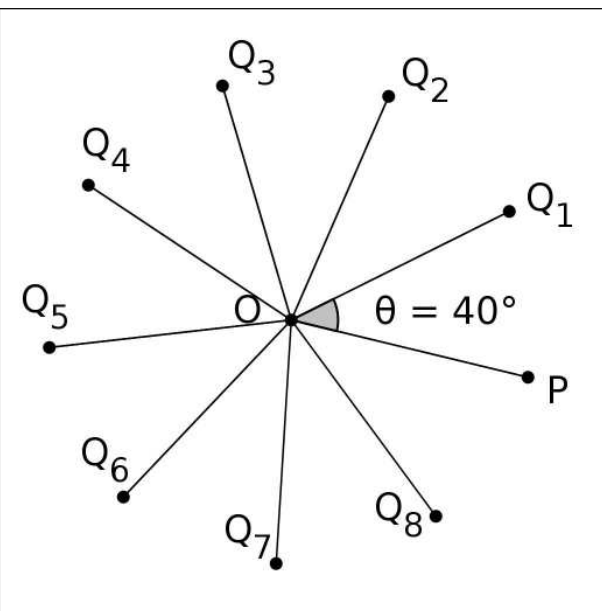

(b) $\theta=40^{\circ}$

Definição 5. Uma figura plana se diz ter simetria rotacional quando podemos encontrar simetria rotacional para cada ponto da figura com um ângul o $\theta$ e centro de simetria rotacional $O$ fixos.

De maneira mais didática, podemos dizer que em uma figura há simetria rotacional se, ao rotacionarmos $\theta$ graus a partir de um referencial $O$, a figura não aparenta ter sido rotacionada. Veja:

Figura 6 - Simetria Rotacional de $60^{\circ}$

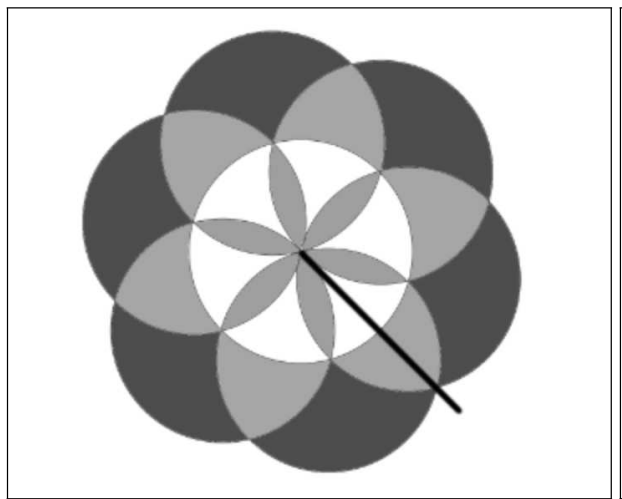

(a) Original

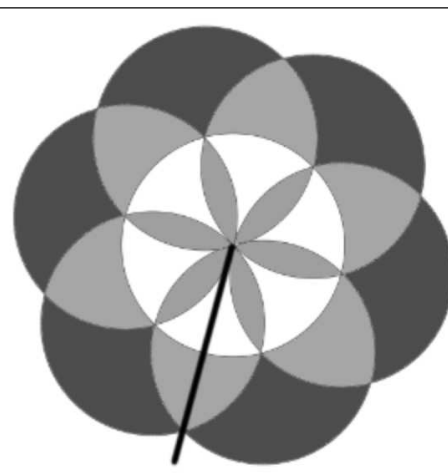

(b) Rotacionada $60^{\circ}$ graus 


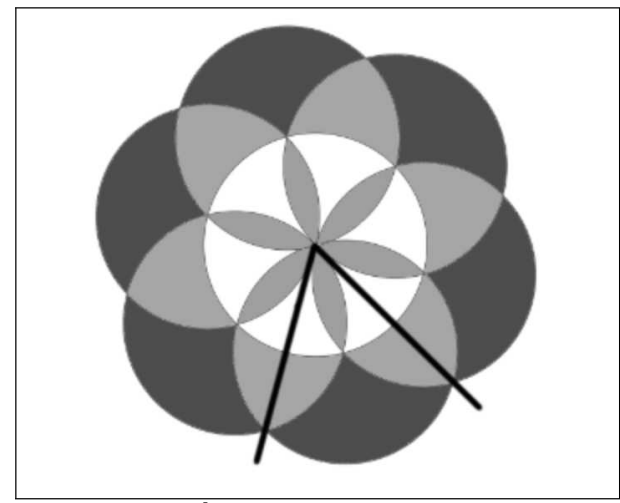

(c) Ângulo destacado

Fonte: Elaborada pelo autor.

\subsection{Polígonos}

Definição 6. Um polígono é uma figura geométrica plana formada por um número finito de pontos $V_{1}, V_{2}, V_{3}, \cdots, V_{n}(n \geq 3)$ e $V_{1}$ é o consecutivo de $V_{n}$ e pelos segmentos de reta $\mathrm{V}_{1} \mathrm{~V}_{2}, \mathrm{~V}_{2} \mathrm{~V}_{3}, \mathrm{~V}_{3} \mathrm{~V}_{4}, \cdots, \mathrm{V}_{\mathrm{n}-1} \mathrm{~V}_{\mathrm{n}}, \mathrm{V}_{\mathrm{n}} \mathrm{V}_{1}$, satisfazendo a seguinte propriedade:

i) Três a três pontos consecutivos não são colineares.

Os pontos $\mathrm{V}_{1}, \mathrm{~V}_{2}, \cdots, \mathrm{V}_{\mathrm{n}}$ são chamados vértices do polígono e os segmentos $\mathrm{V}_{1} \mathrm{~V}_{2}, \mathrm{~V}_{2} \mathrm{~V}_{3}, \cdots, \mathrm{V}_{\mathrm{n}} \mathrm{V}_{1}$ são os lados.

Exemplos:

Figura 7 - Exemplos de polígonos

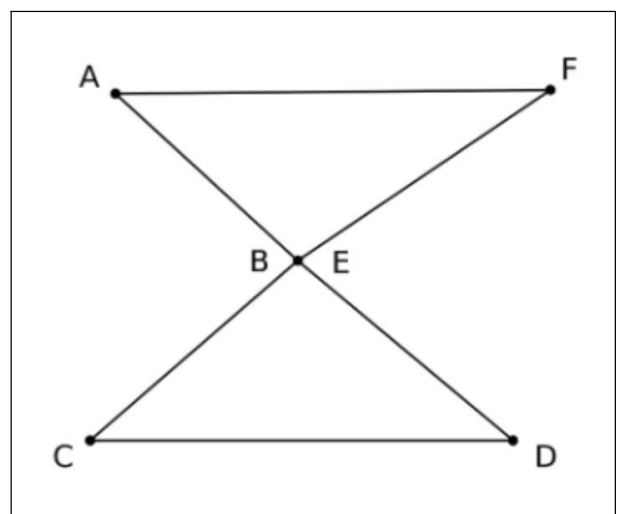

(a) Hexágono

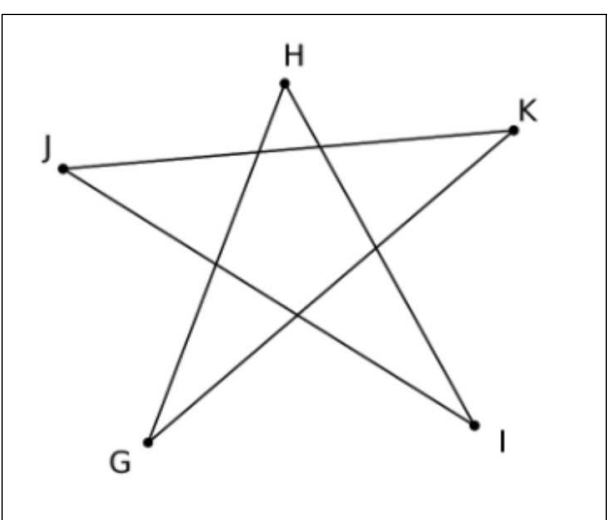

(b) Pentágono 


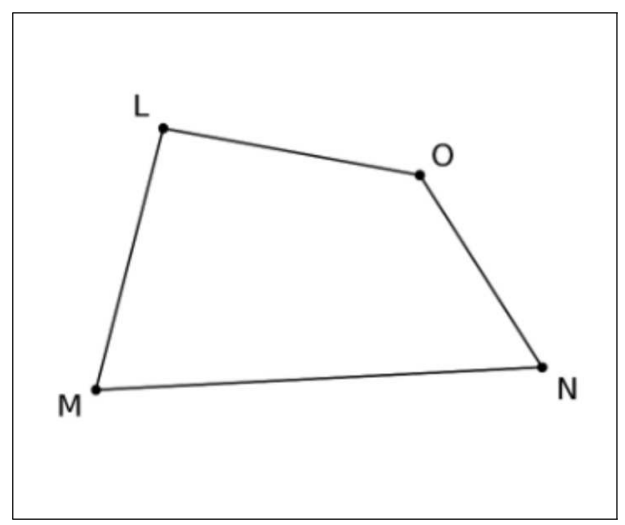

(c) Quadrilátero

Fonte: Elaborada pelo autor.

Definição 7. Chamamos de polígono simples todo polígono em que não haja interseção entre os lados não consecutivos.

Veja alguns exemplos:

Figura 8 - Exemplos de polígonos simples

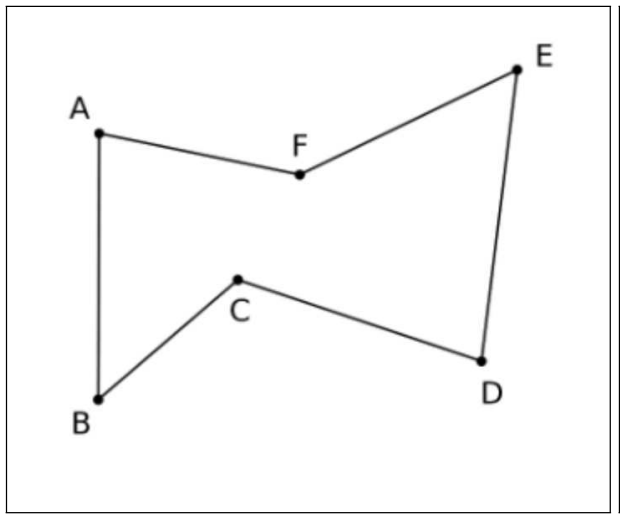

(a) Hexágono

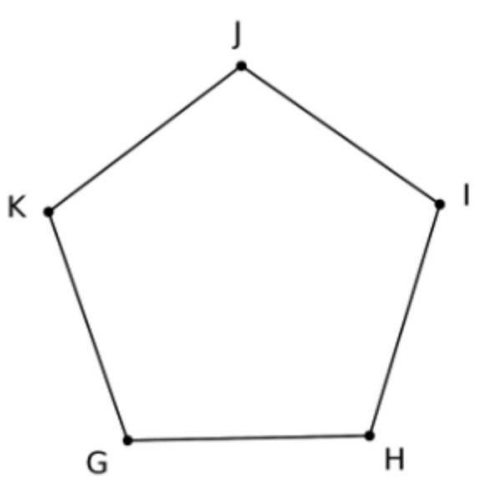

(b) Pentágono

Fonte: Elaborada pelo autor.

A região do plano limitada e delimitada pelos lados do polígono é chamada região interna do polígono e o ângulo de cada vértice que está sobre a região interna é chamado ângulo interno do polígono.

A figura 9 ilustra a região interna do polígono $A B C D E$ e os ângulos internos $\alpha, \beta, \gamma, \delta$ e $\varepsilon$. 
Figura 9 - Região interna e ângulo interno

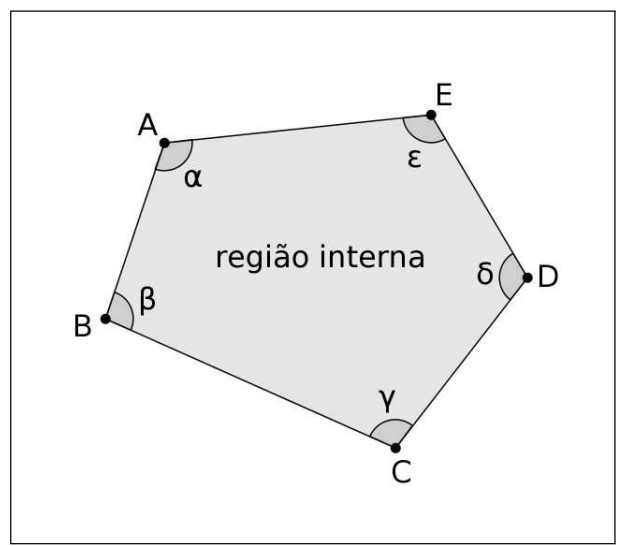

Fonte: Elaborada pelo autor.

Definição 8. Um polígono é dito polígono regular quando seus lados são congruentes entre si e seus ângulos internos também são congruentes entre si .

Exempl os de polígonos regulares:

Figura 10 - Polígonos Regulares

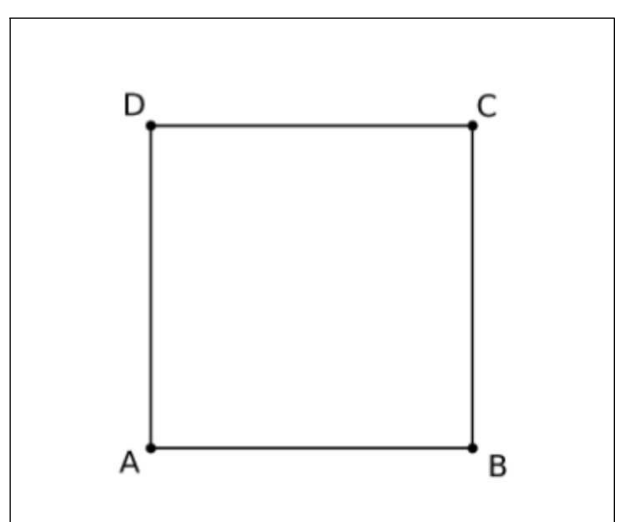

(a) Quadrado

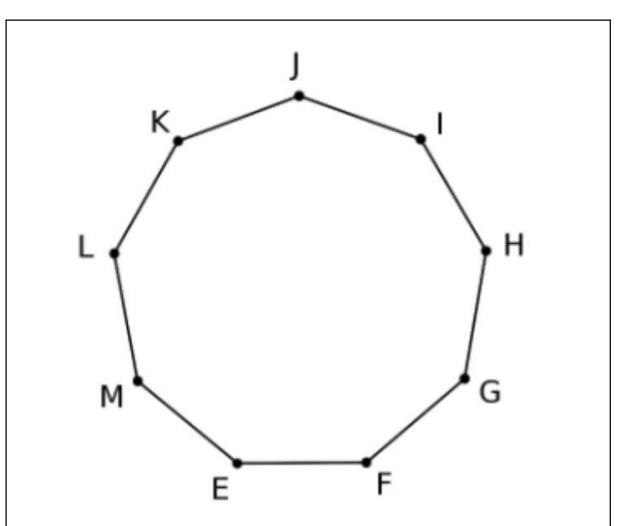

(b) Eneágono

Fonte: Elaborada pelo autor.

Definição 9. Se toda reta que passa por quai squer dois vértices consecutivos de um polígono simples deixa os outros vértices em um mesmo semiplano, dizemos que esse é um polígono convexo. 
Figura 11 - Polígono Convexo e Não-Convexo

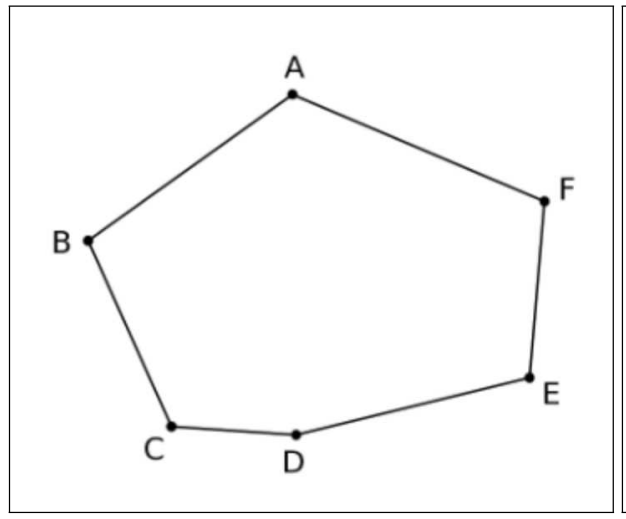

(a) Polígono Convexo

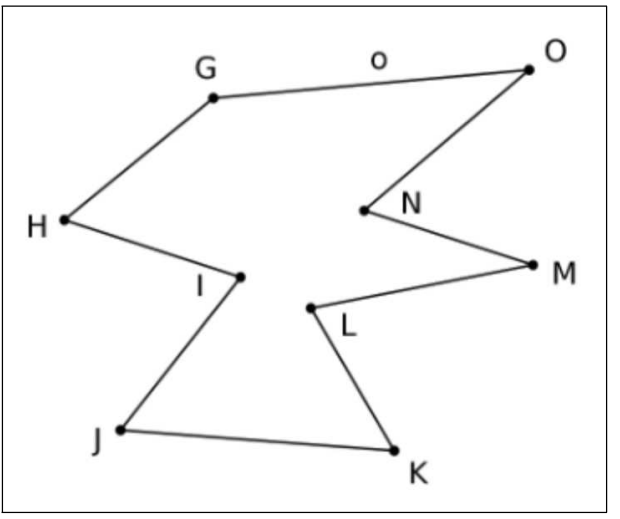

(b) Polígono Não-Convexo

Fonte: Elaborada pelo autor.

Definição 10. Uma região poligonal é a união do polígono com a região interna determinada por ele.

Figura 12 - Região Poligonal

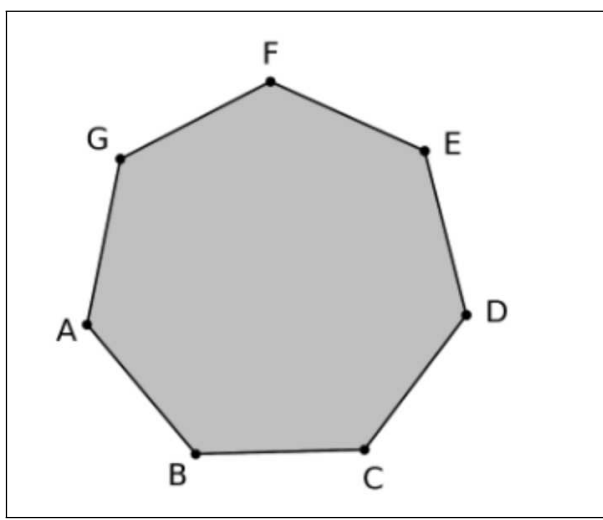

(a) Heptagonal

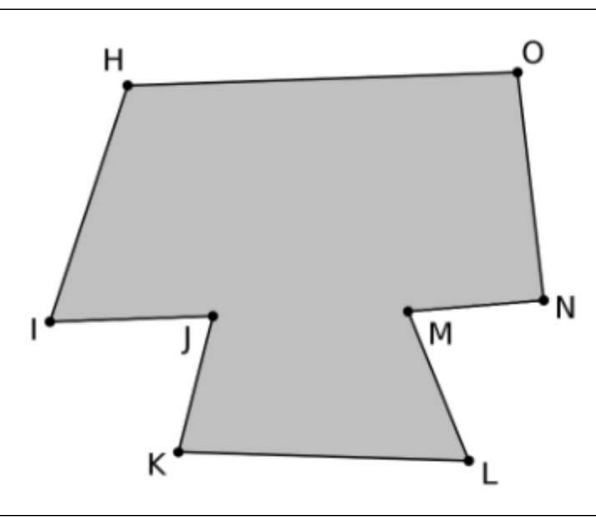

(b) Octogonal

Fonte: Elaborada pelo autor.

\subsection{Poliedros}

Definição 11. Um poliedro é uma região espacial limitada e delimitada por um número finito de regiões poligonais, chamadas faces do poliedro, com as seguintes propriedades:

i) Duas faces se intersectam ou em um vértice, ou em um lado comum, ou não há interseção.

ii) Cadalado de uma face é comum a exatamente duas faces. 
Figura 13 - Exemplos de Poliedros

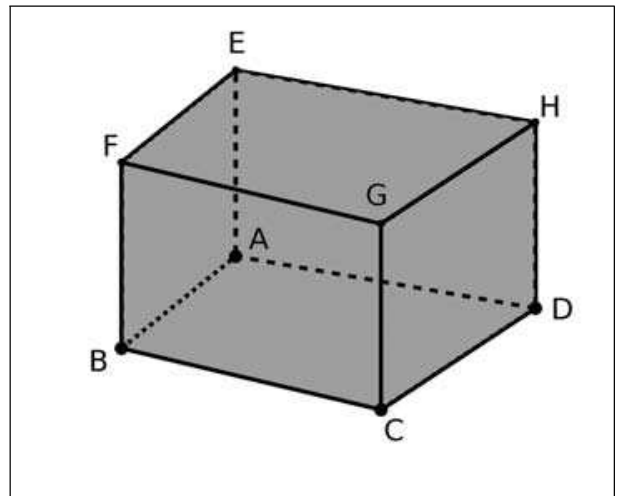

(a) Hexaedro

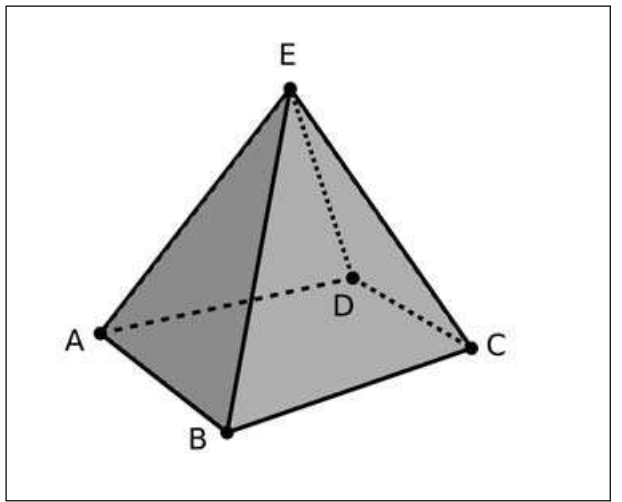

(b) Pentaedro

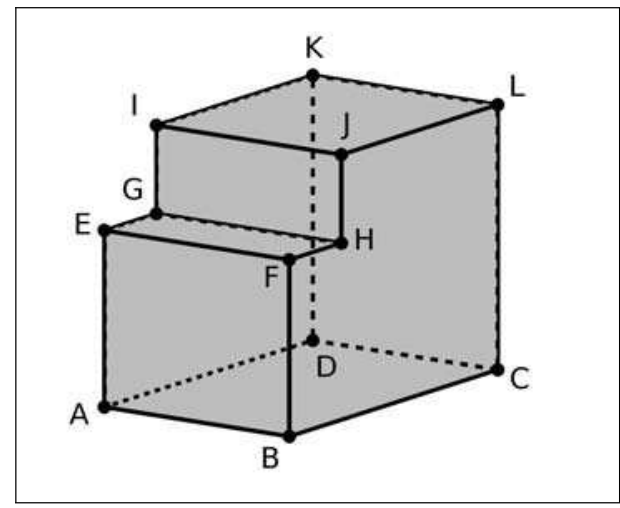

(c) Octaedro

Fonte: Elaborada pelo autor.

Definição 12. Dado um poliedro qual quer, se o plano de cada face deixar as outras faces em um mesmo semiespaço, dizemos que ele é um poliedro convexo.

Figura 14 - Poliedros convexo e não-convexo

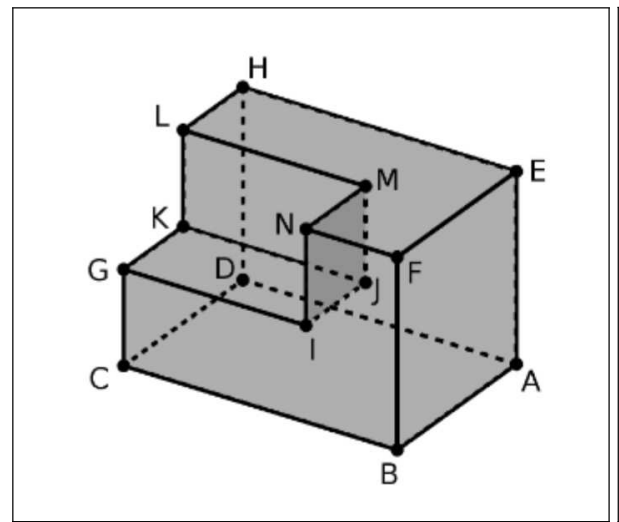

(a) Não-convexo

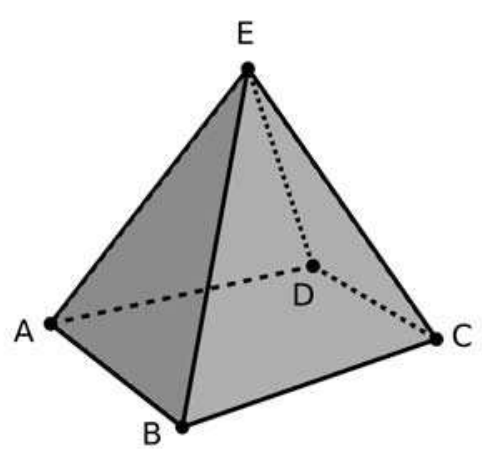

(b) Convexo

Fonte: Elaborada pelo autor. 
Definição 13. Um poliedro convexo é dito regular quando suas faces são polígonos regulares congruentes e seus vértices possuem o mesmo número de arestas concorrentes.

Figura 15 - Poliedros Regulares

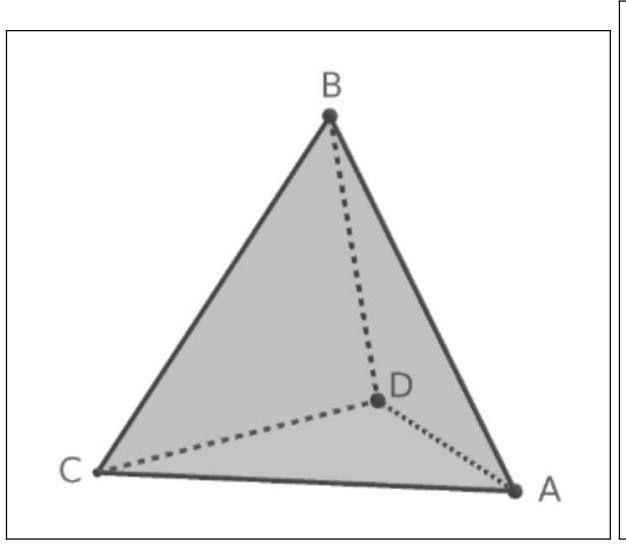

(a) Tetraedro Regular

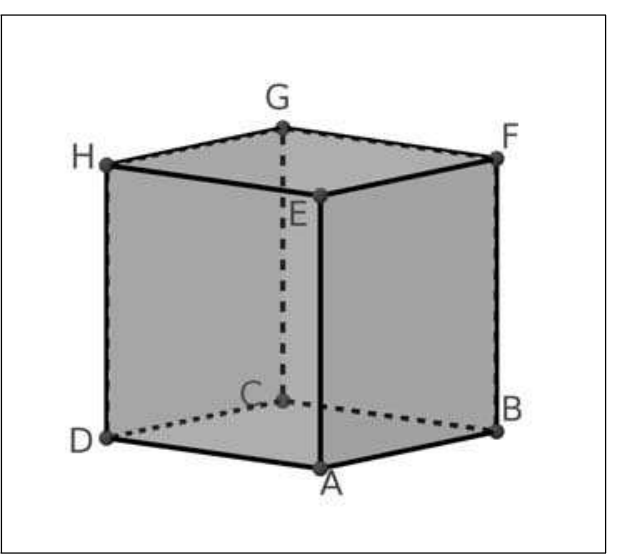

(b) Cubo

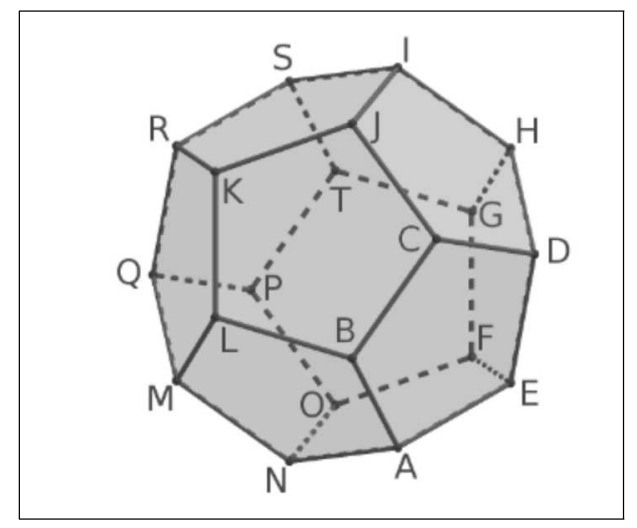

(c) Dodecaedro Regular

Fonte: Elaborada pelo autor. 
CAPÍTULO
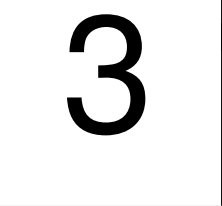

CALEIDOCICLOS

Trazemos, nesse capítulo, o significado e definição de cal eidociclo, exempl os e al gumas cl assificações. Nas seções, detal hamos al gumas propriedades e rel ações matemáticas encontradas nos cal eidocicl os que serão utilizadas nas propostas de atividades posteriores.

Figura 16 - Cal eidociclo

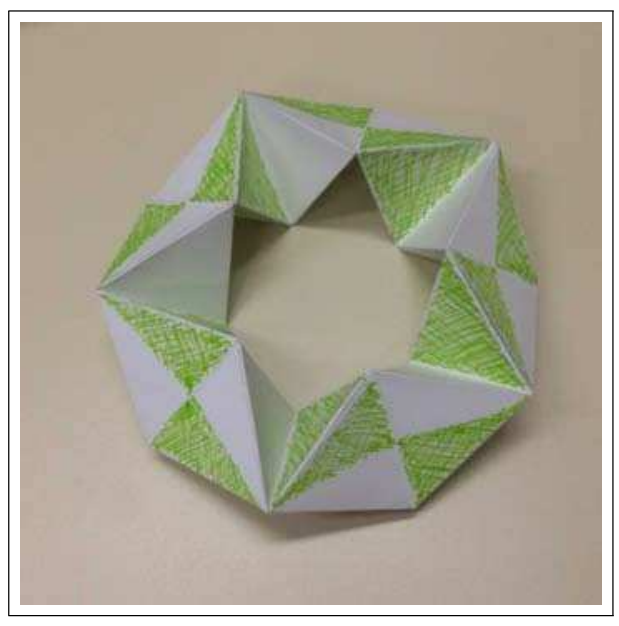

Fonte: Elaborada pelo autor.

A pal avra cal eidociclo vem da junção dos termos gregos Kál os [bonito] + eîdos [forma] + kiklos [ciclo/anel] 
Figura 17 - Cal eidociclos fechados variados com imagens axial e rotacional mente simétricas

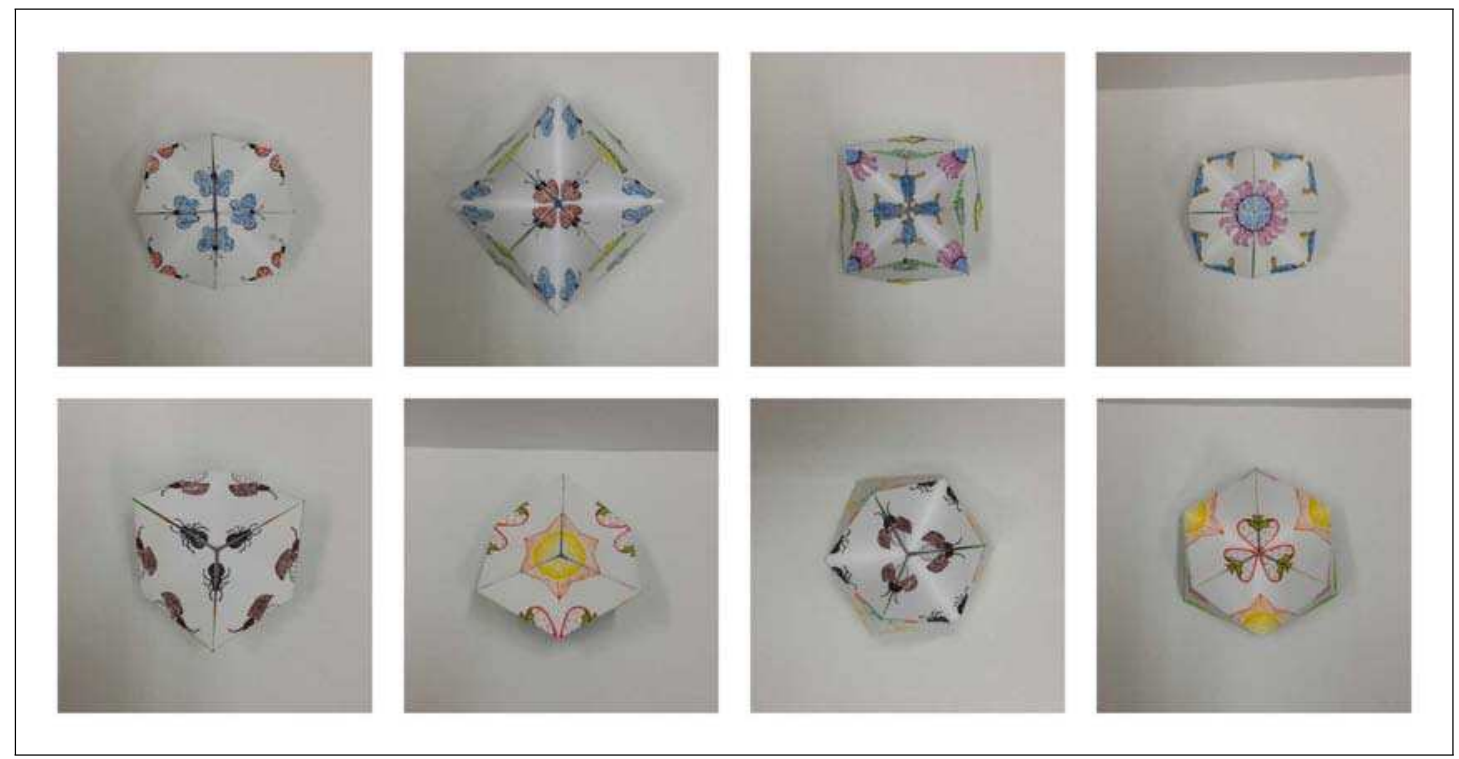

Fonte: Elaborada pelo autor.

Definição 14. Caleidociclo é um anel tridimensional circular composto por uma cadeia de tetraedros idênticos com as seguintes propriedades:

i) dois tetraedros estão ligados por uma única aresta em comum;

ii) cada tetraedro está ligado a exatamente dois outros tetraedros por arestas opostas;

Figura 18 - Exemplo de cal eidociclo com seis tetraedros não-regulares

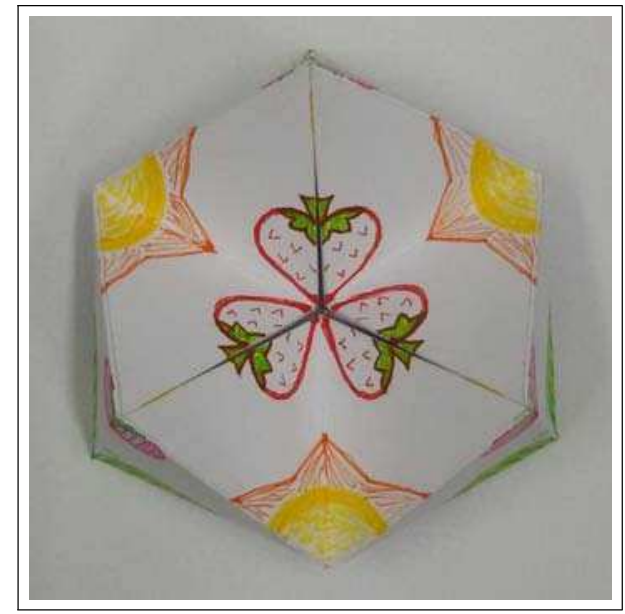

Fonte: Elaborada pelo autor.

Uma característica que o torna especial é a possi bilidade de torcêlo continuadamente para dentro ou para fora na medi da em que mostra diferentes faces dos tetraedros.

Definição 15. Um cal eidociclo é chamado caleidociclo regular quando as arestas de ligação de um tetraedro são ortogonais, caso contrário, é chamado caleidociclo não-regular. 
Figura 19-Cal eidociclo regular de oito tetraedros regul ares e cal eidociclo não-regular de oito tetraedros

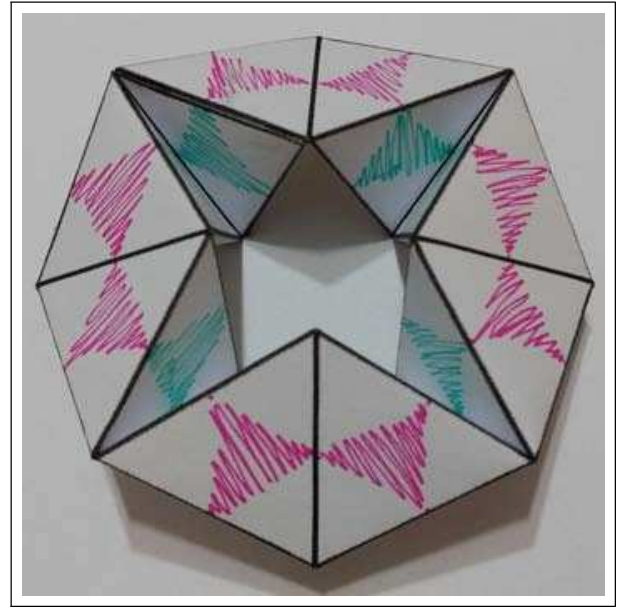

(a) Cal eidociclo Regular

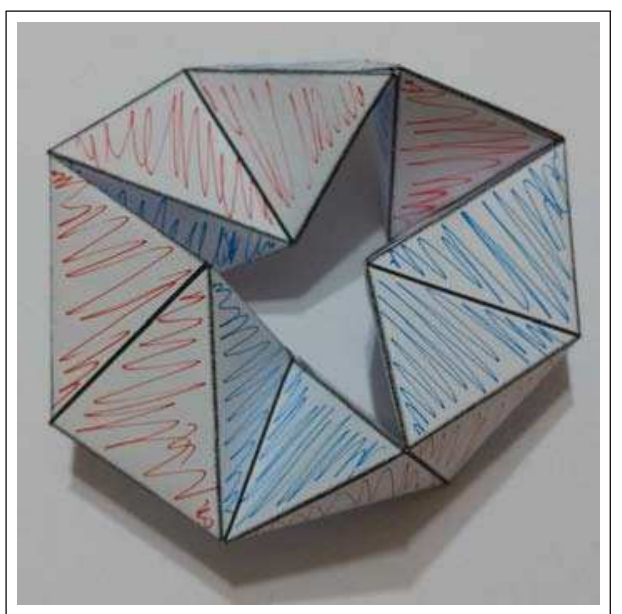

(b) Cal eidociclo Não-regular

Fonte: Elaborada pelo autor.

Neste trabal ho, serão utilizados apenas os cal eidocicl os regulares e, por simplicidade, iremos nos referir apenas como cal eidociclos, caso necessário, deixaremos evidente quando não se tratar de um caleidociclo regular.

Todo cal eidociclo regular pode ser posicionado no espaço canônico como no exemplo da figura 20a:

Figura 20 - Cal eidociclo regular de dez tetraedros regulares local izado no espaço

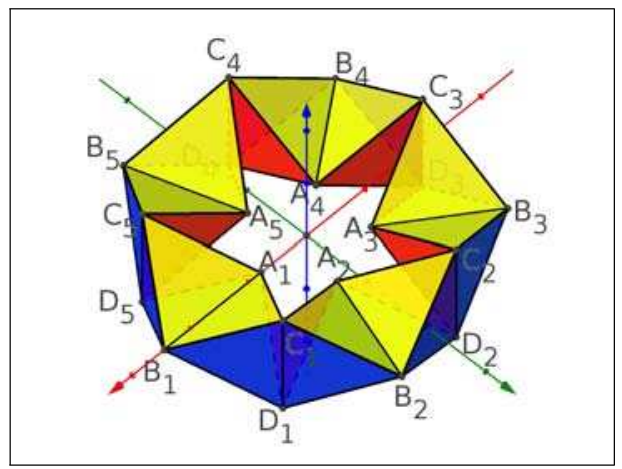

(a) Posição neutra no espaço

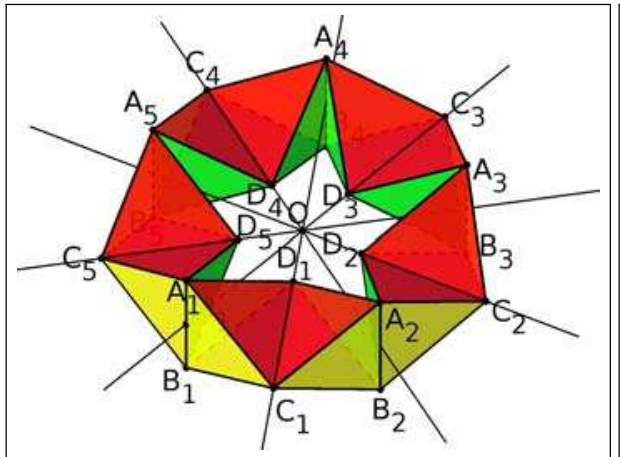

(c) Torção de $90^{\circ}$

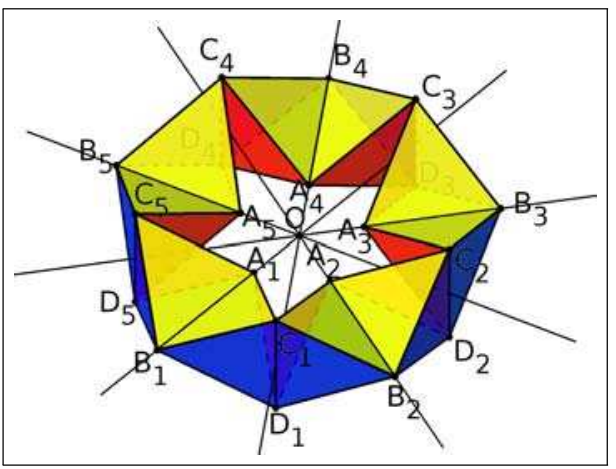

(b) Centro do cal eidociclo

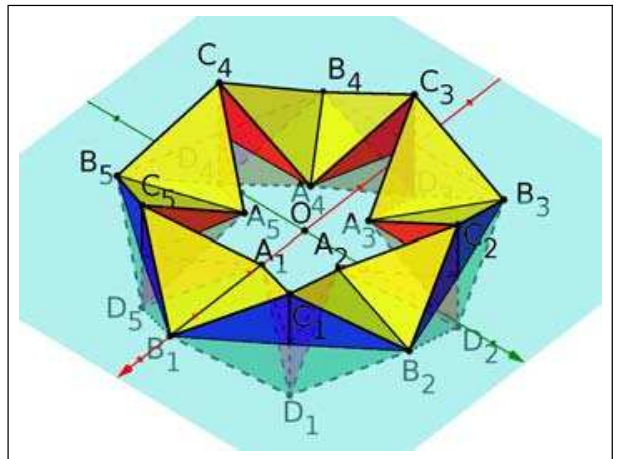

(d) Intersecção com o plano XY 


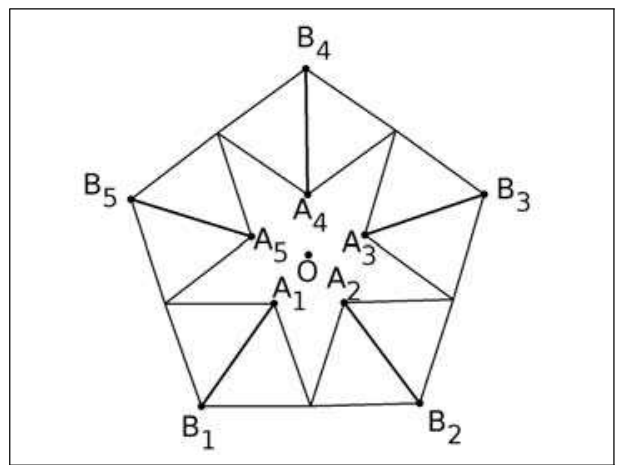

(e) Secção Transversal

Nestas posi ções, que chamaremos posição neutra no espaço, as arestas de ligação estarão paral elas ao eixo $Z$ ou pertencentes ao plano $X Y$. No exemplo $20 a, \overline{C_{i} D_{i}}$ são as arestas paral elas ao eixo $Z$ e $\overline{A_{i} B_{i}}$ são as arestas pertencentes ao plano $X Y$.

As retas suporte das arestas que estão contidas no plano $X Y$ se intersectam em um ponto chamado centro do caleidociclo. Na figura 20b, o centro do cal eidociclo é o ponto O que, neste caso, coincide com a origem do espaço. Na figura 20c, podemos perceber que ao torcer o cal ei dociclo em $90^{\circ}$ há uma al teração no posicionamento das arestas de ligação; as arestas $\overline{\mathrm{A}_{i} \mathrm{~B}_{i}}$ estão agora paral el as ao eixo $Z$ e $\overline{\mathrm{C}_{i} D_{i}}$ estão contidas no plano $X Y$ e com suas retas suporte se intersectando no ponto $O$ centro do cal eidociclo, porém esta nova posição também é uma posi ção neutra no espaço.

Na figura 20d temos a intersecção do plano XY com o cal eidociclo na posição neutra; essa intersecção é chamada secção transversal e está destacada na figura 20 e que será utilizada na definição 16.

\subsection{Caleidociclos com Tetraedros Regulares}

Esse tipo de cal eidocicl o é regular, composto por oito tetraedros regulares no mínimo e não há uma quantidade máxima. $A$ impossi bilidade de compor um cal ei docicl o com menos de oi to tetraedros regulares será tratada na seção 3.2. 
Figura 21 - Cal eidociclo de oito tetraedros regulares

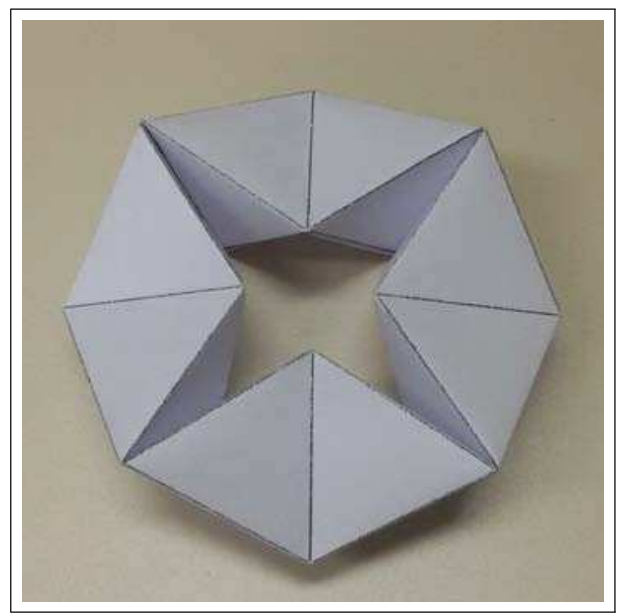

Fonte: Elaborada pelo autor.

Perceba que neste cal eidociclo o centro é vazado, ou seja, em nenhuma posição de torção, o centro ficará fechado. Outra observação importante é que o número de tetraedros sempre é par no caso de serem tetraedros regulares, pois caso seja um número ímpar, ao tentar fechar a cadeia de cal eidociclos para compor o anel, teremos extremidades com arestas perpendiculares, o que contraria a defini ção de cal ei doci clo estando ligados a apenas um ponto (a interseção das arestas) e não a aresta em comum.

Vamos definir al gumas medidas e formas encontradas nos cal eidociclos.

Dado um cal eidociclo regul ar de oito tetraedros em posição neutra no espaço como na figura a seguir,

Figura 22 - Oito tetraedros regulares

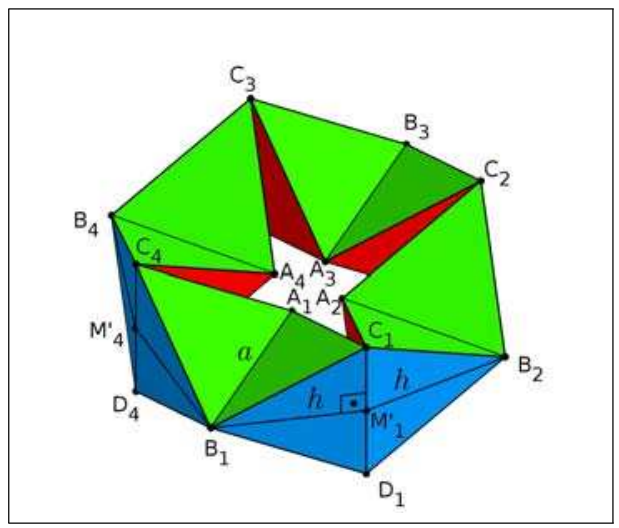

Fonte: Elaborada pelo autor.

fazendo-se uma secção transversal, como visto no início deste capítul o nafigura 20d, e definindo a a medida das arestas, $h$ as al turas das faces el a medida dos segmentos $M_{1} M_{2}, \overline{M_{2} M_{3}}, \overline{M_{3} M_{4}}$, $\overline{\mathrm{M}_{4} \mathrm{M}_{1}}$, temos 
Figura 23 - Secção transversal do cal eidociclo de oito tetraedros regulares

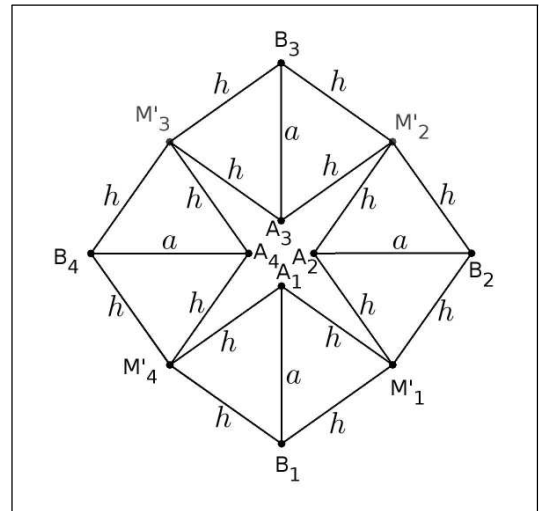

(a) Notações na secção

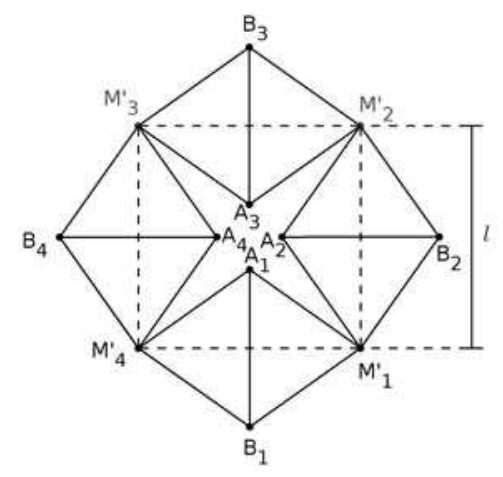

(b) Base do anel

Fonte: Elaborada pelo autor.

Assim, definimos:

Definição 16. O quadrado tracejado apresentado na figura 23b é chamado base do anel.

A relação entre a aresta a, a al tura de face h e o lado I da base do anel iremos trabal har no Capítulo 5 utilizando as propostas de atividades relacionadas com o Teorema de Pitágoras.

\subsection{Caleidociclos Fechados (Tetraedros Não-Regulares)}

Se quiser fazer um cal eidociclo de centro fechado com tetraedros regulares, na tentativa, iremos descobrir que não é possível, veja a imagem:

Figura 24 - Tentativa de cal eidociclo fechado com tetraedros regulares

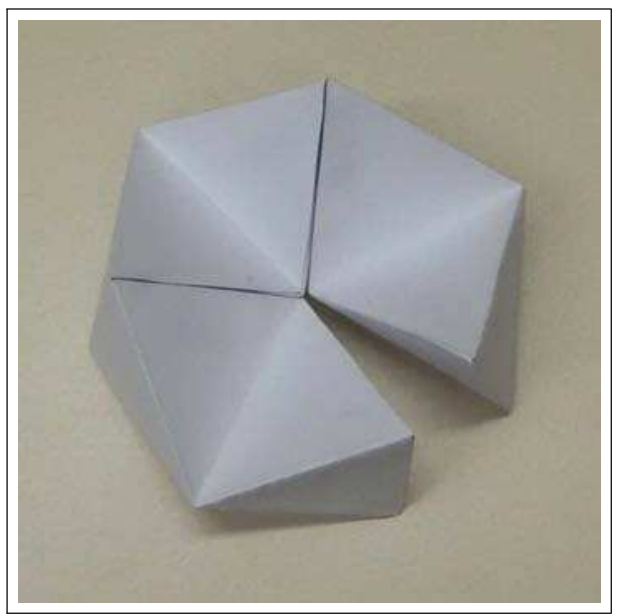

Fonte: Elaborada pelo autor.

Podemos justificar esse fato anal isando como deveria ser a base desse anel. O estudo de ladril hamento do plano com figuras geométricas nos dá um caminho. Ao pôr polígonos idênticos 
com um vértice comum e sem sobreposição, de forma a recobrir todo o plano ao redor desse vértice, é necessário que a medi da do ângulo desse vértice seja um divisor de $360^{\circ}$.

Como estamos utilizando tetraedros regulares, o corte transversal, como feito na figura 23 fica como na imagem:

Figura 25 - Corte transversal da tentativa

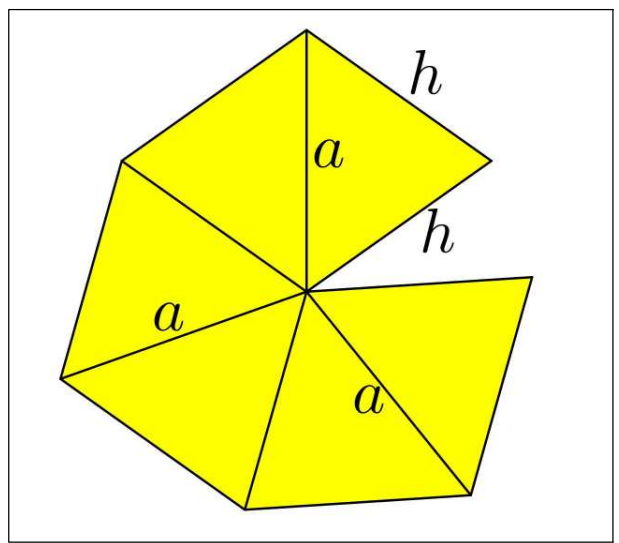

Fonte: Elaborada pelo autor.

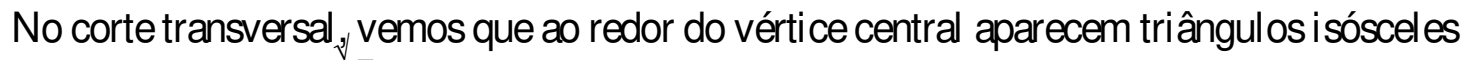
com aresta a e al tura $h=\frac{a}{2}$. O vértice comum do centro do cal eidociclo é composto por um dos vértices desses triângul os da secção transversal, contendo o ângul o $\alpha$ formado entre a e $h$. Pela lei dos cossenos, temos

$$
\begin{aligned}
\mathrm{h}^{2} & =\mathrm{a}^{2}+\mathrm{h}^{2}-2 \mathrm{ah} \cos \alpha \\
2 \mathrm{ah} \cos \alpha & =\mathrm{a}^{2} \\
2 \cos \alpha & =\frac{\mathrm{a}}{\mathrm{h}} \\
\cos \alpha & =\frac{\mathrm{a}}{2 \mathrm{~h}}
\end{aligned}
$$

como

$$
h=\frac{a^{V} \overline{3}}{2}
$$

segue que

$$
\begin{aligned}
\cos \alpha & =\frac{\sqrt{ }}{\sqrt{3}} \\
\cos \alpha & =\frac{\sqrt{3}}{3}
\end{aligned}
$$

portanto

$$
\alpha \approx 54,7356
$$


pois $0<\alpha<\pi / 2$.

Assim, o ângulo a não é divisor de $360^{\circ}$ eportanto não é possível formar um cal eidociclo fechado com seis tetraedros regulares.

Para conseguirmos fechar o cal eidocicl o de seis tetraedros, é necessário esticarmos os tetraedros(al terar as medi das) de forma a conseguirmos um hexágono regular no corte transversal.

Figura 26 - Hexágono do Corte Transversal

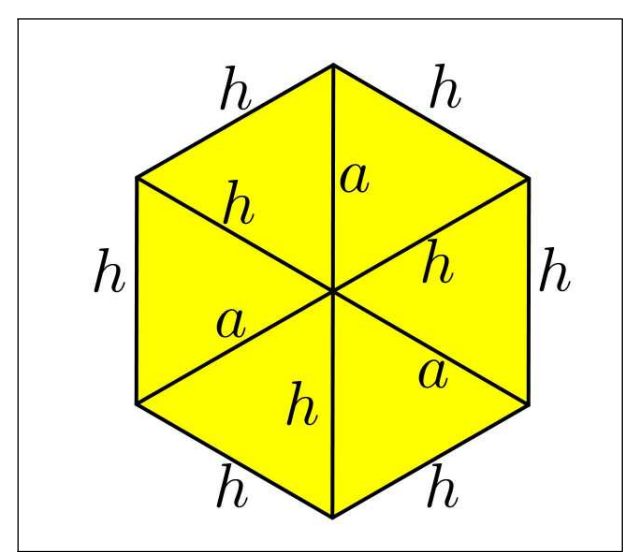

Fonte: Elaborada pelo autor.

Com isso, os tetraedros deixam de ser regulares, as arestas de ligação a ficam com a mesma medida da altura $h$ das faces triangulares isóscel es dos tetraedros e as arestas que não são de ligação podem ser definidas como b. As relações entre as medidas do tetraedro serão abordadas no Capítul o 5 ao apresentar formas de se trabal har o Teorema de Pitágoras na construção do molde/planificação do cal eidociclo.

O mesmo acontece com o cal ei docicl o de oito tetraedros. Para que possamos fechá-lo, é necessário mudanças nas medidas dos tetraedros, que deixam de ser regulares. Veja a figura 27:

Figura 27 - Cal eidociclo fechado com oito tetraedros não-regulares

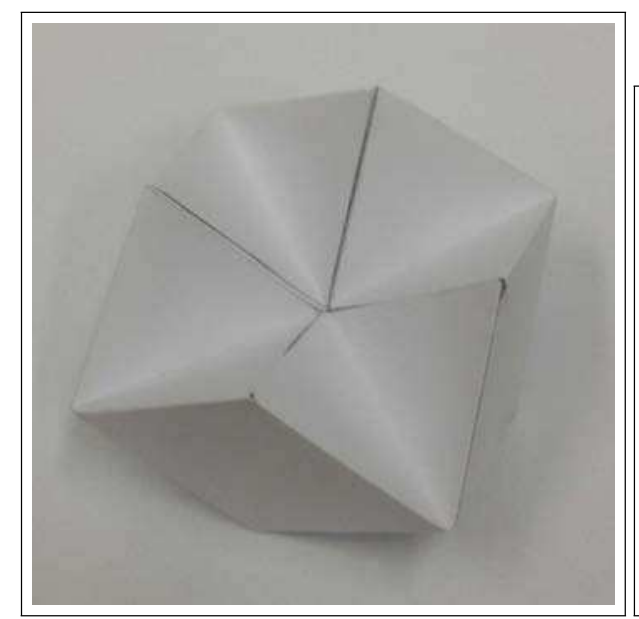

(a) Cal eidociclo já fechado

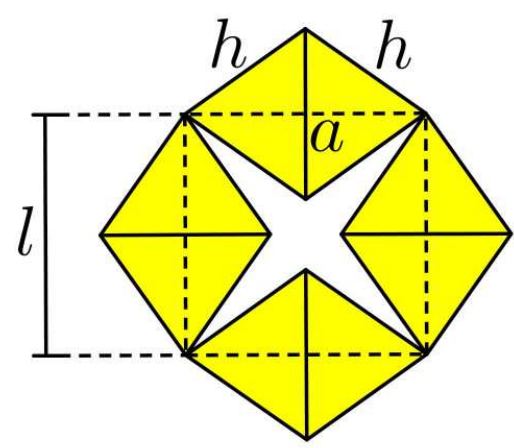

(b) Corte transversal antes de fechar 


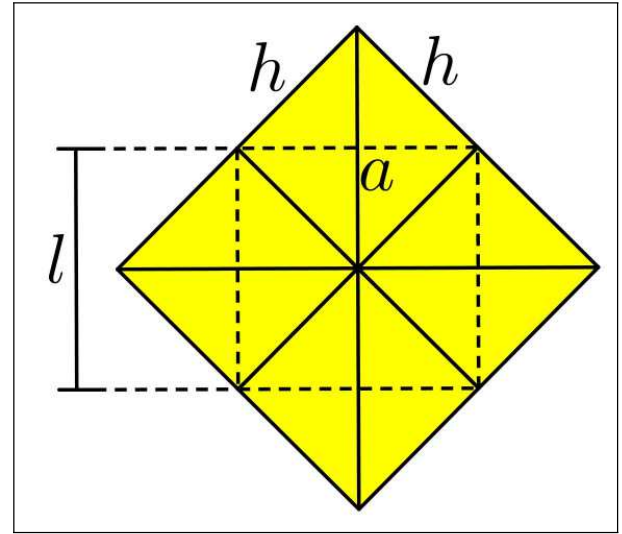

(c) Corte transversal após fechar

Fonte: Elaborada pelo autor.

Val e destacar que, na figura 27b, a medida h é a al tura do triângulo equilátero, face do tetraedro regul ar, já na figura 27c, a medida h é a al tura do triângulo isósceles do tetraedro que não é mai s regul ar. Além disso, a aresta a de ligação é aumentada e as outras arestas que não são de ligação b terão medidas diferentes de a, como visto no comentário abaixo da figura 26.

Mais um exemplo de cal eidociclo fechado, agora com dez tetraedros.

Figura 28 - Cal eidociclo fechado com dez tetraedros não-regulares

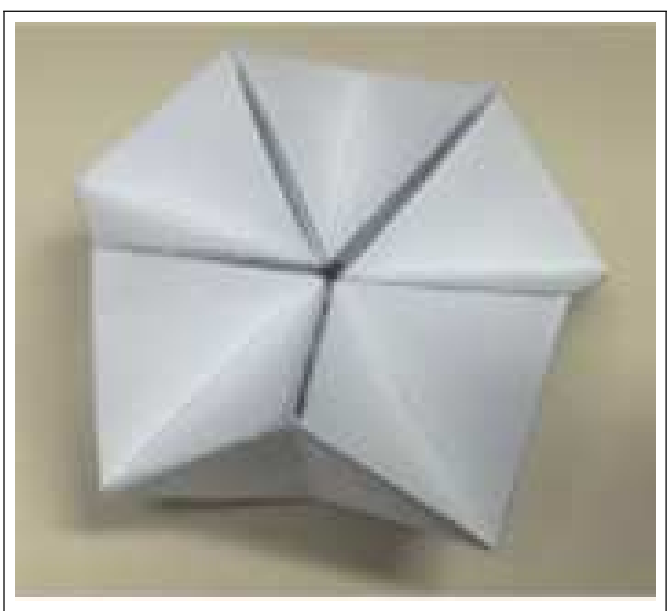

(a) Cal eidociclo já fechado

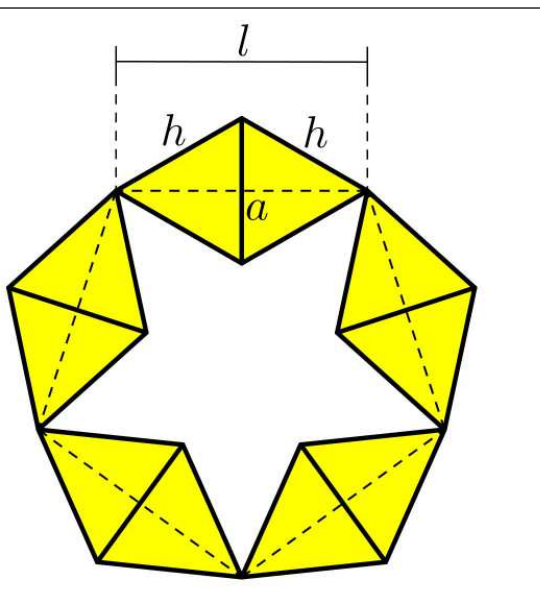

(b) Corte transversal antes de fechar 


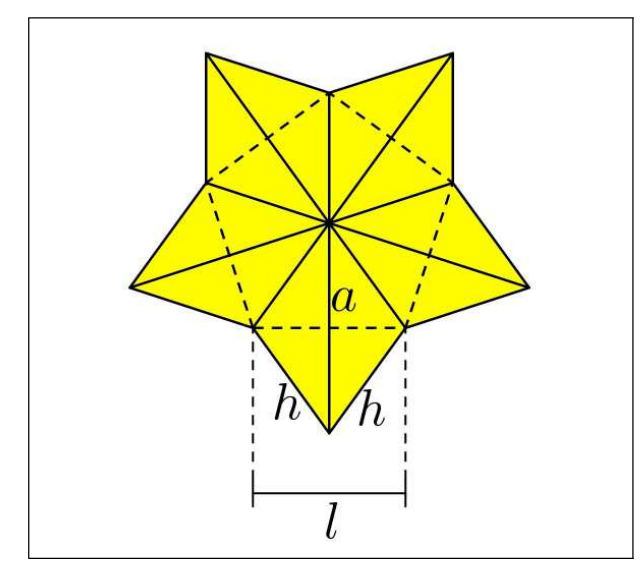

(c) Corte transversal após fechar

Fonte: Elaborada pelo autor.

Perceba que nesse caso, a base do cal eidociclo é um pentágono regular e assim como na figura 27, a medida $\mathrm{h}$ da figura $28 \mathrm{~b}$ corresponde à al tura do triângulo equilátero, face do tetraedro regular, e na figura 70 , a medida $h$ é a al tura do triângul o isóscel es do tetraedro que não é mais regular. 
CAPÍTULO

\section{4}

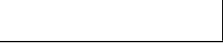

\section{ENSINO DE SIMETRIAS POR MEIO DOS CALEIDOCICLOS}

O currículo do Ensino Fundamental - Anos Finais do Estado de São Paulo sugere o estudo de simetrias no $7^{\circ}$ ano e apresenta uma proposta que expl ora as ideias de si metria axial e rotacional em objetos do dia a dia, na natureza, em mal has quadricul adas e mal has de pontos.

A presentamos uma proposta de atividade envolvendo os cal eidociclos para que sejam desenvolvidas competências e habilidades como:

· identificação, comparação e interpretação de simetrias;

- apreciação das linguagens do desenho, pintura, arquitetura, etc, com base nos padrões geométricos;

mani pul ação de formas geométricas planas e espaciais, e

- criação de imagens com simetria axial e rotacional.

\subsection{Pré-requisitos}

Para trabal har com a simetria axial e rotacional com os cal eidocicl os, é necessário que os al unos tenham visto as noções do que seja cada uma del as. Não há a necessidade de que seja a definição matemática formal, mas no mínimo as noções básicas como, por exemplo, a forma como foi citado em Conceitos Introdutórios.

É possível trabal har com os al unos a construção de imagens com simetria axial e rotacional antes de lidar com os caleidociclos. 


\subsubsection{Simetria axial: proposta de atividade}

Material necessário:

- uma fol ha de papel sulfite;

- uma régua milimetrada;

um lápis preto $n^{0} 2$;

uma borracha brancae

- lápis de cor (caso queiram colorir).

Fazer margem de $2 \mathrm{~cm}$ no papel sulfite e dobrar a folha ao meio na horizontal (ou vertical se preferir) para facilitar o traçado de uma linha dividindo a área de desenho ao meio. Aconsel hase fazer essa divisão fraca, pois há a possi bilidade dela ser apagada ao terminar a construção da simetria e iniciar a coloração.

Para iniciar o desenho em si, peça aos al unos que façam um desenho livre em uma das metades da fol ha. Pode sugerir o desenho de metade de al guma imagem conhecida com simetria axial ou não, ou ainda, utilização livre de linhas curvas, retas, etc. Peça aos al unos que dê preferência a desenhos com linhas bem definidas e sem muito detal hamento, isso facilitará a reflexão daimagem.

Após concl uir o desenho, os al unos deverão dobrar a fol ha ao meio fazendo com que o desenho fique por dentro da dobra. Com o lápis preto inclinado, deverão fazer movimentos de zigue-zague por trás do desenho, pressionando de forma que a imagem fique marcada na outra metade da folha Veja uma sequência na imagem a seguir:

Figura 29 - Sequência da construção da reflexão

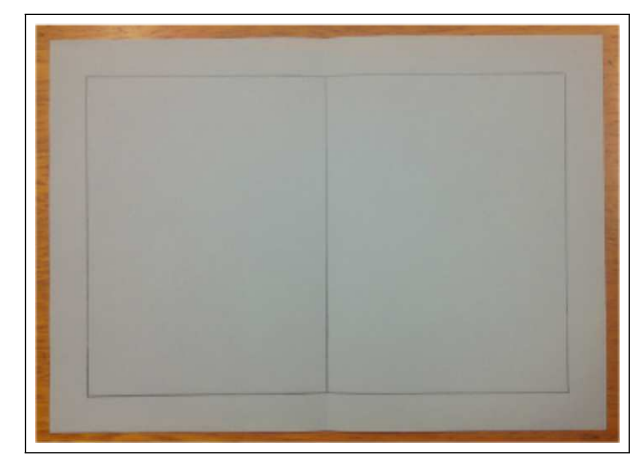

(a) Margens e divisão

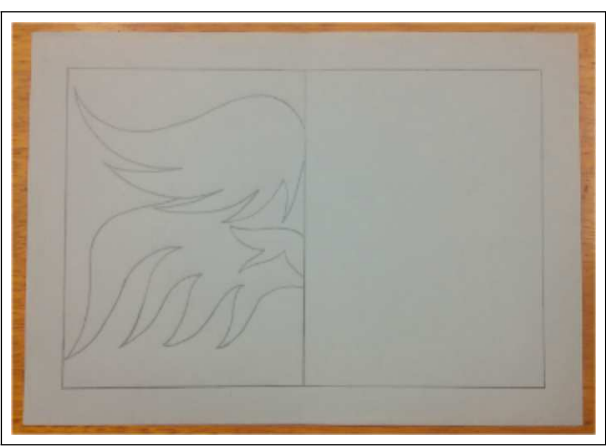

(b) Metade pronto para a reflexão 


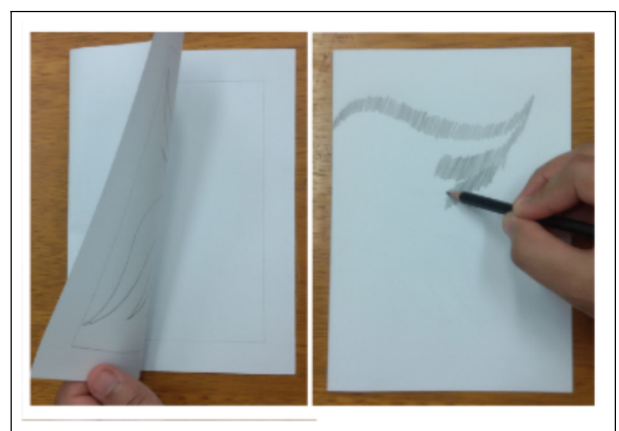

(c) Dobra e marca da reflexão

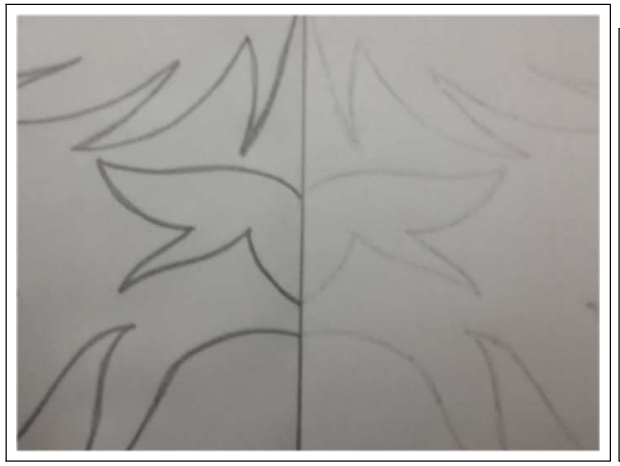

(e) Ampliação da reflexão

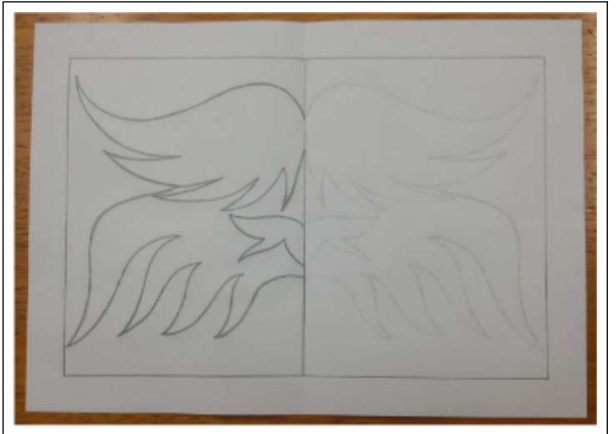

(d) Reflexão antes de reforçar

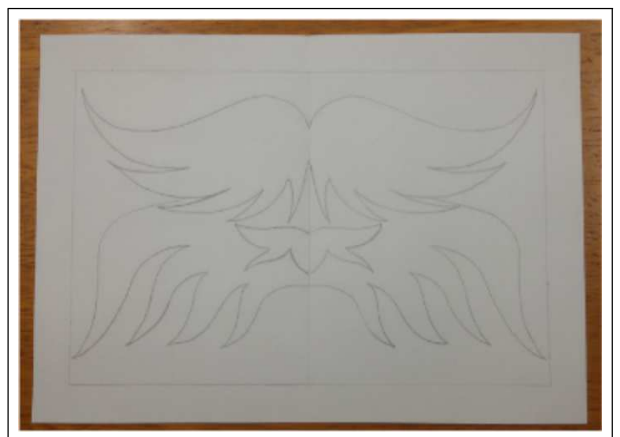

(f) Pronto para colorir

Fonte: Elaborada pelo autor.

Uma outra forma para não dobrar a folha, caso queiram fazer em um painel, é copiar o desenho feito com uma fol ha de caderno fina ou fol ha de papel vegetal, marcando pontos de referência como os cantos da margem, e virar essa fol ha sobre a metade sem desenho, como se estivesse virando uma fol ha em um caderno. Feito isso e al inhados os pontos de referência, devemos fazer os movimentos de zigue zague com o lápis, como citado anteriormente.

Em ambos casos, a reflexão fica com linhas fracas, que devem ser reforçadas em seguida.

Seguem al gumas imagens de trabal hos real izados em sal a:

Figura 30 - Trabal hos de Simetria Axial em papel A3 realizados por al unos de $7^{\circ}$ ano

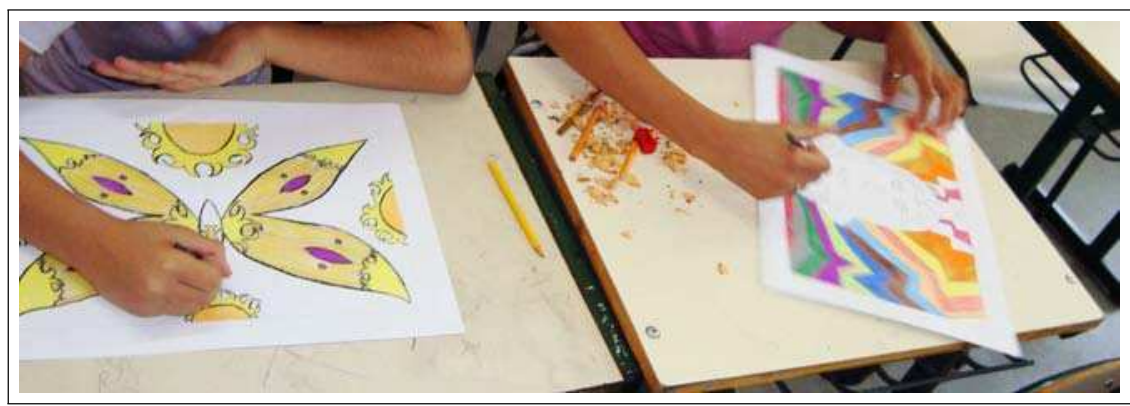

(a) 


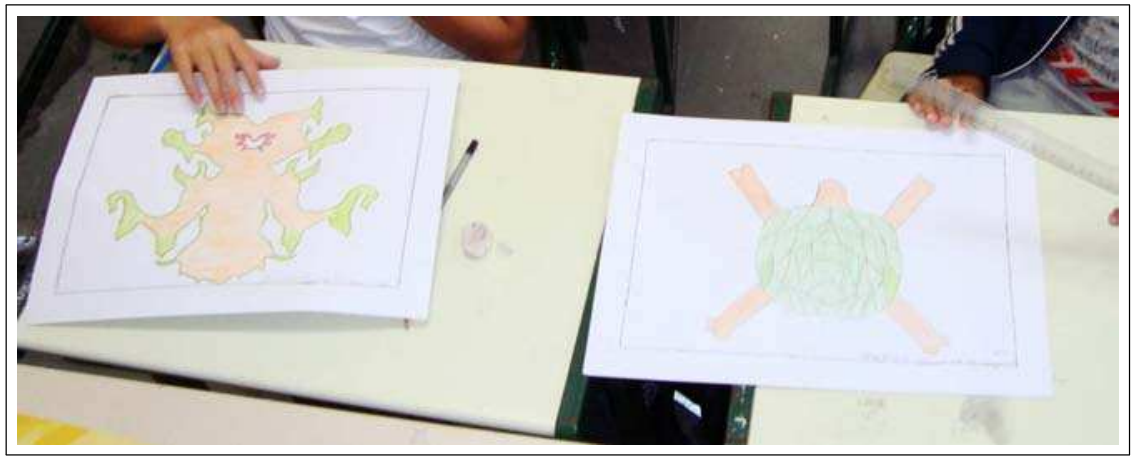

(b)

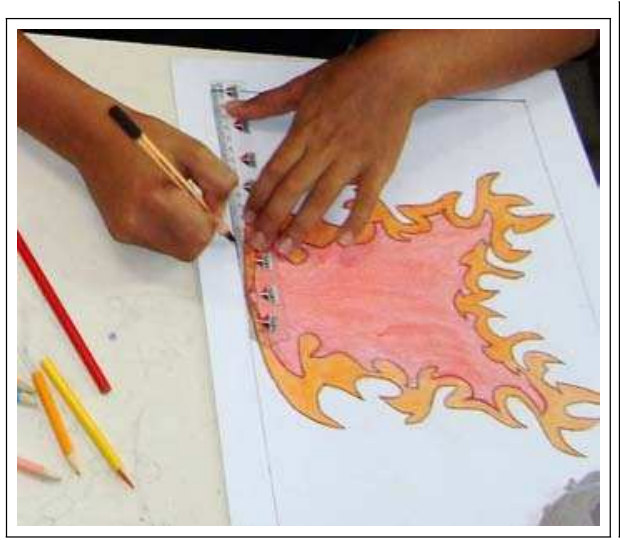

(c)

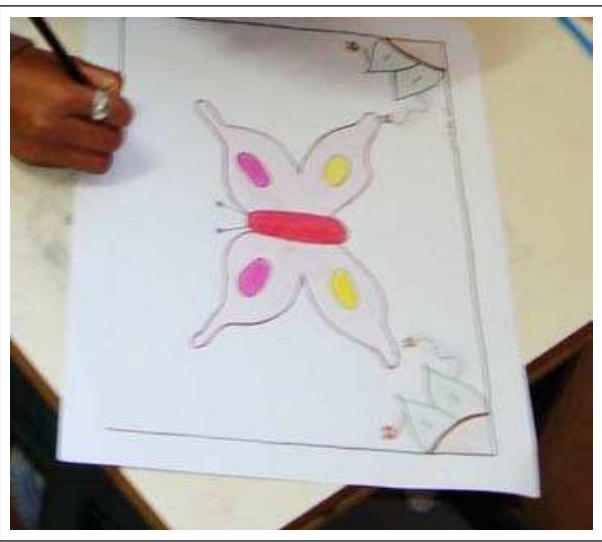

(d)

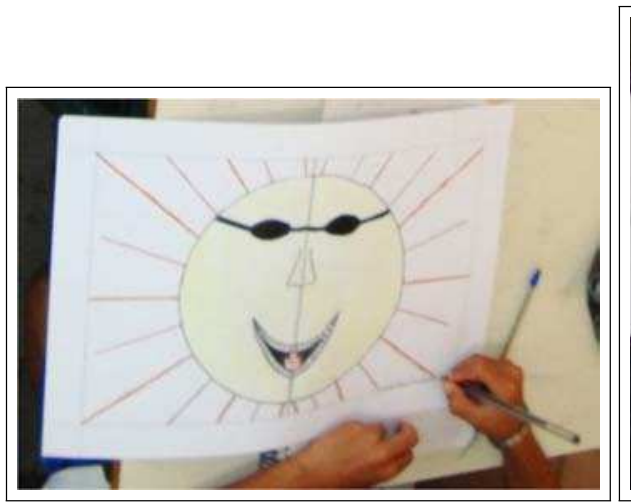

(e)

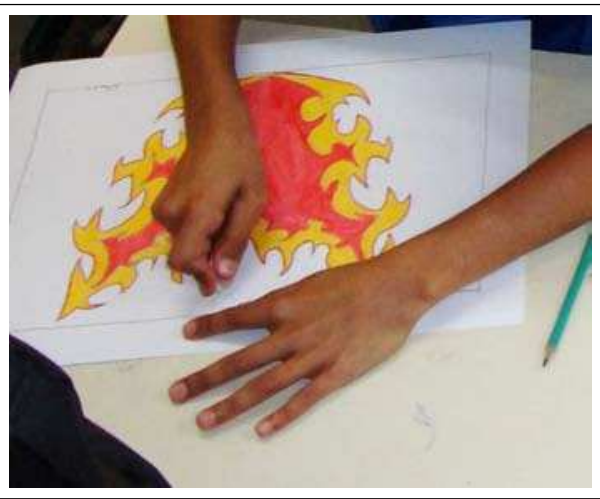

(f) 


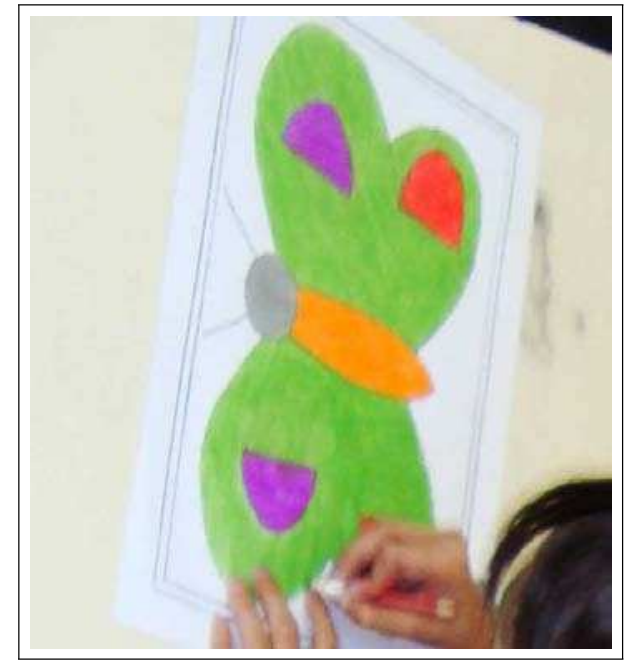

(g)

Fonte: Elaborada pelo autor.

\subsubsection{Simetria rotacional: proposta de atividade}

Material necessário:

- uma fol ha de papel sulfite;

- uma régua milimetrada;

- um compasso;

um transferidor e

uma fol ha de papel vegetal (ou fol ha de caderno fina).

É possível a criação da imagem rotacional mente si métrica sem a utilização do compasso, pois ele será utilizado apenas para cria uma borda para a imagem. O transferidor também pode ser substituído por esquadros, ficando limitado aos ângul os de rotação possíveis de serem criados utilizando estes instrumentos.

Para dar início, construir margem de $2 \mathrm{~cm}$ e marcar um ponto central na folha, que pode ser local izado com medidas ou si mplesmente traçando as diagonais da fol ha de forma fracae apagando-as assim que marcar o centro.

Com o compasso, traçar uma circunferência no centro da fol ha de forma a ocupar o máximo de espaço dentro da margem. Decidir de quantos graus será o ângulo de simetria rotacional, lembrando que o val or desejado deve dividir $360^{\circ}$ em partes iguais. $O$ exemplo a seguir utiliza simetria rotacional de $120^{\circ}$. 
Seguindo com a construção, dividir a circunferência em seis partes iguais de $60^{\circ}$ cada. Essa divisão será para que possamos utilizar duas imagens distintas na rotação, caso deseje apenas uma imagem, pode ser feito apenas em três partes de $120^{\circ}$, ou da forma que preferir.

Nesse momento já é possível a construção do desenho, que deverá estar sobre uma das divisões dos setores, que será a ref erência para que seja repetida no ângul o de $120^{\circ}$.

O desenho pode ser simétrico axial tendo como eixo de simetria a divisória dos setores, mas não é necessário que seja.

Seguem as imagens que são utilizadas no exemplo, uma com simetria axial e outra não.

Figura 31 - Exemplos para criar simetria rotacional

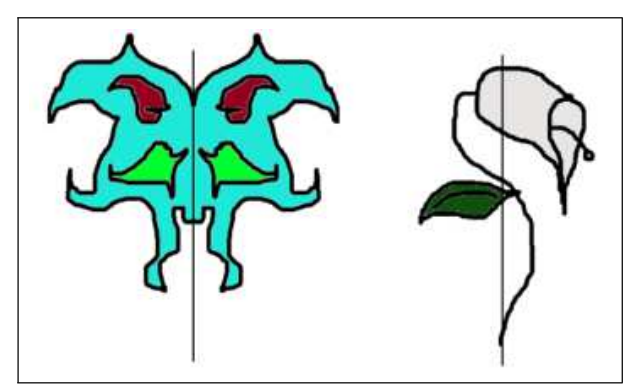

Fonte: Elaborada pelo autor.

Para reproduzir a imagem exata na rotação de $120^{\circ}$ basta usar a fol ha de papel vegetal, copiar a imagem incl uindo o eixo de ref erência até o centro de rotação, pintar de lápis preto $n^{\circ} 2$ a parte de trás da fol ha de papel vegetal onde está a cópia do desenho e posicionar no eixo de rotação $120^{\circ}$ onde a imagem deve ser idêntica.

Caso haja mais imagens a ser reproduzidas, basta seguir o mesmo procedimento, até que todas el as apareçam idênticas na rotação desejada

Figura 32 - Simetria Rotacional com e sem Simetria Axial

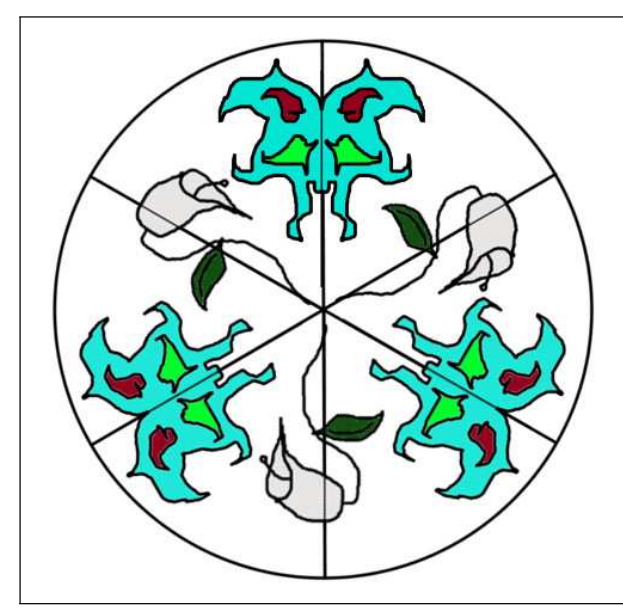

Fonte: Elaborada pelo autor. 


\subsection{Proposta de Atividade: simetria com o caleidociclo}

Material necessário:

- molde do cal eidociclo disponível no Apêndice A figura 56

tesoura

cola

- lápis de cor (ou canetinhas)

A proposta tem variações de acordo com o nível de habilidades que a turma se encontra Por isso, apresentamos primeiramente a proposta para turmas em nível básico que contempla o reconhecimento e identificação das si metrias.

Entregue o molde para cada um dos al unos e peça para darem cores ao desenho antes de iniciar o recorte. Lembre-os que deverão estar atentos para utilizar as mesmas cores nas partes correspondente a uma imagem.

A pós a col oração, já se pode recortar o contorno do molde e iniciar a dobra em todas as linhas retas. Para facilitar a montagem, dê a sugestão de dobrarem para os dois lados e marcar a dobra com uma régua (vincar a dobra).

Paraconcluir, bastaajustar a peça como na figura 33 e utilizar cola Sugerimos autilização de col a branca, sem excesso e bem espal hada, principal mente se utilizarem papel sulfite, pois outros tipos de cola dificultam esta etapa por não colarem direito ou exigirem mai or pressão.

Figura 33 - Exemplo de como montar o cal eidociclo - parte 1

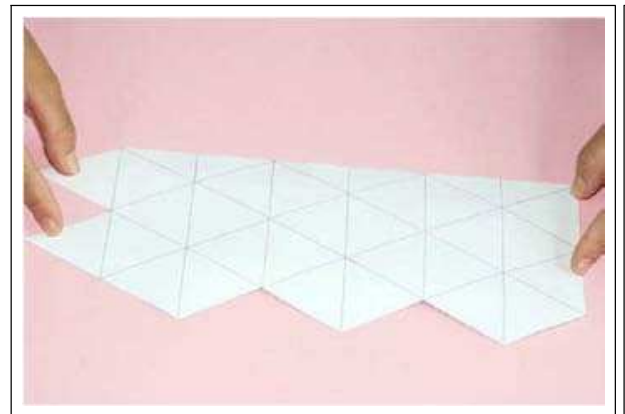

(a)

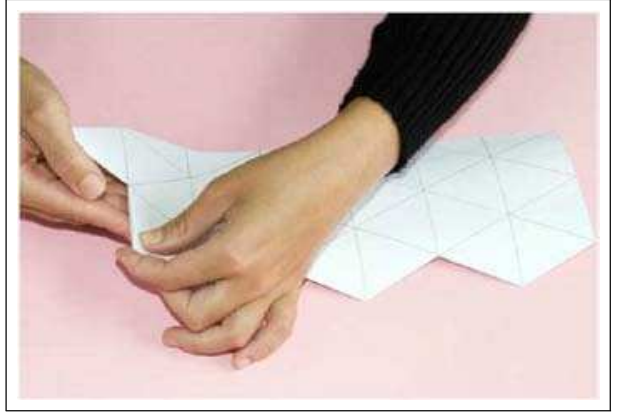

(b) 


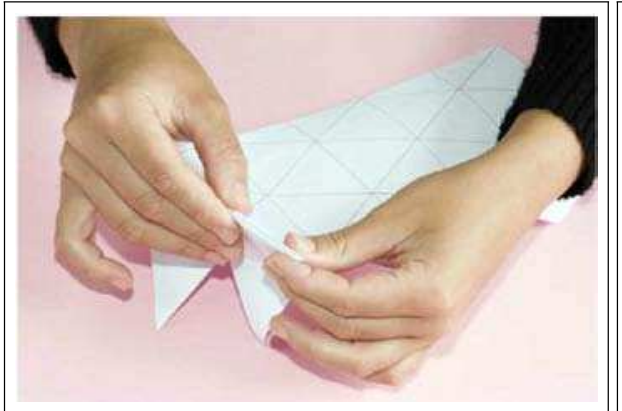

(c)

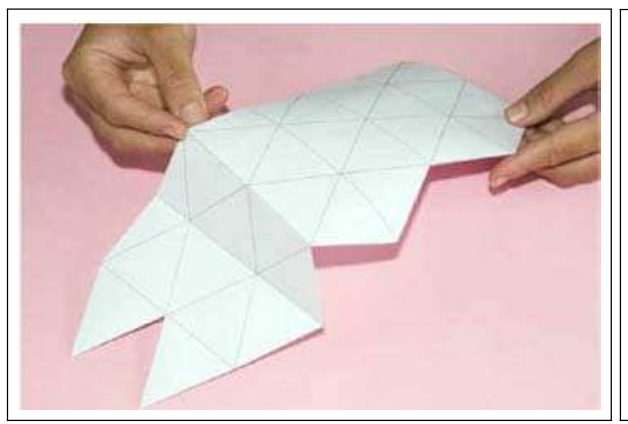

(e)

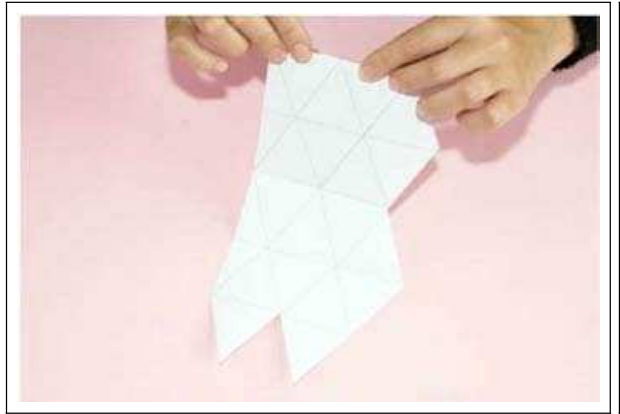

(g)

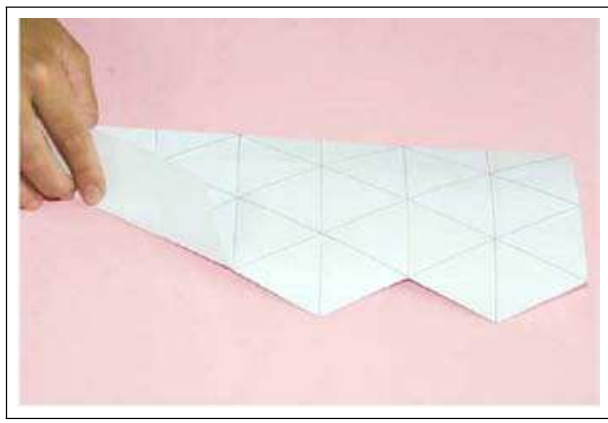

(i)

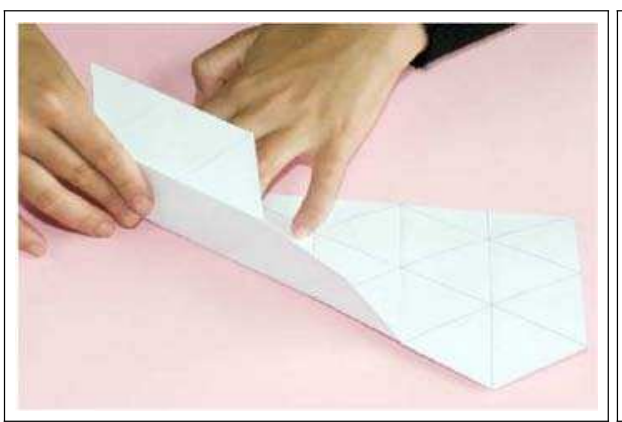

(k)

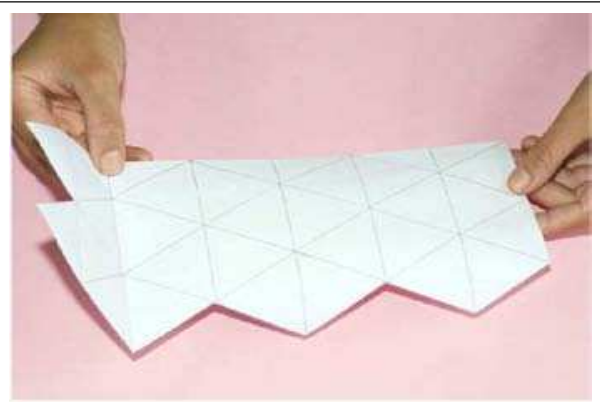

(d)

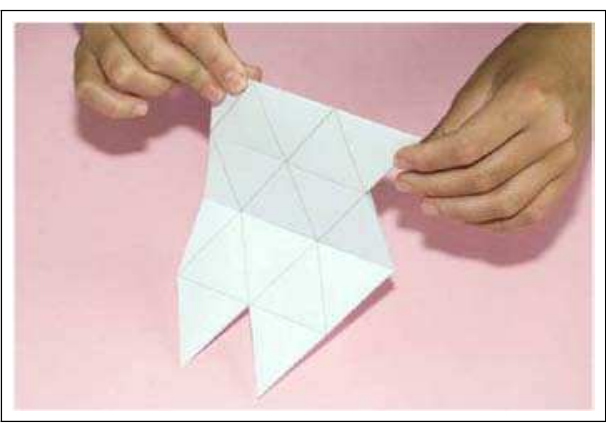

(f)

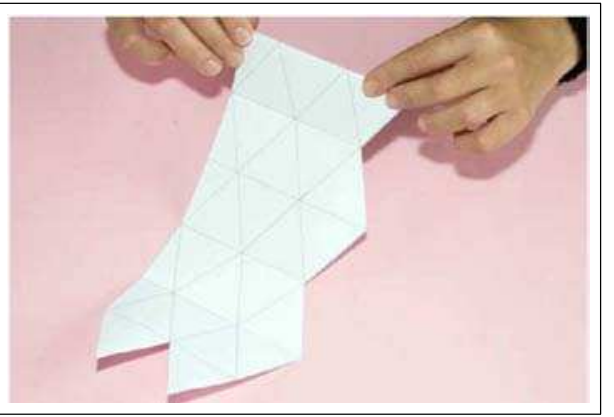

(h)

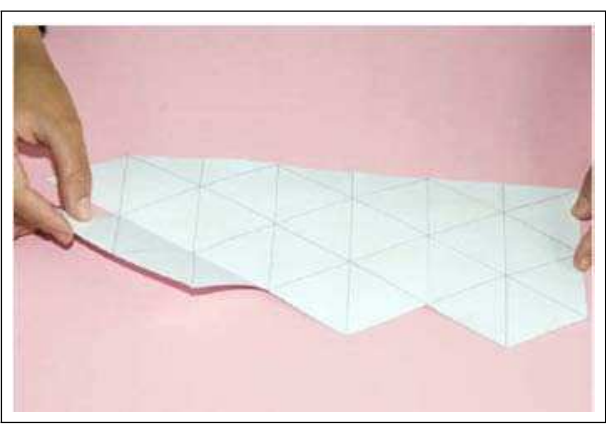

(j)

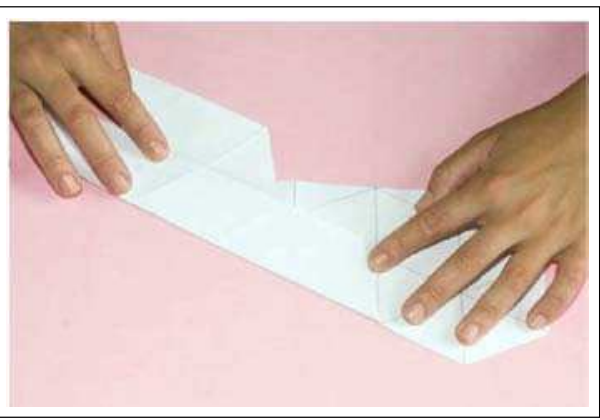

(I) 


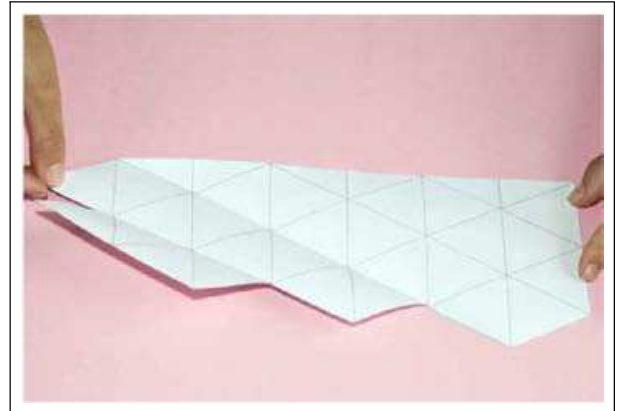

(m)

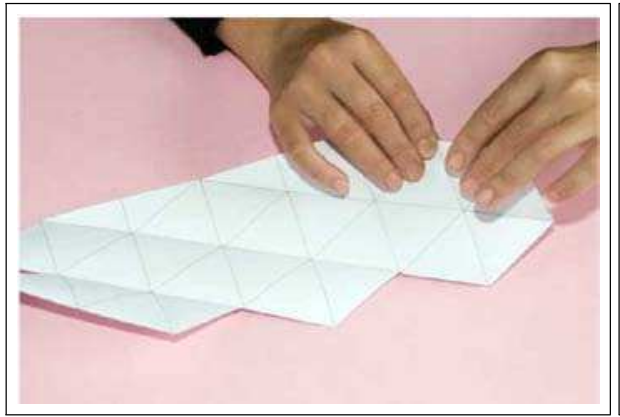

(0)

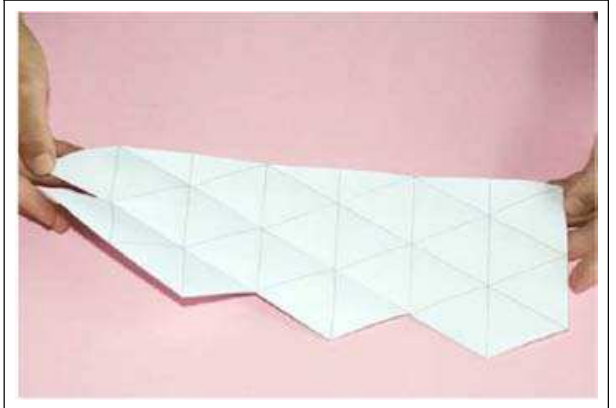

(q)

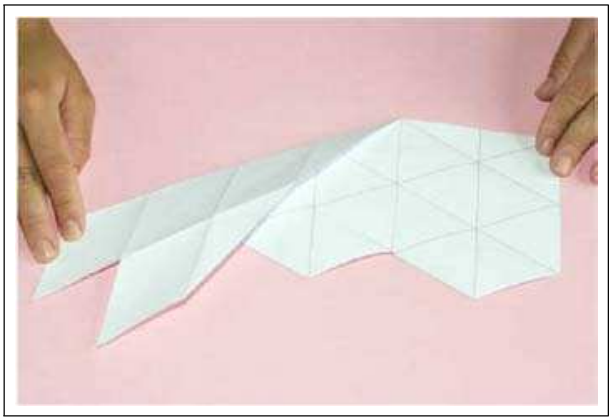

(s)

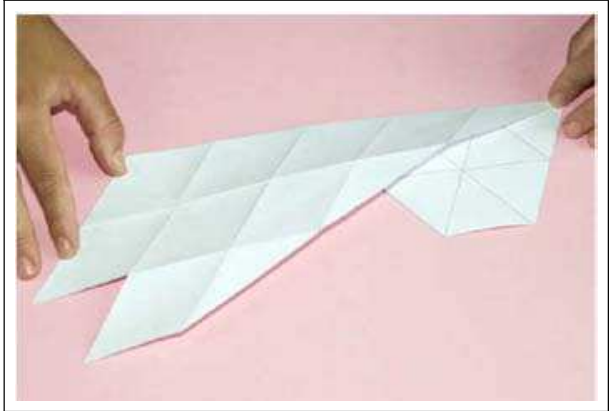

(u)

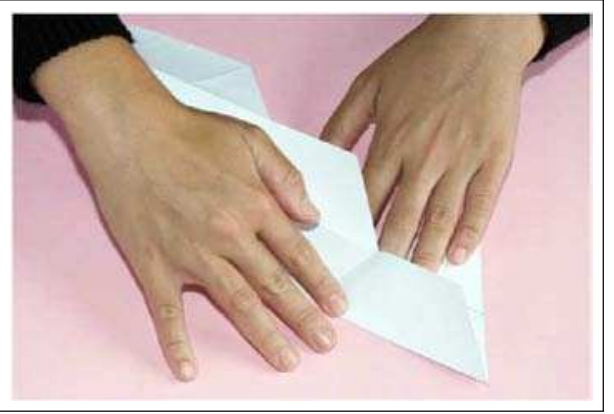

(n)

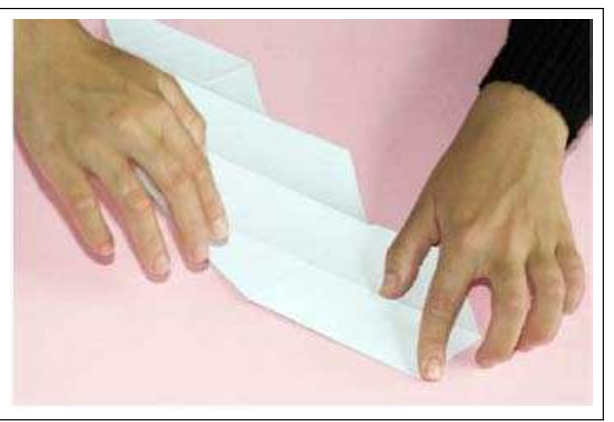

(p)

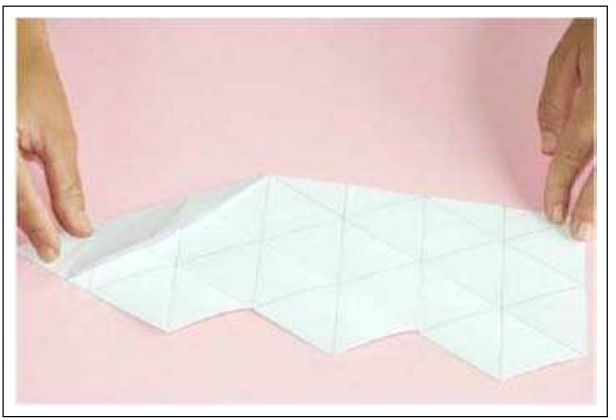

$(\mathrm{r})$

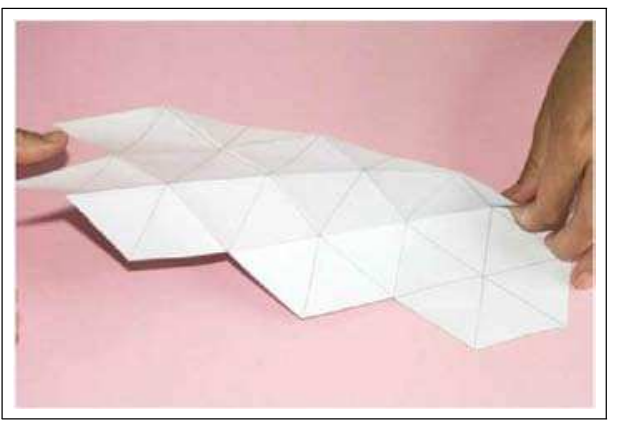

(t)

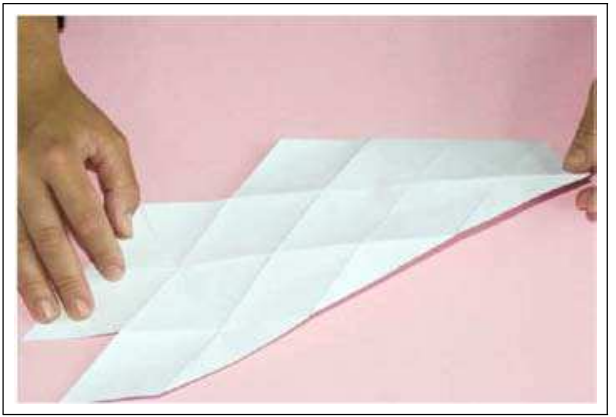

(v) 


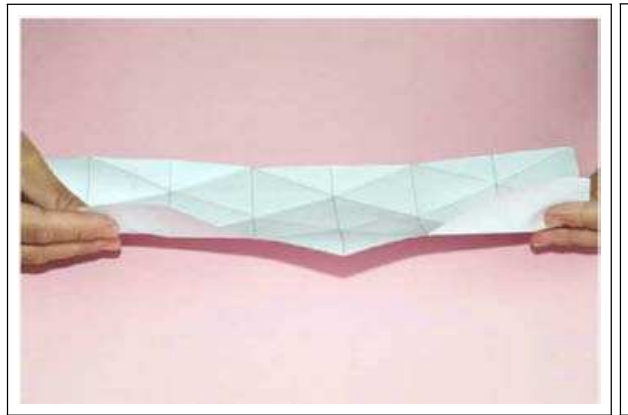

(w)

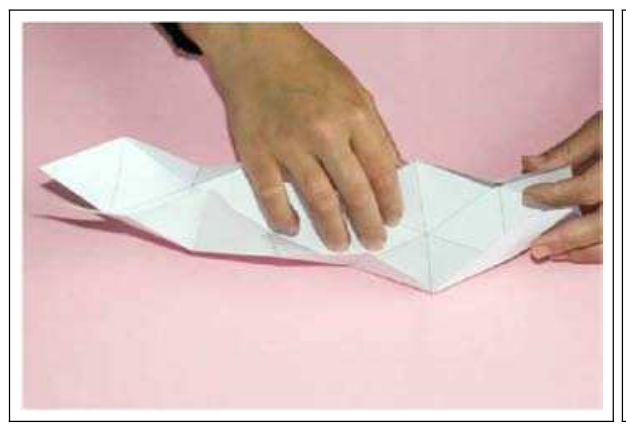

(y)

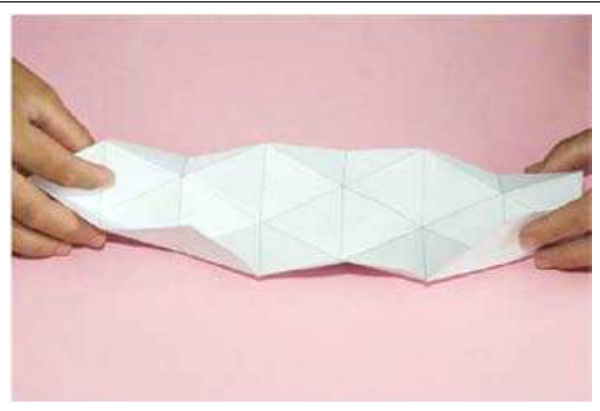

$(\mathrm{x})$

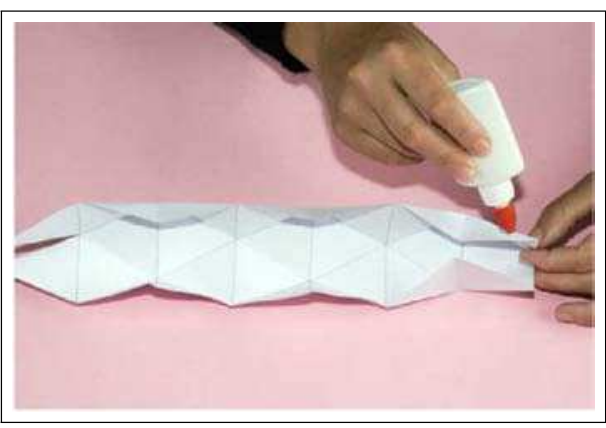

( $)$

Fonte: Brasil (b).

Figura 34 - Exemplo de como montar o cal eidociclo - parte 2

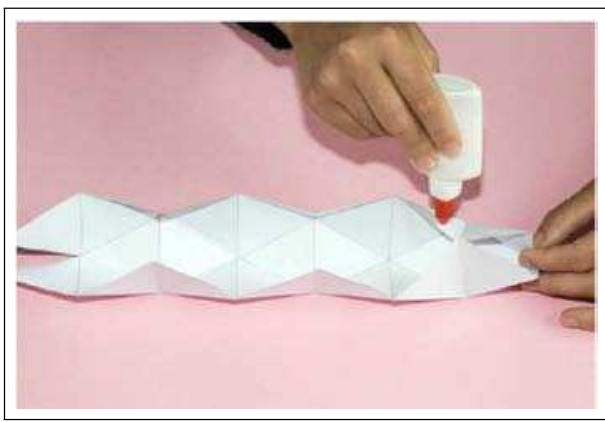

(a)

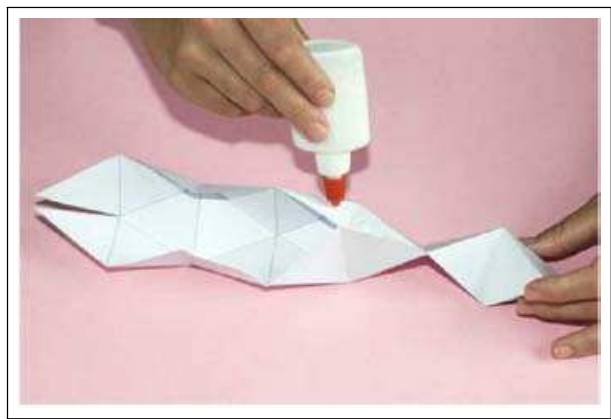

(c)

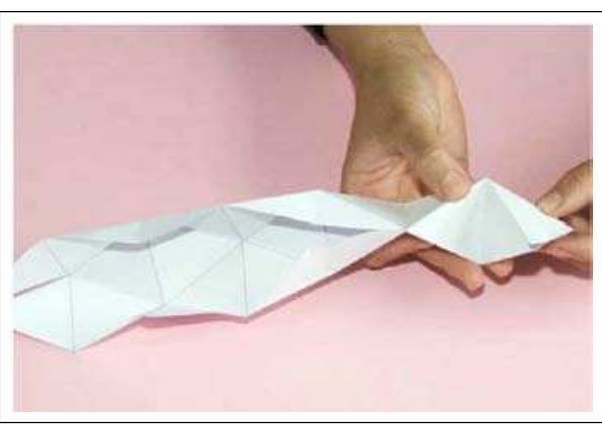

(b)

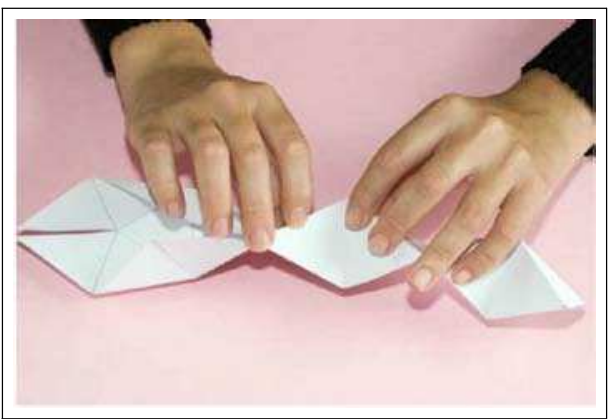

(d) 


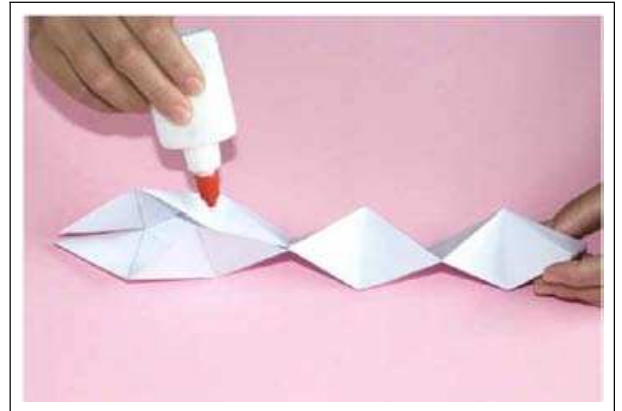

(e)

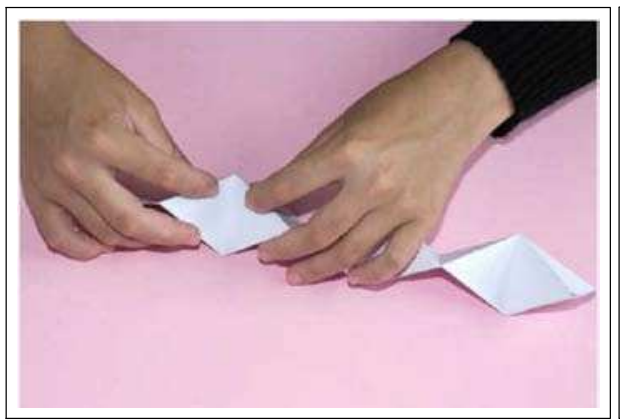

(g)

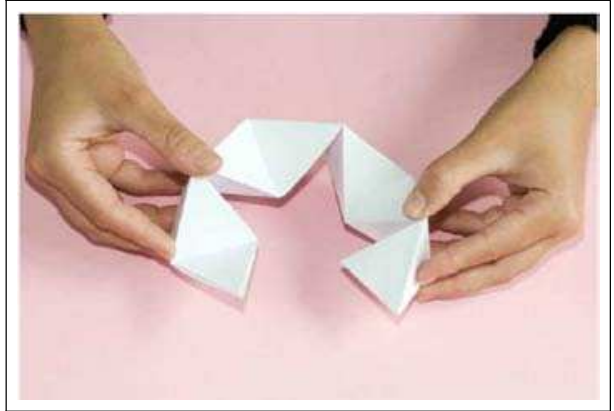

(i)

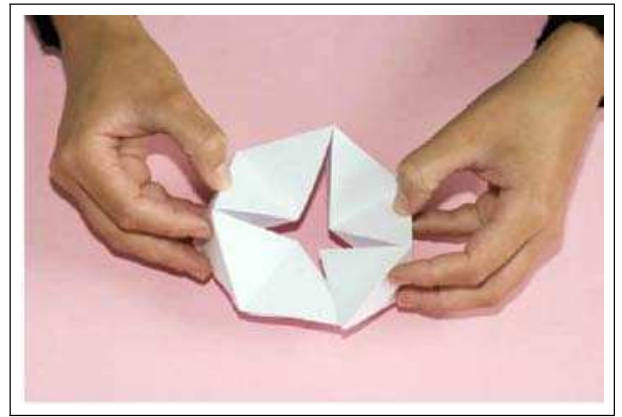

(k)

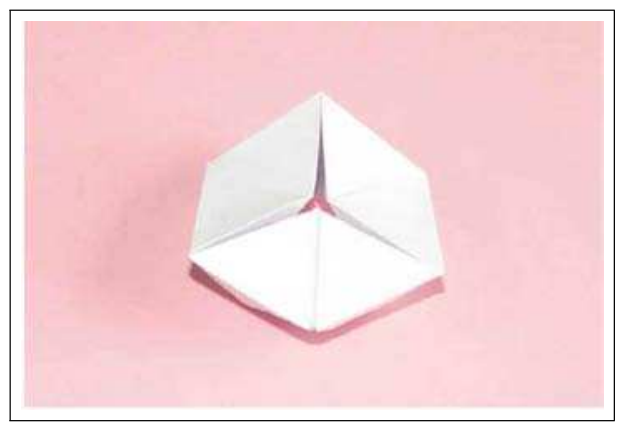

(m)

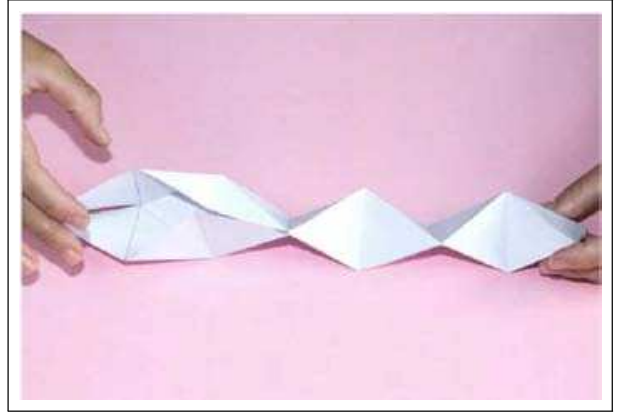

(f)

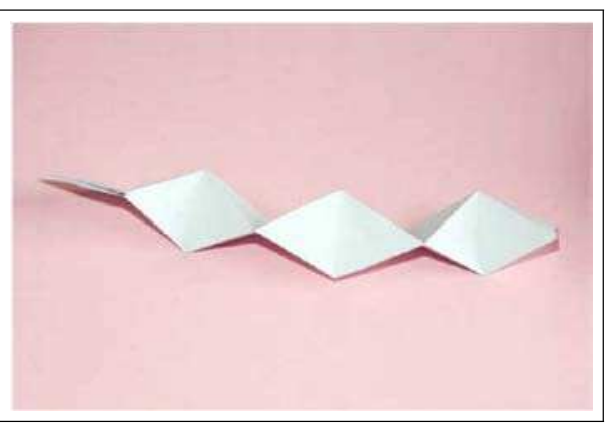

(h)

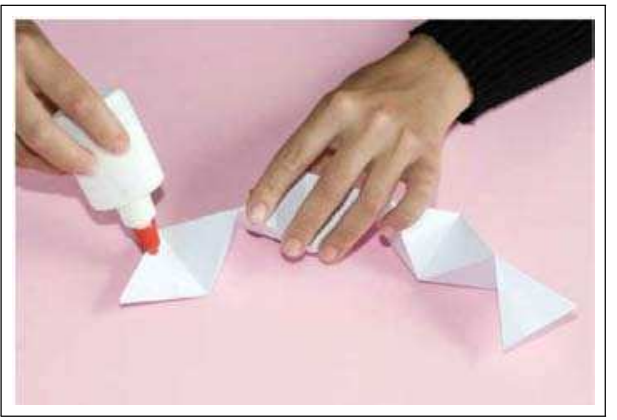

(j)

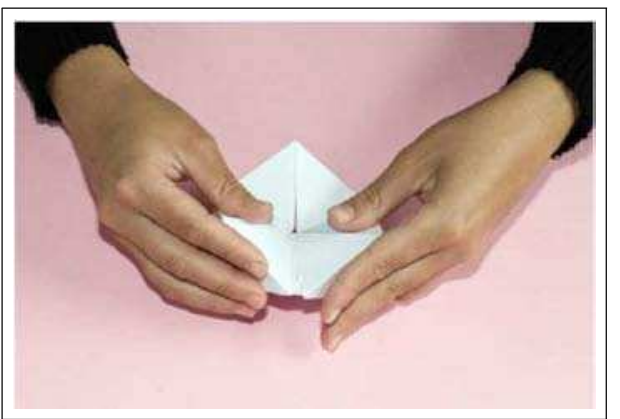

(I)

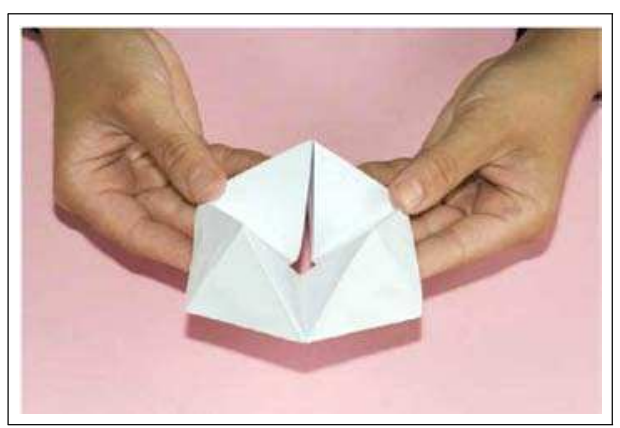

(n)

Fonte: Brasil (b). 
É possível ver essa sequência no endereço < http://webeduc.mec.gov.br/portal doprofessor/ matematica/condigital2/midias/experimentos/Geometria_e_arte/construindo.html >.

A primeira variação serve para turmas em nível adequado, cujas habilidades se destacam na capacidade de identificar e construir simetrias. Para esse grupo sugerimos o molde sem imagens da figura 57 Apêndice $A$ e que sejam indicadas quais as faces que completam uma imagem, deixando ao aluno a tarefa de criar as imagens, colori-las e concluir o processo de montagem.

Uma segunda variação é indica para turmas em nível avançado em que al ém das habilidades anteriores, os al unos são capazes de local izarem as regiões do mol de que se compl etam, a fim de criarem as imagens que aparecerão como si metria rotacional (e com possi bilidade de terem simetria axial local mente também). Nessa situação, incentiva-se mais o raciocíni o e abstração na tarefa de prever as faces do mol de que irão se relacionar no cal eidociclo.

Caso haja interesse, ainda para o grupo de nível básico, é possível utilizar um molde sem imagens (Apêndice A, figura 57), montar o cal eidocicl o e então criar as imagens. Para isso, aconsel hase o uso de canetinhas, pois não haverá a necessi dade de aplicar muita pressão ao desenhar como teria com lápis de cor. 


\section{TEOREMA DE PITÁGORAS, LEI DOS COSSENOS E RELAÇÃO FUNDAMENTAL DA TRIGONOMETRIA: APLICAÇÕES NA CONSTRUÇÃO DO CALEIDOCICLO}

Tradicional mente, as aplicações do Teorema de Pitágoras estão relacionadas com al turas e sombras de prédios, portões de madeira com sarrafo na diagonal, estruturas de madeira para tel hados, distância entre três cidades, rampas, escadas e escadarias, entre outras. Saindo um pouco dessa tradição, propomos a construção do mol de dos cal eidocicl os como forma de perceber a necessi dade do conhecimento do teorema e apl icálo nessa construção.

As seções a seguir, apresentam casos em que o teorema seráutilizado na planificação dos cal eidociclos. Durante a construção, há imagens para acompanhar o processo, mas os moldes em si, estão disponíveis no Apêndice A.

\subsection{Caleidociclo com Tetraedro Regular: altura de face}

A planificação para o tetraedro regular não tem segredos, pois como as faces dos tetrae dros são triângul os equiláteros, basta criar uma mal ha com triângul os equiláteros.

O número de triângul os que devemos por na planificação, pode ser descrito usando linhas e col unas de triângul os equiláteros. Como visto no Capítul o 3 , os cal ei dociclos com tetraedros regul ares possuem número par de tetraedros sendo no mínimo oito. Assim, o número de colunas de triângul os da planificação deverá ser nove, uma a mais para usar como aba na colagem; o mesmo ocorre para as linhas, como são necessários quatro triângul os para fazer um tetraedro, utilizaremos cinco linhas de triângul os, uma a mais para usar como aba de col agem.

A planificação abaixo é de um cal eidociclo com oito tetraedros regulares. 
Figura 35 - Planificação com oito tetraedros regulares

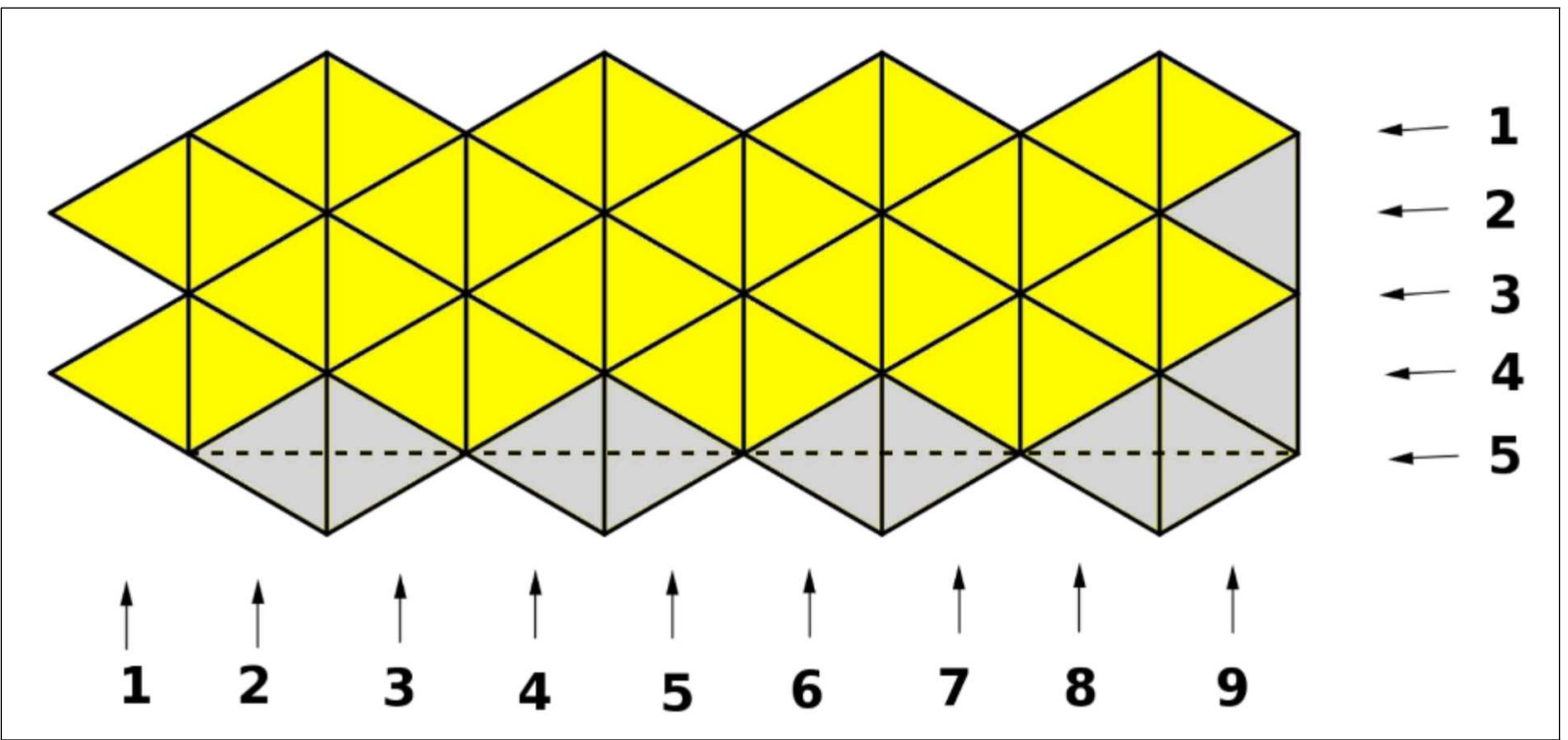

Fonte: Elaborada pelo autor.

Como visto na figura 23, temos no corte transversal a aresta a, a al tura de face h e a medida I do lado da base quadrada do anel que está tracejada. Mostraremos primeiro a relação entre a al tura de face e a aresta.

Como a al tura de um triângulo equilátero o divide em dois triângul os retângul os congruentes, usando o teorema de Pitágoras, temos

$$
\begin{aligned}
a^{2} & =(a / 2)^{2}+h^{2} \\
h^{2} & =a^{2}-(a / 2)^{2} \\
h^{2} & =\frac{4 a^{2}-a^{2}}{s \frac{4}{3 a^{2}}} \\
h & =\frac{\sqrt{4}}{3} \\
h & =\frac{a \sqrt{2} .}{}
\end{aligned}
$$

Relacionando o lado I da base do anel com a aresta a

$$
\begin{aligned}
& h^{2}=(I / 2)^{2}+(a / 2)^{2} \\
& h^{2}=\frac{l^{2}+a^{2}}{4} .
\end{aligned}
$$

Como h $=\frac{a^{\sqrt{ }} \overline{3}}{2}$ 


$$
\begin{aligned}
\frac{3 a^{2}}{4} & =\frac{1^{2}+a^{2}}{4} \\
3 a^{2}-a^{2} & =1^{2} \\
2 a^{2} & =1^{2} \\
a \overline{2} & =1 \sqrt{ } \overline{2} \\
a & =\frac{I^{2}}{2} .
\end{aligned}
$$

Mais al gumas mudanças de variáveis, e ficamos com $\mathrm{h}$ também em função de l.

$$
\begin{aligned}
& h=\frac{a^{\sqrt{3}}}{v^{2} \overline{2} \sqrt{3}} \\
& h=\frac{\frac{1^{2}}{\sqrt{2}}}{h=\frac{1 \frac{2}{6}}{4} .}
\end{aligned}
$$

Apesar de não ser necessário ef etuar esses cál culos para a construção do molde dos cal eidocicl os de tetraedros regulares, a rel ação entre a altura de face, a aresta e o lado da base do anel serve de introdução para as planificações com tetraedros não regulares.

Para construir a planificação de qual quer outro cal eidociclo com tetraedros regulares, basta acrescentar um número par de colunas na planificação anterior, ou seja, se quiséssemos fazer um cal eidociclo com 14 tetraedros regul ares, bastaria acrescentar seis col unas ao mol de, resultando 15 colunas e 5 linhas de triângulos equiláteros. E o raciocínio é o mesmo para caleidocicl os com quantidades mai ores de tetraedros regulares.

\subsection{Caleidociclo fechado e as relações das medidas}

Veremos que as rel ações entre as medi das dos tetraedros e o lado da base do anel são um pouco diferentes das vistas na seção anterior. Um dos fatos que leva a esse raciocínio é que, para conseguirmos fechar o cal ei dociclo, é necessário modificar o tetraedro e assim, modificar o ângulo dos vértices que se encontram no centro, como visto no capítulo 3, seção 3.2.

Consideraremos inicial mente o cal eidociclo fechado de dez tetraedros para rel acionarmos as medidas.

Na figura 70, da secção transversal do cal eidociclo, temos a medidal do lado da base do anel, a aresta a e altura de face $h$. Primei ramente, destacamos um dos triângulos de base a e altural/2: 
Figura 36 - Triângulo isósceles de base a e altural/ 2

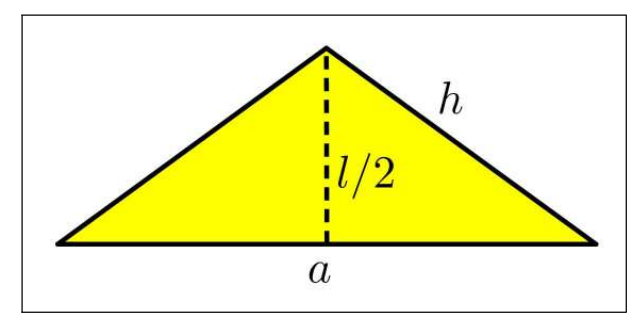

Fonte: Elaborada pelo autor.

O ângulo a tem medida $36^{\circ}$, pois divide a circunferência central do cal eidociclo em 10 partes iguais. A partir da lei dos cossenos, temos

$$
\begin{aligned}
h^{2} & =h^{2}+a^{2}-2 a h \cos 36^{\circ} \\
2 a h \cos 36^{\circ} & =a^{2} \\
h & =\frac{a^{2}}{2 a \cos 36^{\circ}} \\
h & =\frac{a}{2 \cos 36^{\circ}} .
\end{aligned}
$$

Destacando agora, um dos triângul os retângulos formados pel os segmentos a/ 2, h el/ 2 , e utilizando o teorema de Pitágoras, temos

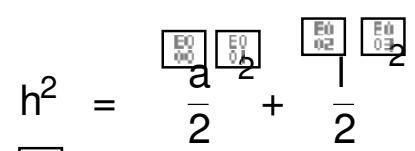

$$
\begin{aligned}
& {\frac{a}{2 \cos 36^{\circ}}}^{\text {熙 }}=\frac{a^{2}}{4}+\frac{l^{2}}{4} \\
& \frac{a^{2}}{4 \cos ^{2} 36^{\circ}}=\frac{a^{2}}{4}+\frac{l^{2}}{4} \\
& \frac{a^{2}}{\cos ^{2} 36^{\circ}}=a^{2}+l^{2} \\
& \frac{a^{2}-a^{2} \cos ^{2} 36^{\circ}}{\cos ^{2} 36^{\circ}}=1^{2} \\
& a^{2}\left(1-\cos ^{2} 36^{\circ}\right)=1^{2} \cos ^{2} 36^{\circ} \\
& a^{2} \operatorname{sen}^{2} 36^{\circ}=1^{2} \cos ^{2} 36^{\circ} \\
& a^{2}=\frac{I^{2} \cos ^{2} 36^{\circ}}{\operatorname{sen}^{2} 36^{\circ}} \\
& a^{2}=1^{2} \cot ^{2} 36^{\circ} \\
& a=1 \cot 36^{\circ} \text {. }
\end{aligned}
$$

Para que possamos deixar tudo em função de I, basta fazer mais uma substituição 


$$
\begin{aligned}
h & =\frac{a}{2 \cos 36^{\circ}} \\
h & =\frac{1 \cot 36^{\circ}}{2 \cos 36^{\circ}} \\
h & =\frac{1}{2 \operatorname{sen} 36^{\circ}} .
\end{aligned}
$$

Agora, para construir um cal eidocicl o fechado de dez tetraedros, basta definir a medidal do lado da base do anel pentagonal, pois

$$
\begin{aligned}
& a=1 \cdot \cot 36^{\circ} \\
& h=\frac{1}{2 \operatorname{sen} 36^{\circ}} .
\end{aligned}
$$

Podemos generalizar essas relações. Dado n o número de lados da base do anel, com $n \geq 3$, el a medida do lado da base, temos

$$
\begin{aligned}
& \alpha=\frac{360^{\circ}}{2 \mathrm{n}} \\
& a=1 \cdot \cot \alpha \\
& h=\frac{1}{2 \operatorname{sen} \alpha} .
\end{aligned}
$$

Assim, se quisermos fazer um cal eidociclo fechado de base hexagonal de lado I $=5 \mathrm{~cm}$, teremos as medidas

$$
\begin{aligned}
& \alpha=\frac{360^{\circ}}{2 \cdot 6}=30^{\circ} \\
& a=5 \cdot \cot 30^{\circ} \approx 8,66 \mathrm{~cm} \\
& h=\frac{5}{2 \operatorname{sen} 30^{\circ}}=5 \mathrm{~cm} .
\end{aligned}
$$


Figura 37 - Planificação do cal eidociclo fechado com 12 tetraedros (base hexagonal)

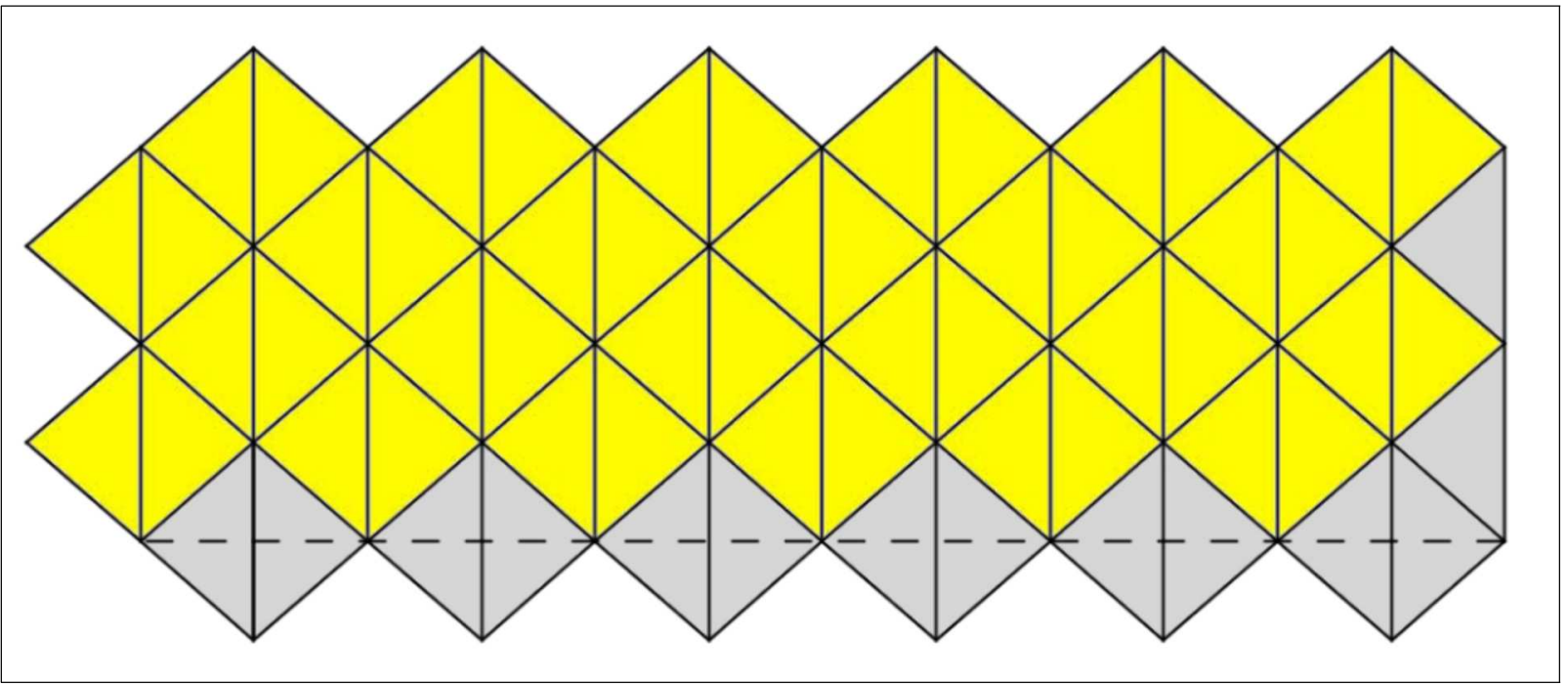

Fonte: Elaborada pelo autor.

\subsection{Propost as de Atividades}

Como nesse capítul o apresentamos conhecimentos matemáticos presentes no currículo do $8^{\circ}$ e $9^{\circ}$ ano do Ensino Fundamental e $1^{a}$ série do Ensino Médio, apresentamos propostas diferentes para cada objetivo.

\subsubsection{Ensino Fundamental: $8^{\circ}$ e $9^{\circ}$ anos}

Material necessário:

- molde do cal eidociclo de oito tetraedros regulares disponível no Apêndice A, figura 68

- lápis, borracha e papel (para os cál cul os)

- régua milimetrada

- compasso

Primeiramente, entregue o molde aos al unos, seja individual mente ou em grupos, e peça para que recorte no contorno e montem o cal eidociclo. Caso seja a primeira atividade com cal eidociclo da turma, deve-se ter uma atenção especial para que façam todas as dobras corretas e a final ização com a col agem.

Depois que os al unos exploraram os movimentos do cal eidociclo, o professor deve apresentar a definição de base do anel do cal eidociclo, lembre-se que é possível mostrar a imagem 23 do corte transversal. 
Após a definição da base do anel, deve-se questionar: "Como podemos garantir que a base do anel do cal eidociclo tenha $10 \mathrm{~cm}$ de lado?' .

Caso nenhum al uno tenha sugerido a utilização da al tura de face do cal ei dociclo, anal ise novamente a imagem 23 atentando para as medidas envolvidas.

As medi das h e a dos triângul os que aparecem na secção transversal , são respectivamente, da al tura de face e da aresta dos tetraedros. Também é possível relacionar a medidal do lado da base do anel com o triângulo citado.

O prof essor pode informar a relação da altura de face $h$ com a aresta a, que é $h=\frac{a^{\sqrt{ }} \overline{3}}{2}$ visto na seção 5.1, ou orientar os cál culos no triângulo equilátero para dedução dela.

Feito isso, deve-se iniciar o cálculo da rel ação entre a aresta a e o lado I observados na secção.

$$
\begin{aligned}
& h^{2}=(l / 2)^{2}+(\mathrm{a} / 2)^{2} \\
& \mathrm{~h}^{2}=\frac{\mathrm{I}^{2}+\mathrm{a}^{2}}{4} .
\end{aligned}
$$

Como $h=\frac{a^{\sqrt{ }} \overline{3}}{2}$

$$
\begin{aligned}
\frac{3 a^{2}}{4} & =\frac{l^{2}+a^{2}}{4} \\
3 a^{2}-a^{2} & =l^{2} \\
2 a^{2} & =1^{2} \\
\sqrt[a]{2} & =1 \sqrt{ } \overline{2} \\
a & =\frac{I^{2} .}{2}
\end{aligned}
$$

Portanto, para que o lado I da base do anel seja $10 \mathrm{~cm}$, é necessário que

$$
\begin{aligned}
& a=\frac{l^{\sqrt{2}}}{2 \sqrt{ }} \\
& a=\frac{10 \cdot \overline{2}}{2} \\
& \mathrm{a}=5 \cdot \overline{2} \\
& a \approx 7 \mathrm{~cm} \text {. }
\end{aligned}
$$

E com ajuda de um compasso, os alunos podem fazer a mal ha triangular da medida desejada sempre utilizando a ponta seca do compasso nas intersecções das circunferências, como mostram as figuras a seguir. 
Figura 38 - Sequência da construção da mal ha
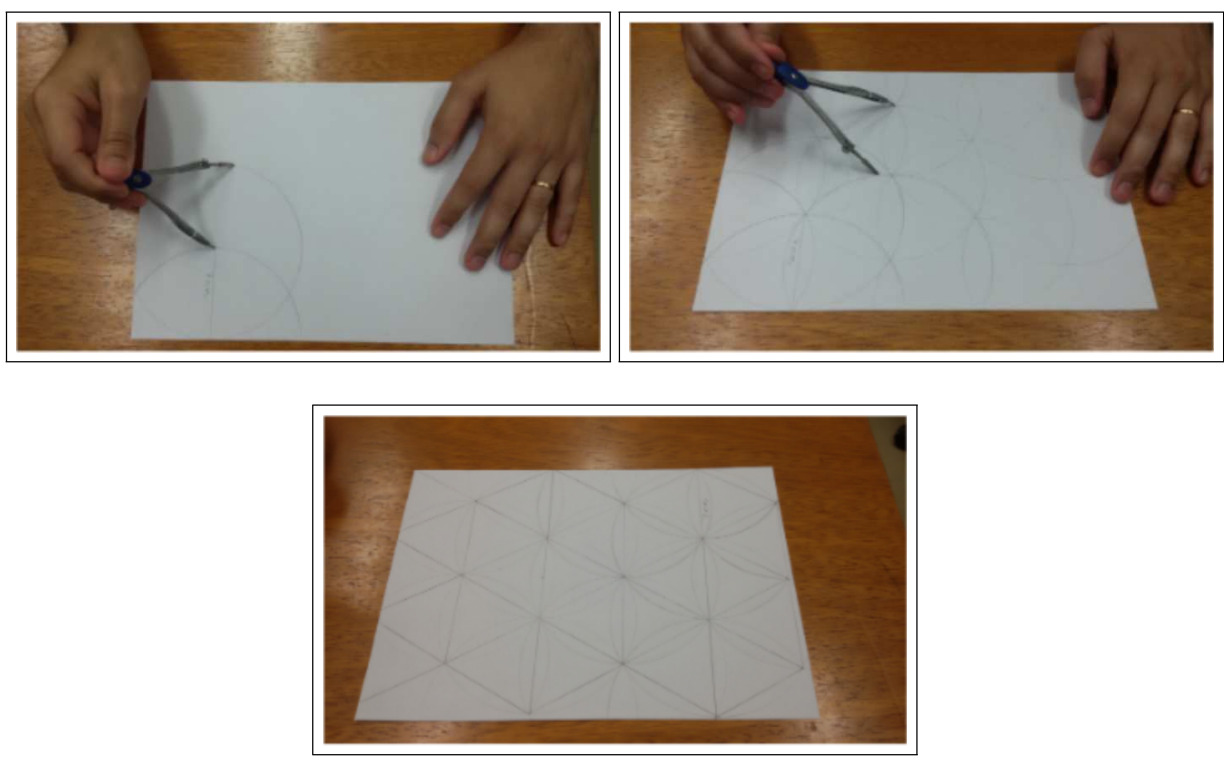

Fonte: Elaborada pelo autor.

Dependendo da medida adotada para o lado I da base do anel, a folha A4 poderá ser pequena para compor uma malha suficiente para o caleidociclo. Sugerimos que utilizem a fol ha A3 para esses casos ou incentivem os al unos a juntarem duas mal has para compl etarem o caleidociclo.

\subsubsection{Ensino Médio: $1^{\mathrm{a}}$ série}

Material necessário:

· molde do caleidociclo disponível no Apêndice A, figuras 68 e 69

- tesoura

- cola

- lápis de cor (ou canetinhas)

- sulfite

- régua

- compasso

Primeiramente, entregue o molde aos al unos, seja individual mente ou em grupos, e peça para que recortem no contorno e montem o cal eidociclo. Caso seja a primeira atividade com 
cal ei dociclo da turma, deve-se ter uma atenção especial para que façam todas as dobras corretas e a finalização com a colagem.

Depois dos al unos explorarem os cal eidociclos, provavel mente já terão percebido que, apesar dos dois terem oito tetraedros, um deles é fechado no centro do anel e o outro não. A partir dessa constatação, o professor deve aguçar a curiosidade questionando qual deve ser a relação entre as medidas do triângulo da mal ha, para que seja garantido que o cal ei dociclo seja de centro fechado.

O professor pode apresentar o cál cul o utilizado para definir a forma geral das medidas, mostrando a utilização da lei dos cossenos.

Seja n, o número de lados da base do anel; I, a medida do lado da base do anel; a, a aresta comum a dois tetraedros do cal eidociclo; $h$, a al tura de face dos tetraedros com base a; $\alpha$, é o ângulo formado entre h ea.

Figura 39 - Notações para o triângulo i isósceles

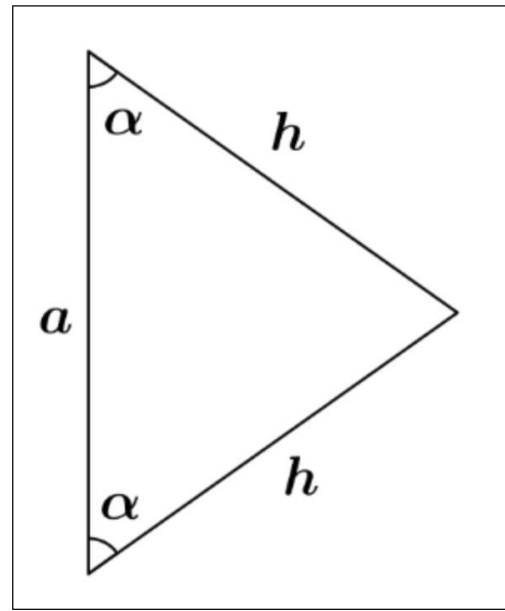

Fonte: Elaborada pelo autor.

Usando as notações da Figura 39 e utilizando a lei dos cossenos, temos:

$$
\begin{aligned}
h^{2} & =h^{2}+a^{2}-2 a h \cos \alpha \\
2 a h \cos \alpha & =a^{2} \\
h & =\frac{a^{2}}{2 a \cos \alpha} \\
h & =\frac{a}{2 \cos \alpha} .
\end{aligned}
$$

Agora, por meio do triângulo retângulo 
Capítul o 5. Teorema de Pitágoras, Lei dos Cossenos e Relação Fundamental da trigonometria: aplicações na 68 construção do caleidociclo

Figura 40 - Metade do triângulo isósceles da Figura 39

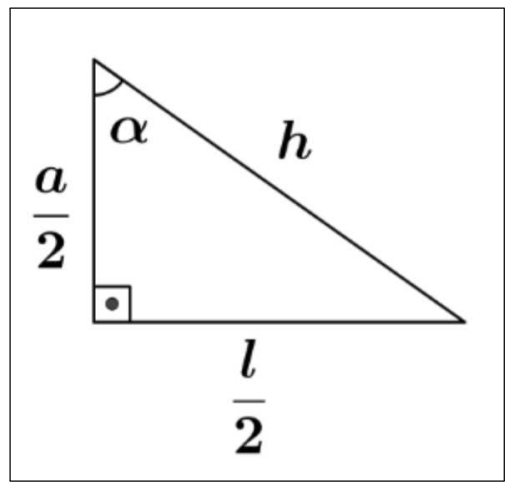

Fonte: Elaborada pelo autor.

e utilizando o teorema de Pitágoras, temos:

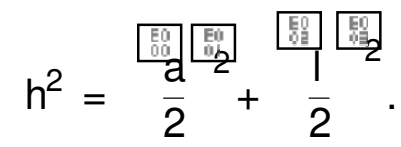

Substituindo I em II, temos:

$$
\begin{aligned}
\frac{a}{2 \cos \alpha} & =\frac{a^{2}}{2}+\frac{a^{2}}{2} \\
\frac{a^{2}}{4 \cos ^{2} \alpha} & =\frac{a^{2}}{4}+\frac{1^{2}}{4} \\
\frac{a^{2}}{\cos ^{2} \alpha}-a^{2} & =1^{2} \\
\frac{a^{2}-a^{2} \cos ^{2} \alpha}{\cos ^{2} \alpha} & =1^{2} \\
\frac{a^{2}\left(1-\cos ^{2} \alpha\right)}{\cos ^{2} \alpha} & =1^{2}
\end{aligned}
$$

e utilizando a relação fundamental da trigonometria, obtemos:

$$
\begin{aligned}
\frac{a^{2} \operatorname{sen}^{2} \alpha}{\cos ^{2} \alpha} & =I^{2} \\
a^{2} \operatorname{sen}^{2} \alpha & =I^{2} \cos ^{2} \alpha \\
a^{2} & =\frac{I^{2} \cos ^{2} \alpha}{\operatorname{sen}^{2} \alpha} \\
a^{2} & =I^{2} \cot ^{2} \alpha \\
a & =I \cot \alpha .
\end{aligned}
$$

Deixando h em função de I, temos: 


$$
\begin{aligned}
& h=\frac{I \cot \alpha}{2 \cos \alpha} \\
& h=I \cdot \frac{\cos \alpha}{\operatorname{sen} \alpha} \cdot \frac{1}{2 \cos \alpha} \\
& h=\frac{1}{2 \operatorname{sen} \alpha} .
\end{aligned}
$$

Assim, a mal ha a ser construída deve ser de triângulos isósceles de base $a=1 \cot \alpha$, $h_{m}=\frac{1}{2 \operatorname{sen} \alpha}$ e $\alpha=\frac{360}{2 n}$.

Figura 41 - Triângulo I sósceles da Mal ha

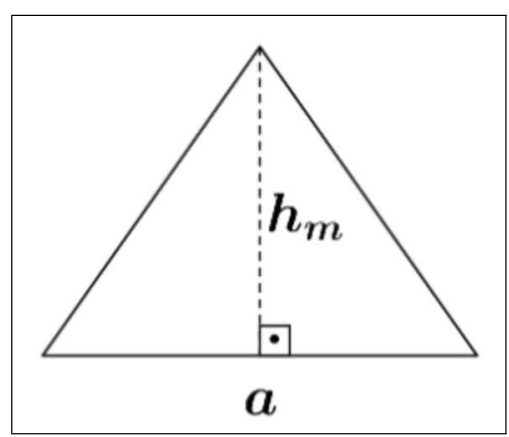

Fonte: Elaborada pelo autor.

Com base nesses dados, definidos o número n de lados e a medidal do lado do anel do cal eidociclo, peça aos al unos para cal cularem os val ores de $\alpha$, a e h.

Por exemplo, se $n=6$ el $=3 \mathrm{~cm}$, temos:

$$
\begin{aligned}
\alpha & =30^{\circ} \\
\mathrm{a} & \approx 5,2 \mathrm{~cm} \\
\mathrm{~h}_{\mathrm{m}} & =3 \mathrm{~cm} .
\end{aligned}
$$

E o triângulo base para a malhaé

Figura 42 - Triângulo Isósceles base para mal ha

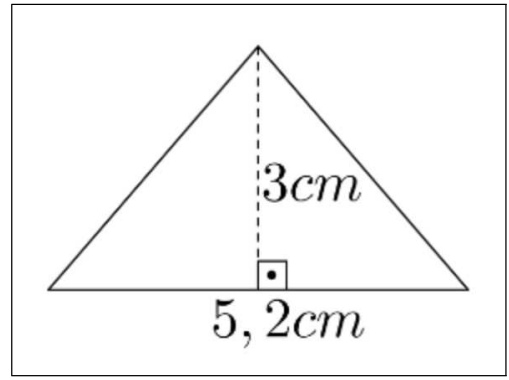

Fonte: Elaborada pelo autor. 
Capítul o 5. Teorema de Pitágoras, Lei dos Cossenos e Relação Fundamental da trigonometria: aplicações na 70 construção do caleidociclo

De forma semel hante à proposta feita anteriormente para os $8^{\circ}$ e $9^{\circ}$ anos do Ensino Fundamental, o professor pode entregar a fol ha de sulfite e deixar que el es criem uma mal ha, utilizando a régua e compasso, com as medidas que qui serem ou que forem el eitas pela turma.

Existe a possi bilidade do professor ir induzindo a turma a chegar nas relações descritas acima, porém, isso depende muito do nível de aprendizagem da turma que apenas o professor poderá aval iar e decidir o que for mel hor, para que a atividade não se torne desinteressante. 
CAPÍTULO

\section{6}

\section{CALEIDOCICLO: VOLUME E ÁREA DE} SUPERFÍCIE

As habilidades matemáticas envolvidas nos cál cul os de vol ume e área de superfície estão presentes no currículo da $2^{\mathrm{a}}$ série do Ensino Médio do Estado de São Paulo. Nele, apresenta-se o cál culo do volume e área de prismas, pirâmides e cilindros.

Apresentamos alguns caleidociclos que podem ser usados para trabal har com essas habilidades.

\subsection{O Milagre Shinsei}

Figura 43 - Milagre Shinsei e seus caleidociclos

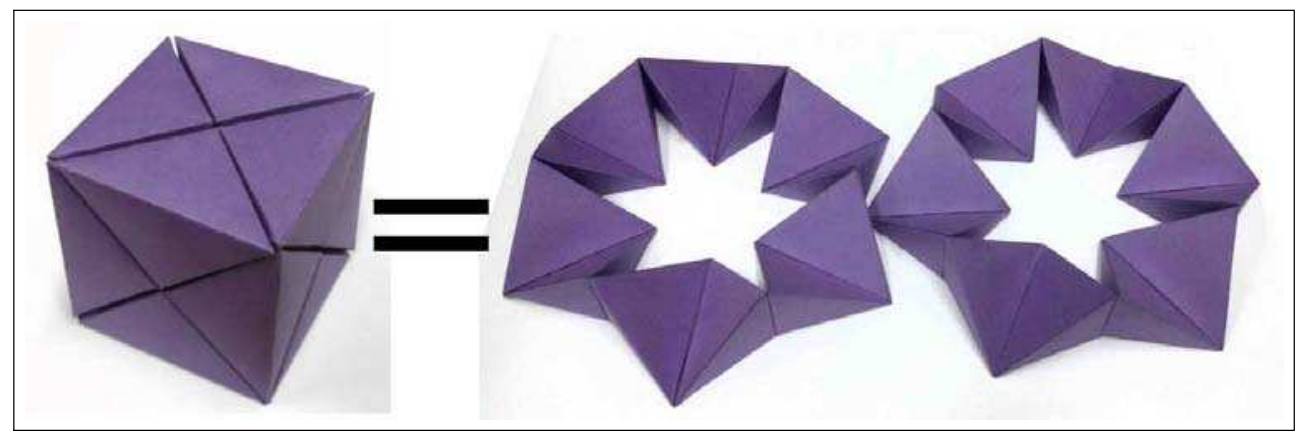

Fonte: Elaborada pelo autor.

É composto por dois cal eidocicl os abertos cada um contendo doze tetraedros não regulares. Juntos, esses cal eidociclos podem formar um cubo. A partir do cubo formado por eles, é possível cal cul ar uma aproximação do vol ume do cal eidociclo. O tetraedro utilizado é especial , pois três de suas faces são triângulos retângulos. 
As medidas necessárias para a construção do tetraedro desse cal eidociclo, podem ser retiradas a partir do cubo que se deseja formar com os dois cal ei dociclos.

Figura 44-Medidas do tetraedro a partir do cubo

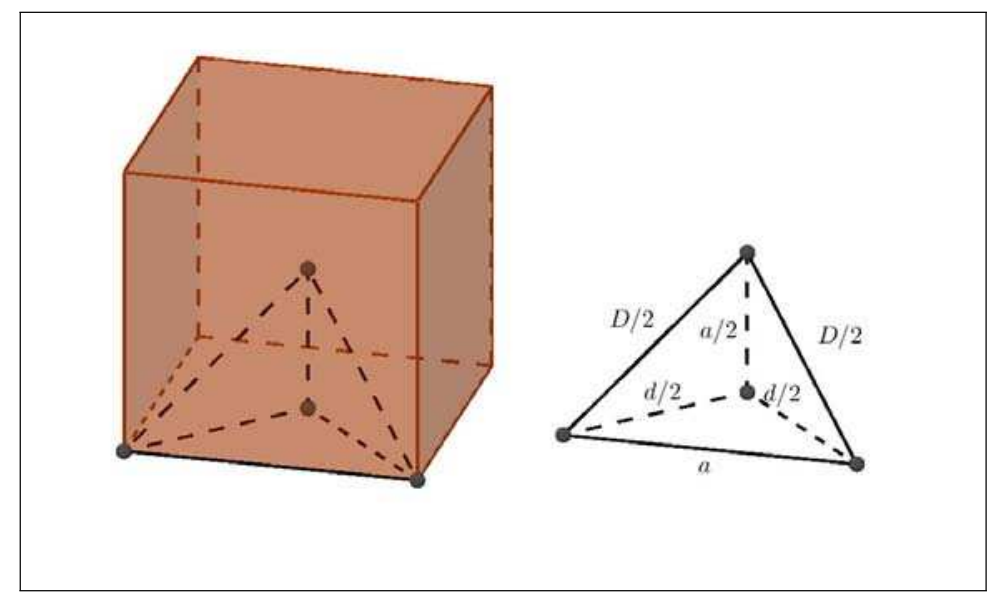

Fonte: Elaborada pelo autor.
$a=$ aresta do cubo
$\mathrm{d}=$ diagonal do quadrado (face do cubo)
$\mathrm{D}=$ diagonal do cubo

Dada a medida a da aresta, podemos cal cular as medidas necessárias para se construir uma planificação para o cal eidociclo. Pois

$$
\begin{aligned}
& d=a_{\sqrt{ }}^{\sqrt{2}} \\
& D=a^{\overline{3}} .
\end{aligned}
$$

Figura 45 - Planificação de dois tetraedros do Milagre Shinsei

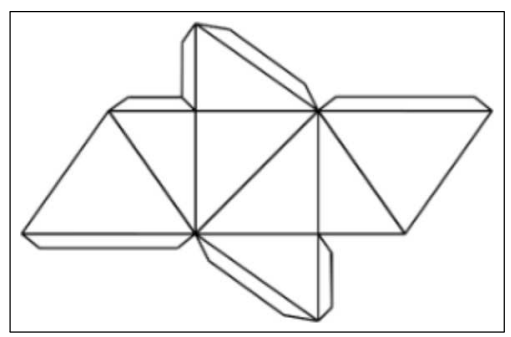

Fonte: Elaborada pelo autor.

Um molde que pode ser usado é a planificação de metade de um dos caleidociclos (Figura 46), sendo assi m necessário quatro desses moldes para construir os dois cal eidociclos que compõem o Milagre Shinsei. 
Figura 46 - Planificação de metade do cal eidociclo

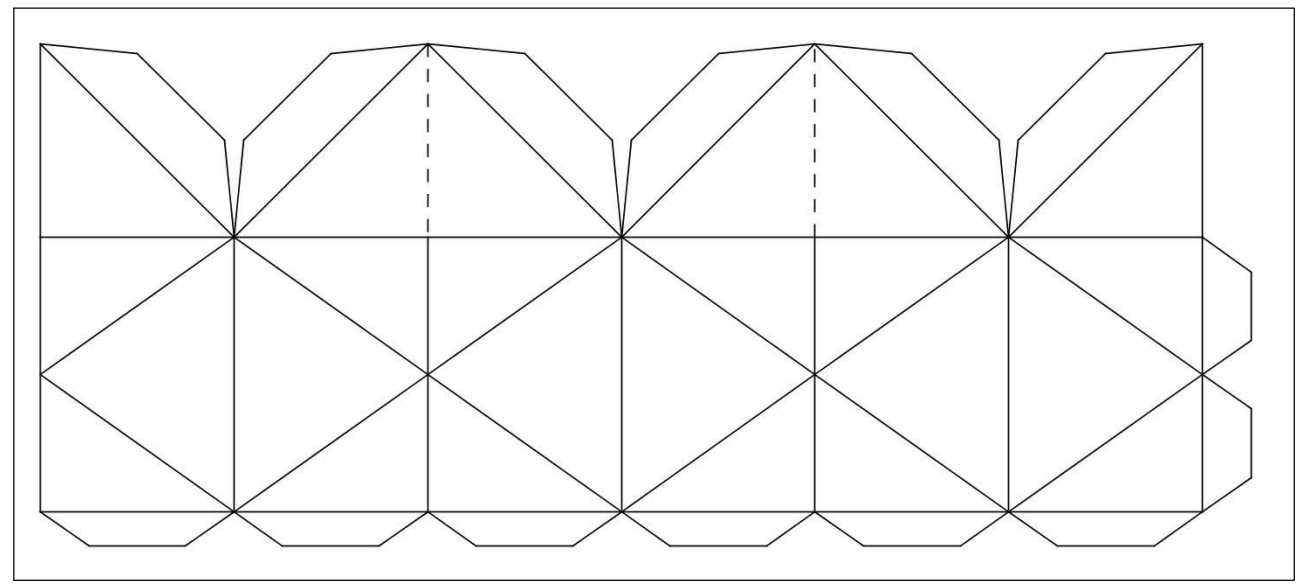

Fonte: Elaborada pelo autor.

Nesse mol de, devemos ficar atentos aos dois segmentos pontilhados que indicam corte no molde além do corte no contorno. Sugerimos também que seja unida as duas metades antes de ir fechando os tetraedros.

\subsection{Cubo Invertível}

Este cal ei dociclo é formado por seis tetraedros de faces idênticas. Cada face tem formato de triângulo retângul o e em dois desses triângul os ocorrem que um dos catetos tem metade da medida do outro cateto.

Figura 47 - Cubo invertível

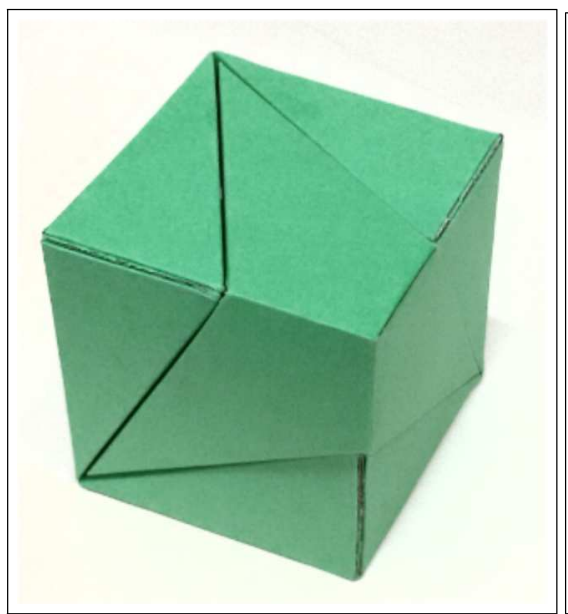

(a) Cubo Invertível 01

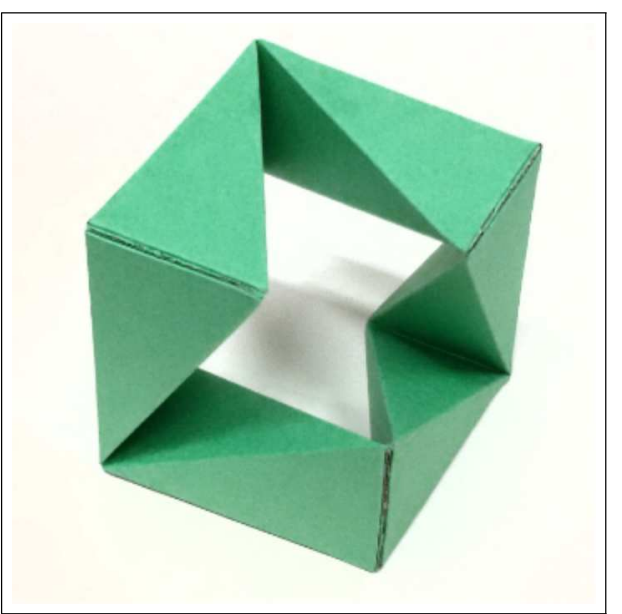

(b) Cubo Invertível 02 


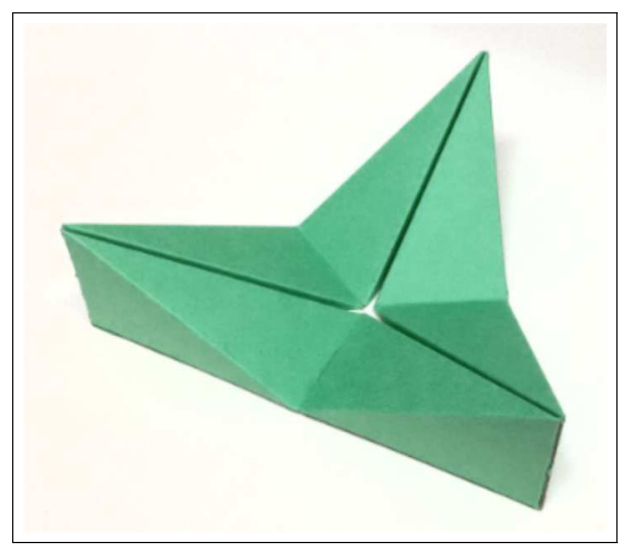

(c) Cubo Invertível 03

Fonte: Elaborada pelo autor.

O nome dele vem do fato de lembrar a forma de um cubo em uma determinada posição de sua torção. Além disso, ele pode formar um cubo ao completar o espaço com outras duas peças chamadas raio do cubo invertível que também está disponibilizada no Apêndice A figura 60.

As medi das para a construção da planificação deste cal eidociclo, pode ser feita a partir do cubo no qual ele está contido como mostram as figuras a seguir.

Figura 48 - Cubo invertível e suas medidas

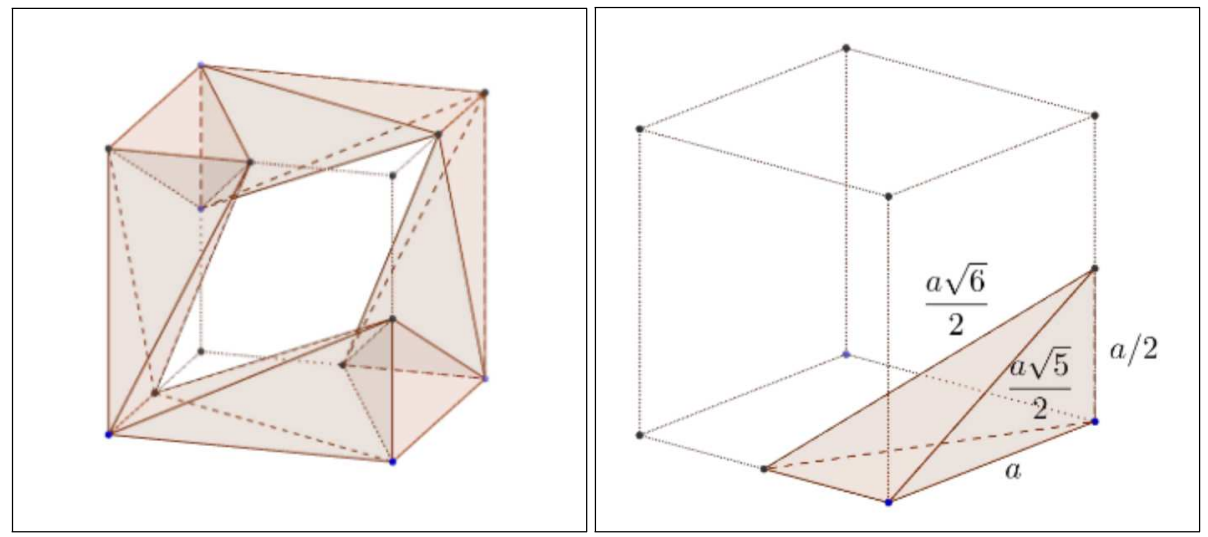

(a) Tetraedro dentro do cubo

(b) Tetraedro destacado 


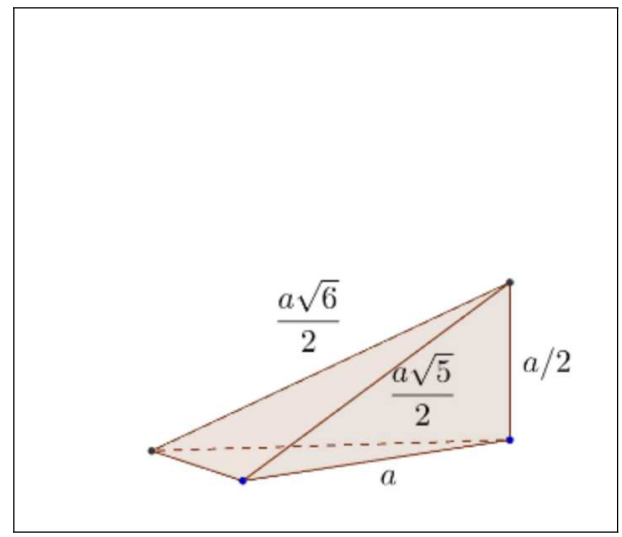

(c)

Fonte: Elaborada pelo autor.

As medidas foram cal cul adas utilizando o Teorema de Pitágoras. Nos triângul os retângulos pertencentes as faces do cubo, denotando por $h_{1}$ a hipotenusa, temos:

$$
\begin{aligned}
& \mathrm{h}_{1}^{2}=\frac{\mathrm{a}_{2}^{2}}{\mathrm{~h}_{1}^{2}}=\frac{\mathrm{a}^{2}}{\mathrm{~s}^{4}}+\mathrm{a}^{2} \\
& \mathrm{~h}_{1}=\frac{5 \mathrm{a}^{2}}{\frac{\sqrt{\mathrm{E}}}{4}} \\
& \mathrm{~h}_{1}=\frac{\mathrm{a}_{\overline{5}}}{2} .
\end{aligned}
$$

Para os triângul os retângul os do tetraedro que estão no interior do cubo e, denotando por $\mathrm{h}_{2}$ a hipotenusa deles, temos:

$$
\begin{aligned}
& \mathrm{h}_{2}^{2}=\frac{\mathrm{a}^{\mathrm{E}} \mathrm{E}_{2}}{2}+\frac{\mathrm{a}_{\overline{5}} !_{2}}{2} \\
& \mathrm{~h}_{2}^{2}=\frac{\mathrm{a}^{2}}{\mathrm{~s}^{4}}+\frac{5 \mathrm{a}^{2}}{4} \\
& \mathrm{~h}_{2}=\frac{6 \mathrm{a}^{2}}{4} \\
& \mathrm{~h}_{2}=\frac{\mathrm{a}_{\overline{6}}}{2} .
\end{aligned}
$$

Apresentamos metade do molde para que se possa verificar uma possível montagem. 
Figura 49 - Planificação de metade do Cubo Invertível

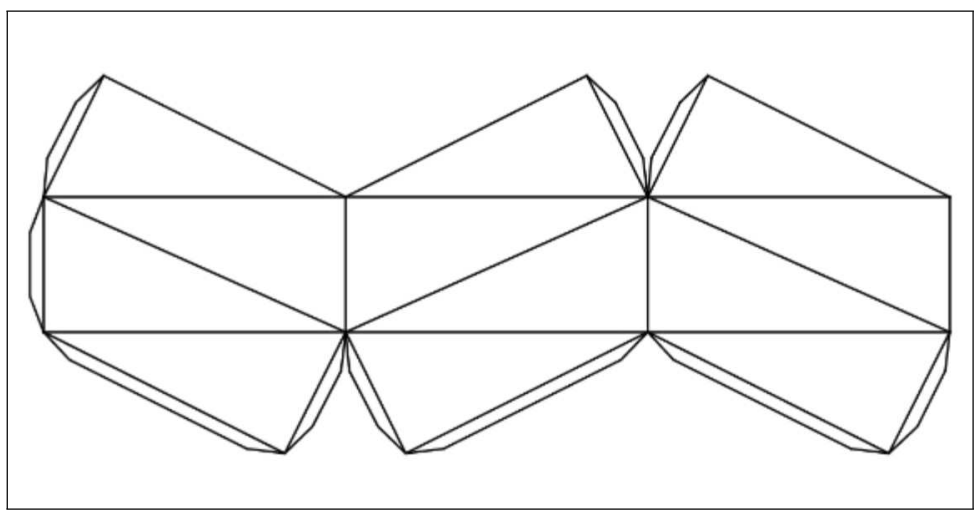

Fonte: Elaborada pelo autor.

Lembramos que todos os mol des utilizados estão di sponíveis no A pêndice A.

\subsection{Propost as de Atividades}

Dividi mos esta seção em duas partes para que possamos anal isar os casos para cada um dos cal ei dociclos apresentados nas seções 6.1 e 6.2 .

\subsubsection{O Milagre Shinsei}

Material necessário:

molde do Milagre Shinsei disponível no Apêndice A figura 63

- tesoura

cola

O professor deve distribuir um molde para cada al uno, pedir que monte o molde e auxiliar nesta tarefa para que o cal ei docicl o fique o mel hor possível. Há a possibilidade de deixar que cada al uno faça seus dois cal ei doci cl os ou que cada al uno faça um del es e depois formem duplas para compor o cubo, ou ainda, em casos de necessidade de reduzir ao máximo o tempo da construção, em quartetos, em que cada al uno recortará e dobrará metade de um dos cal ei dociclos. Assim, a cada dois al unos haverá um cal eidocicl o e a cada quatro al unos será possível compor um cubo. 
Figura 50 - Os dois cal eidociclos do Milagre Shinsei

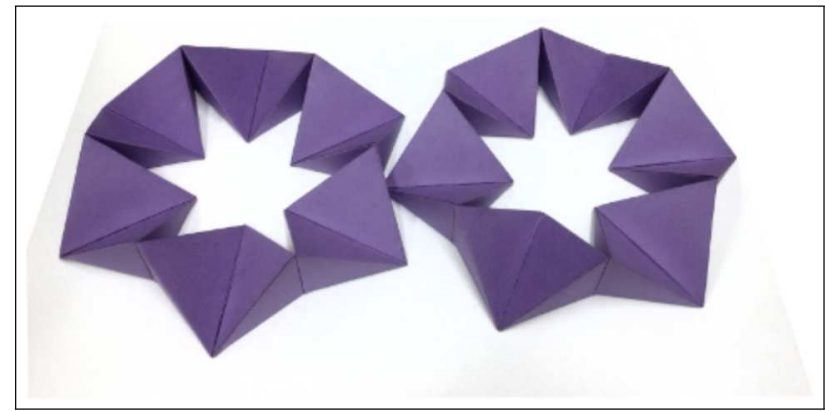

Fonte: Elaborada pelo autor.

Feitos os cal eidociclos, peça aos al unos que tentem formar um cubo utilizando dois cal eidocicl os. Provavel mente al guns irão descobrir a possi bi lidade de formar outros poliedros nessa tentativa, isso será interessante para as próximas etapas, mas o professor deverá insistir que concluam a etapa da construção do cubo.

Figura 51 - Milagre Shinsei

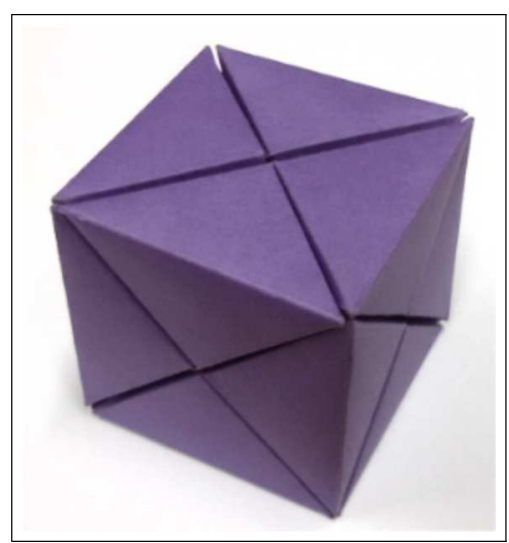

Fonte: Elaborada pelo autor.

As medidas do molde pode variar durante a impressão dos mesmos, por isso é importante que não se apeguem as medi das reais nos poliedros, mas sim a medida da aresta que deve ser adotada para os cálcul os das áreas. A adoção da medi da pode ser feita pelo professor ou sugerida pelos alunos.

A pós a construção do cubo e adotada a medida da aresta, peça aos al unos que cal culem o volume e a área do cubo. Incentive-os a concl uir que um cal eidociclo possui vol ume igual a metade do volume do cubo e que cada tetraedro dos cal eidocicl os possui $\frac{1}{24}$ do volume do cubo.

Feito isso, é hora de modificar o poliedro. Peça a eles que formem outro poliedro utilizando os dois cal eidociclos. Abaixo temos al guns poliedros que podem aparecer. 
Figura 52-Milagre Shinsei Modificado

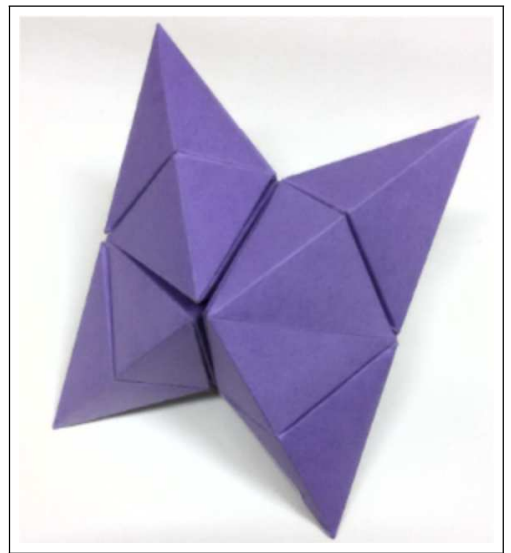

(a)

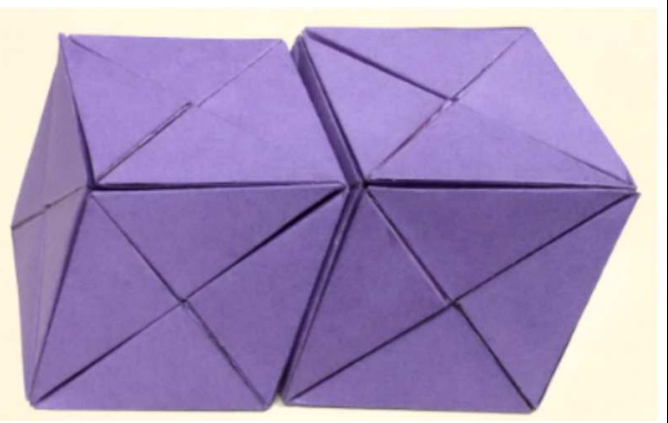

(b)

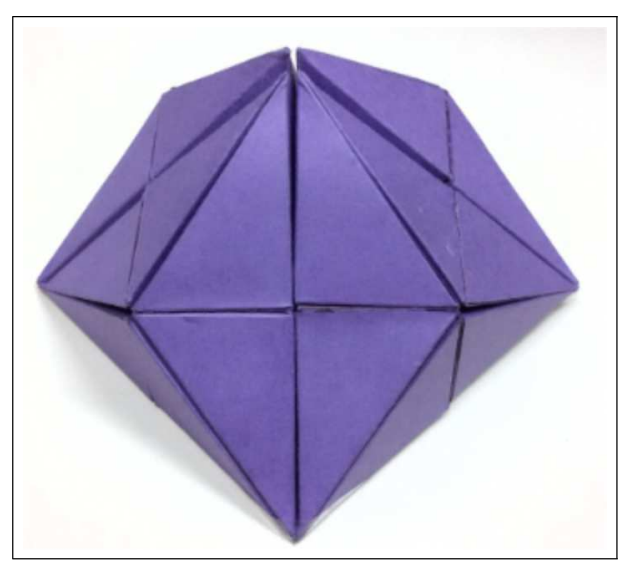

(c)

Fonte: Elaborada pelo autor.

Se o professor desejar, poderárelembrar as definições de pol iedro convexo e não-convexo conforme eles forem formando os poliedros.

A pós completarem al gum poliedro, expl ore a ideia do vol ume desses poliedros serem iguais ao do cubo, independente do formato, atentando apenas para que não haja nenhum espaço interno ao novo poliedro que não contenha tetraedros. Veja um exemplo não desejado: 
Figura 53 - Poliedro com “buraco" interno

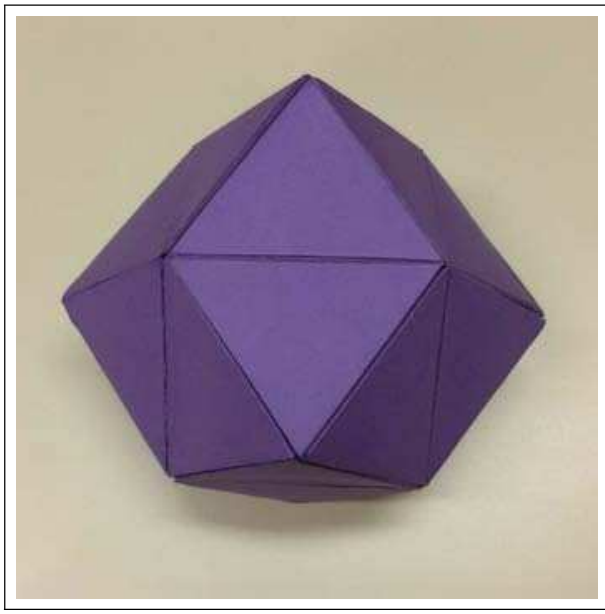

(a) Aparentemente correto

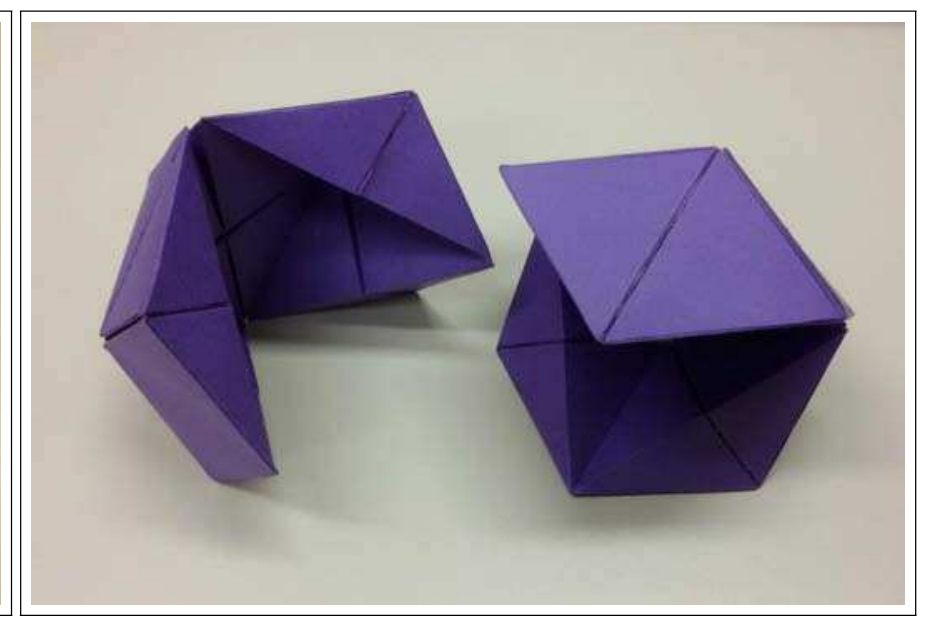

(b) Aberto, com "buracos"

Fonte: Elaborada pelo autor.

Agora, questione sobre a área de superfície dos poliedros. Peça que cal culem as áreas e anal isem se confere com a resposta dada anteriormente. É nesse momento que deve ficar claro que mesmo tendo vol ume constante, a área de superfície pode variar de acordo com o poliedro formado.

O professor pode aval iar a participação dos al unos ou ainda pedir que respondam as perguntas em uma fol ha para registro de atividade aval iativa, assim como pode ser regi strado as imagens com câmera fotográfica e publicál as nos murais, blog, jornal ou página da escola. $O$ material ainda pode ser aproveitado em possíveis feiras de ciências.

\subsubsection{Cubo Invertível}

Material necessário:

- molde do Cubo Invertível disponível no Apêndice A figura 59

- tesoura

cola

Assim que distribuir o molde para todos os al unos, peça para recortarem e colarem formando o cal eidociclo. É possível, assim como na proposta anterior, que se faça em duplas para dimi nuir o tempo gasto na montagem.

O professor pode pedir que os al unos movimentem o cal ei dociclo de forma a encontrarem o formato de triângul os equiláteros em quatro formas diferentes, seja vazado ou preenchido. 
Figura 54 - Quatro posições com forma de triângulo equiláteros

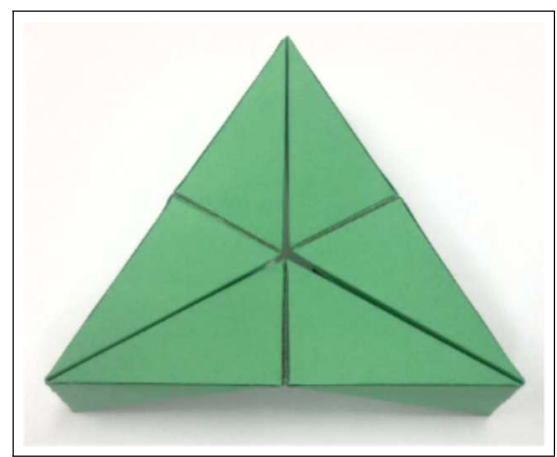

(a)

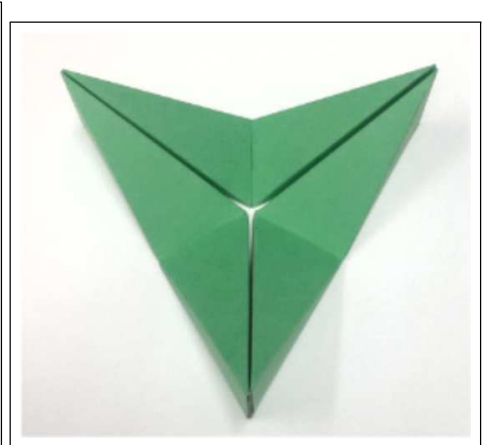

(b)

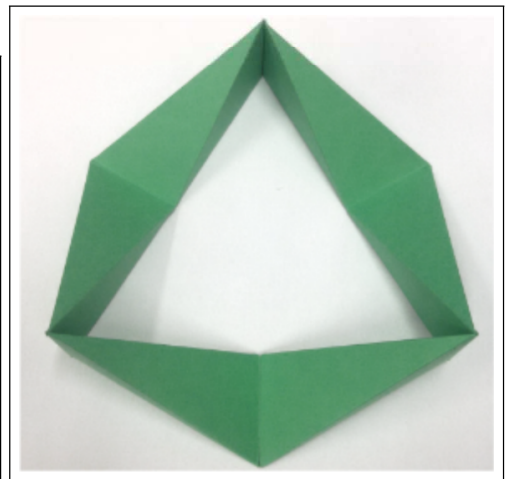

(c)

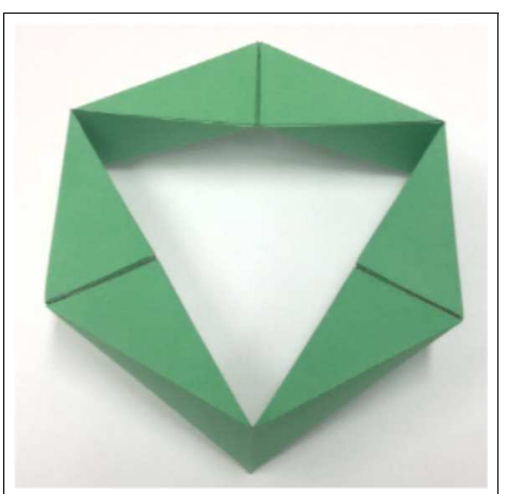

(d)

Fonte: Elaborada pelo autor.

Depois de manipular o cal eidociclo com a atividade anterior, peça aos alunos que movimentem o cal eidocicl o até encontrarem uma posi ção que lembre um cubo; é aconsel hável que fique claro que o cal eidociclo sozinho não irá formar um cubo, mas que, em determinada posi ção ele aparenta parte de um cubo.

Figura 55 - O cal eidociclo lembrando um cubo

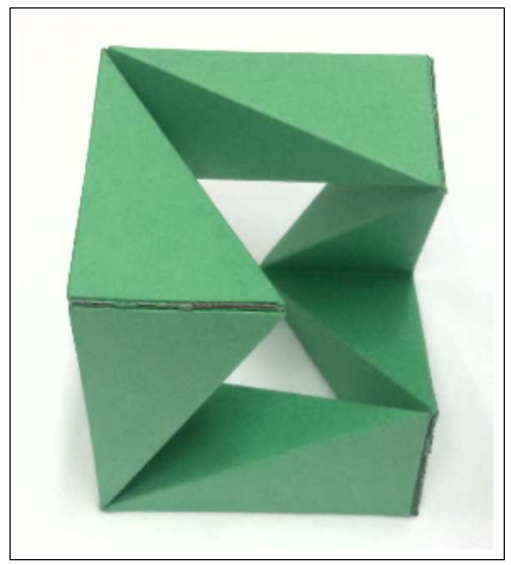

Fonte: Elaborada pelo autor. 
Antes de calcular o volume do caleidociclo, é interessante propor aos alunos uma estimativa aproximada do volume em relação ao volume do cubo aparente. Feito isso, defina uma medida da aresta e cobre o cál culo do volume do cal eidociclo a partir do volume de um dos tetraedros, lembrando que as medi das do tetraedro, em rel ação à aresta do cubo, podem ser encontradas na seção 6.2.

Por fim, peça que mostrem que o volume do cal ei dociclo é um terço do volume do cubo. Assim como na proposta anterior, o prof essor pode utilizar essas atividades como aval iações. 

CAPÍTULO

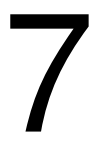

\section{CONCLUSÃO E CONSIDERAÇÕES FINAIS}

O objetivo principal deste trabal ho foi al cançado, ou seja, apresentamos propostas de atividades com caleidociclos diferenciados que possam contribuir com a aprendizagem de habilidades e competências matemáticas. As propostas variaram conforme o nível de ensi no e ano, al ém de variações de acordo com o nível de aprendi zado das turmas.

Durante a sistematização de atividades já aplicadas anteriormente por nós, surgiram novas ideias que foram el aboradas e apresentadas neste trabal ho, outras possi bi lidades se mostraram durante al gumas demonstrações e general izações, como por exempl o a utilização da lei dos cossenos para general izar medidas necessárias na construção de mal has de cal eidociclos fechados.

Deixamos evidente que há uma necessi dade de aprof undamento das rel ações matemáticas presentes nos cal eidocicl os e possíveis demonstrações em afirmações relacionadas ao número de tetraedros necessário para se formar um cal eidociclo, ou definir e explorar os cal eidociclos cujo centro se al terna entre fechado e aberto, ou ai nda definir e explorar cal eidocicl os com anel retorcido.

O estudo dessas variações dos cal eidocicl os, além do val or científico matemático, pode trazer novas apli cações de habilidades e competências possíveis de serem trabal hadas nos Ensi nos Fundamental e Médio. 

ALVES, C. M. F. O estudo da simetria atr avés da ar te de Maurits Cornelis Escher. Dissertação (Mestrado) - Instituto de Matemática Pura e Aplicada - IMPA, Rio de Janei ro, 2014. Nenhuma citação no texto.

BORIN, J. Jogos e Resol ução de Problemas: Uma estratégia para as aul as de matemática. $6^{a}$. ed. São Paul o: CAEM-IME-USP, 2007. v. 6. 100 p. (Centro de Aperfeiçoamento do Ensino de Matemática - CAEM, v. 6). Citado na página 23.

BRASIL. Ministério da Educação. Simetria - [S.I.:s.n., 20--]. (Série Plano de Aula; Matemática). 10 p. Nenhuma citação no texto.

. Ministério da Educação - Produção de Conteúdos Educacionais Digitais Multimídia para Matemática Cal eidociclos - [S.I.:s.n., 20--]. (Série Guia do Professor: conteúdos di gitais). Disponível em: <http://webeduc.mec.gov.br/portal doprofessor/matematica/condigital2/midias/ experimentos/Geometria_e_arte/index.html>. Acesso em: 24 set. 2014. Citado 2 vezes nas páginas 56 e 57.

BRASI L, L. A. S. Aplicações da teor ia de Piaget ao ensino da Matemática. [S.I.]: ForenseUniversitária, 1977. Citado na página 23.

BUSH, L. M. A group theoretic approach to kaleidocycles and cubeocycles. The Journal of the Summer Undergraduate Mathematical Science Resear ch Institute (SUMSRI), Miami, p. 24, 2003. Disponível em: <http://www.units.muohio.edu/sumsri/sumj/2003/kal eidocycles. pdf > . Acesso em: 24 set. 2014. Nenhuma citação no texto.

D’AMBROSIO, U. Educação matemática: Da teoria à prática 8ª ed. Campinas, SP: Papirus, 2001. 120 p. (Col eção Perspectivas em Educação Matemática). Citado na página22.

DUVAL, R. [Aprendizagem M atemática]. Estrasburgo: [s.n.], 1972. Citado na página 23.

FOLDPLAY. Make your very own photo kal eidocycle. Disponível em: <http://foldplay.com/ kal eidocycl e.action>. Acesso em: 24 set. 2014. Nenhuma citação no texto.

FRAISSE, P.; PIAGET, J. Traité de Pyschologie Expérimentale. Paris: Presses Universitai res de France - PUF, [19-- ?]. 224 p. (Traité Psycholo, Tome 7). Citado na página 23.

JOHNSON, D. A.; RISING, G. R. Guidelines for Teaching Mathematics. Belmont, Califórnia: Wadsworth Publishing Company, 1972. Citado na página 21.

LIMA, E. L. Isometrias. 2. ed. Rio de Janeiro: SBM, 2007. 94 p. (Coleção do Professor de Matemática). Nenhuma citação no texto.

MATHEMATISCHE BASTELEIN. Kaleidocycles. Disponível em: <http://www. mathematische-basteleien.de/kal eidocycles.htm>. Acesso em: 24 set. $2014 . \quad$ Nenhuma citação no texto. 
MENDES, I. A. Matemática e investigação em sala de aula: tecendo redes congnitivas na aprendizagem. 2. ed. São Paulo: Editora Livraria da Física, 2009. 214 p. Nenhuma citação no texto.

MOYSÉS, L. Aplicações de Vygotsky à educação matemática. $7^{\text {a }}$. ed. Campinas, SP: Papi rus, 2006. 176 p. (Col eção Magistério: Formação e Trabal ho Pedagógico). Citado na página22.

OLIVEIRA, S. R. de. Espelhos e simetrias. Matemática Multimídia, p. 12, [20--]. Nenhuma citação no texto.

PAPER MODELSOF POLYHEDRA. Pictures of Kaleidocycles. Disponível em: <http://www. korthal saltes.com/cuadros.php?type=ka>. Acesso em: 24 set. 2014. Nenhuma citação no texto.

REIS, E. R. S. dos. Estudo de simetria e seu ensino no nível fundamental e médio. Dissertação (Mestrado) - Instituto de Ciências Matemáticas e de Computação - ICMC, Universidade de São Paulo - USP, São Carlos, 2013. Nenhuma citação no texto.

SÃO PAULO (ESTADO). Secretaria da educação. Currículo do Estado de São Paulo: Matemática e suas tecnol ogias - 1. ed. atual. São Paulo: SE, 2011. 72 p. Nenhuma citação no texto.

SILVA, A. M. Simetr ias planase alguns problemas de ladrilhamento. Dissertação (Mestrado) — Universidade Federal do ABC, Santo André, 2013. Nenhuma citação no texto.

THE HEBREW UNIVERSITY OF JERUSALEM. Mathematics and Computer Science Library. Disponível em: <http://www.mahuji.ac.il/ library/models.htm\#plastic>. Acesso em: 25 set. 2014. Nenhuma citação no texto.

TINOCO, M. J. I sometrias. Dissertação (Mestrado) - Departamento de Matemática, Facul dade de Ciências da Universidade do Porto, Porto, 2012. Nenhuma citação no texto.

VITTI, C. M. Matemática com prazer, a partir da história e da geometria. $2^{\mathrm{a}}$. ed. Piracicaba: Editora UNIMEP, 1999. 103 p. Citado 2 vezes nas páginas 21 e 22.

VYGOTSKY, L. S. A for mação social da mente: o desenvolvimento dos processos psicológicos superiores. 4. ed. São Paul o: Martins Fontes, 1991. 168 p. (Coleção Psicologia e Pedagogia). Nenhuma citação no texto.

VYGOTSKY, L. S.; LURIA, A. R.; LEONTIEV, A. N. Linguagem, desenvolvimento e aprendizagem. 13. ed. São Paul o: Icone, 2014. 228 p. (Coleção Educação Crítica). Nenhuma citação no texto.

WALKER, W.; SCHATTSCHNEIDER, D. Caleidociclos de M. C. Escher. São Paulo: Taschen Editora, 1997. 40 p. Nenhuma citação no texto.

WEYL, H. Symmetry. 5. ed. Princeton, New Jersey: Princenton University Press, 1952. 168 p. Nenhuma citação no texto. 
APÊNDICE

A

MOLDES DOS CALEIDOCICLOS

Os moldes dos cal ei docicl os usados neste trabal ho estão a seguir. Existem muitos outros moldes ou sites em que se possa encontrar outros moldes. Nas referências existem al guns links onde poderão ser encontradas mais opções. 
Figura 56 - Cal eidociclo de Seis Tetraedros com Desenhos

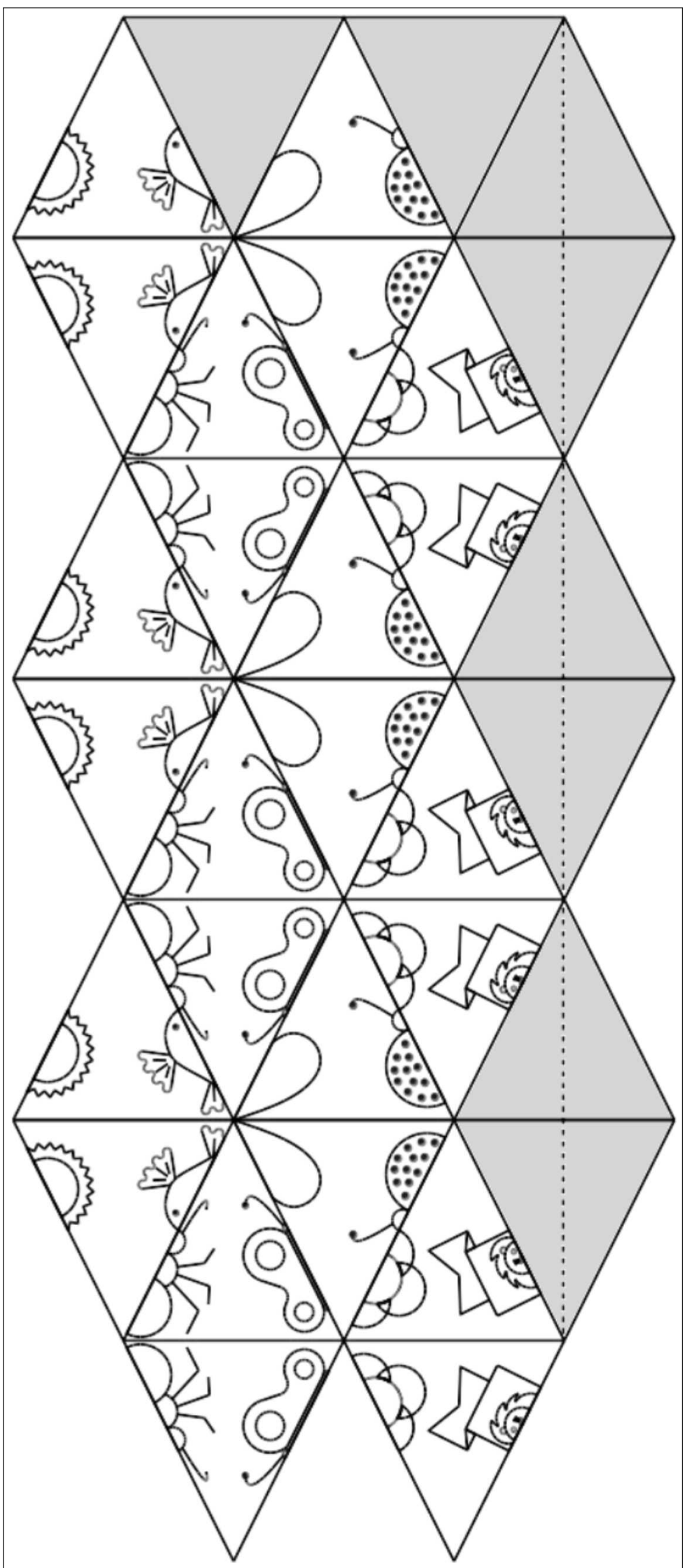

Fonte: Elaborada pelo autor. 
Figura 57 - Cal eidociclo de Seis Tetraedros sem Desenhos

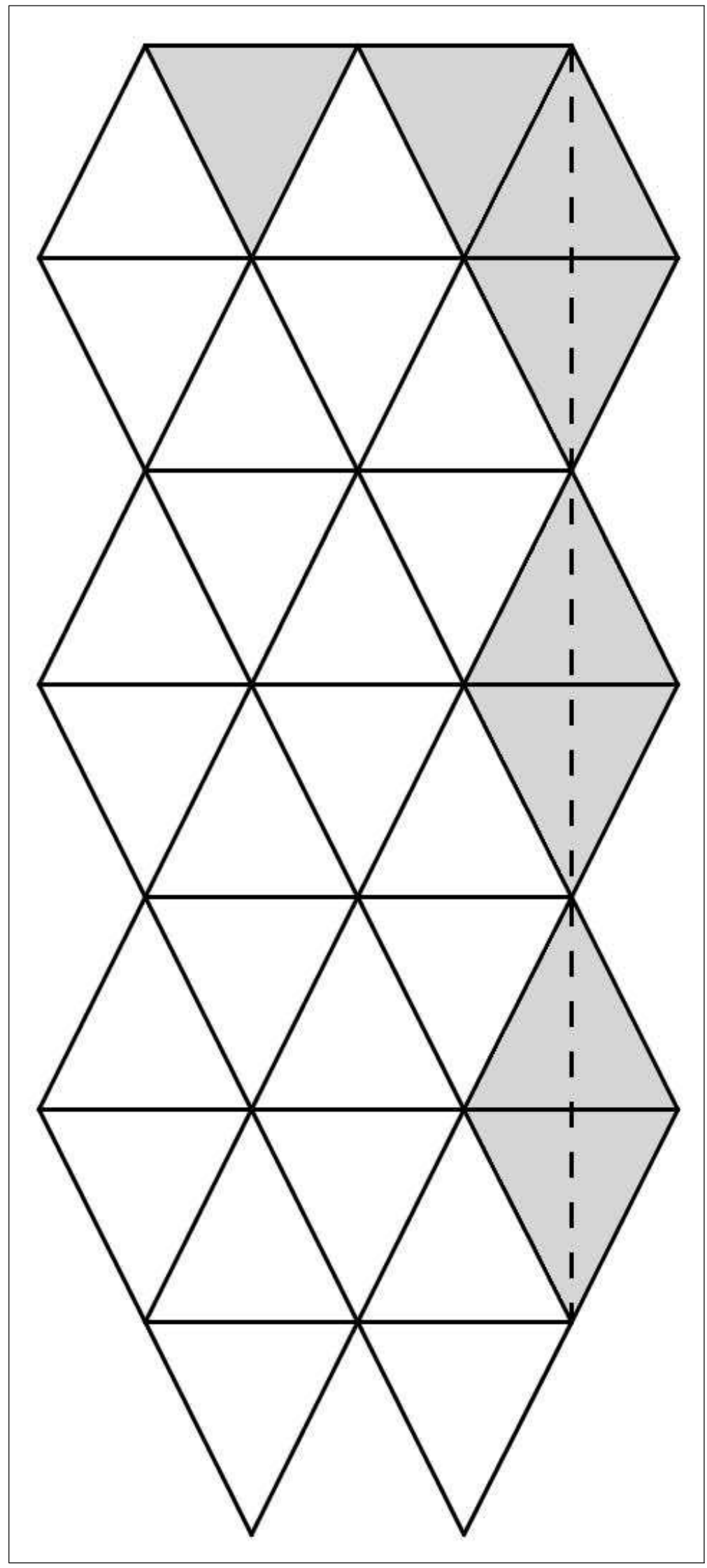

Fonte: Elaborada pelo autor. 
Figura 58 - Cal eidociclo Fechado com 12 Tetraedros

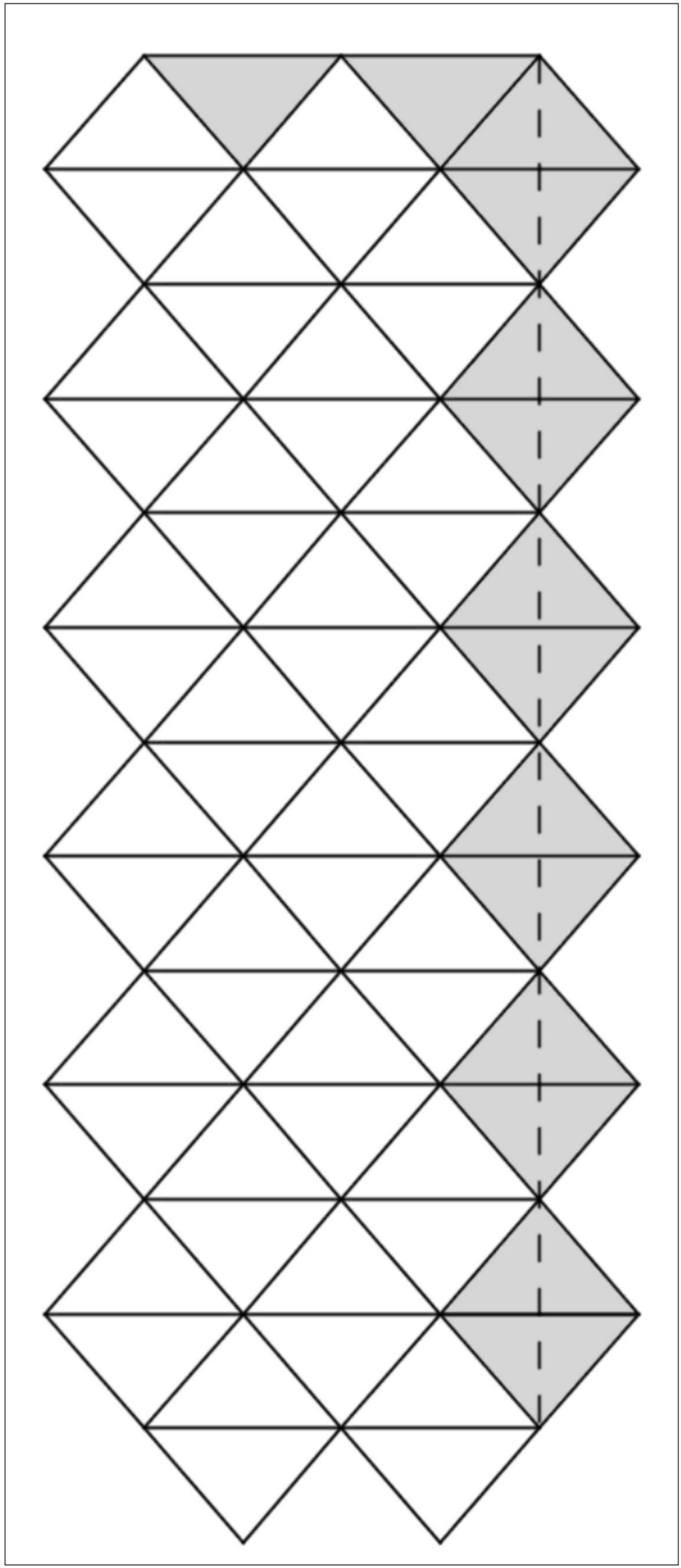

Fonte: Elaborada pelo autor. 
Figura 59 - Cal eidociclo Cubo Invertível
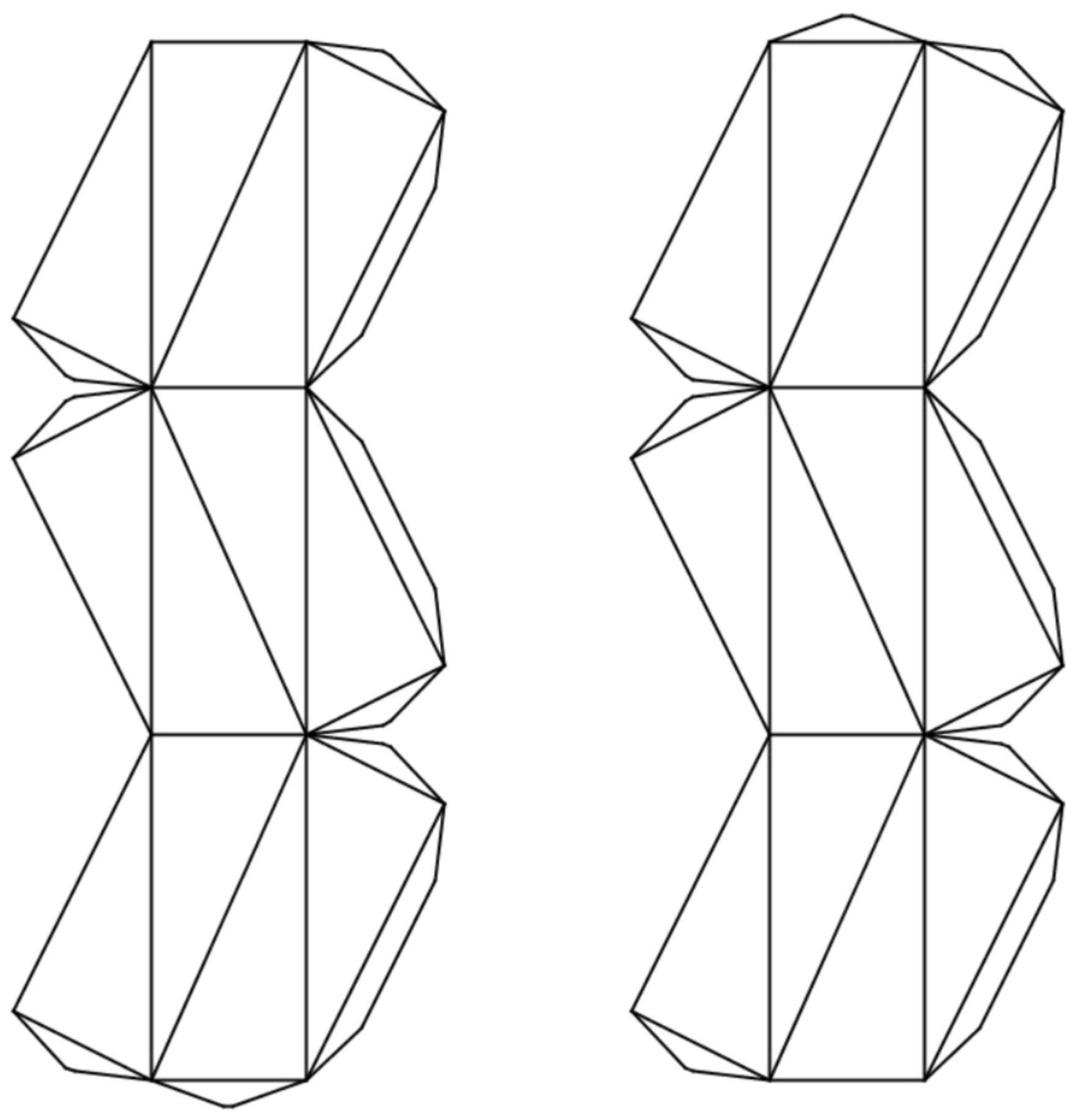

Fonte: Elaborada pelo autor. 
Figura 60 - Raio Do Cubo Invertível

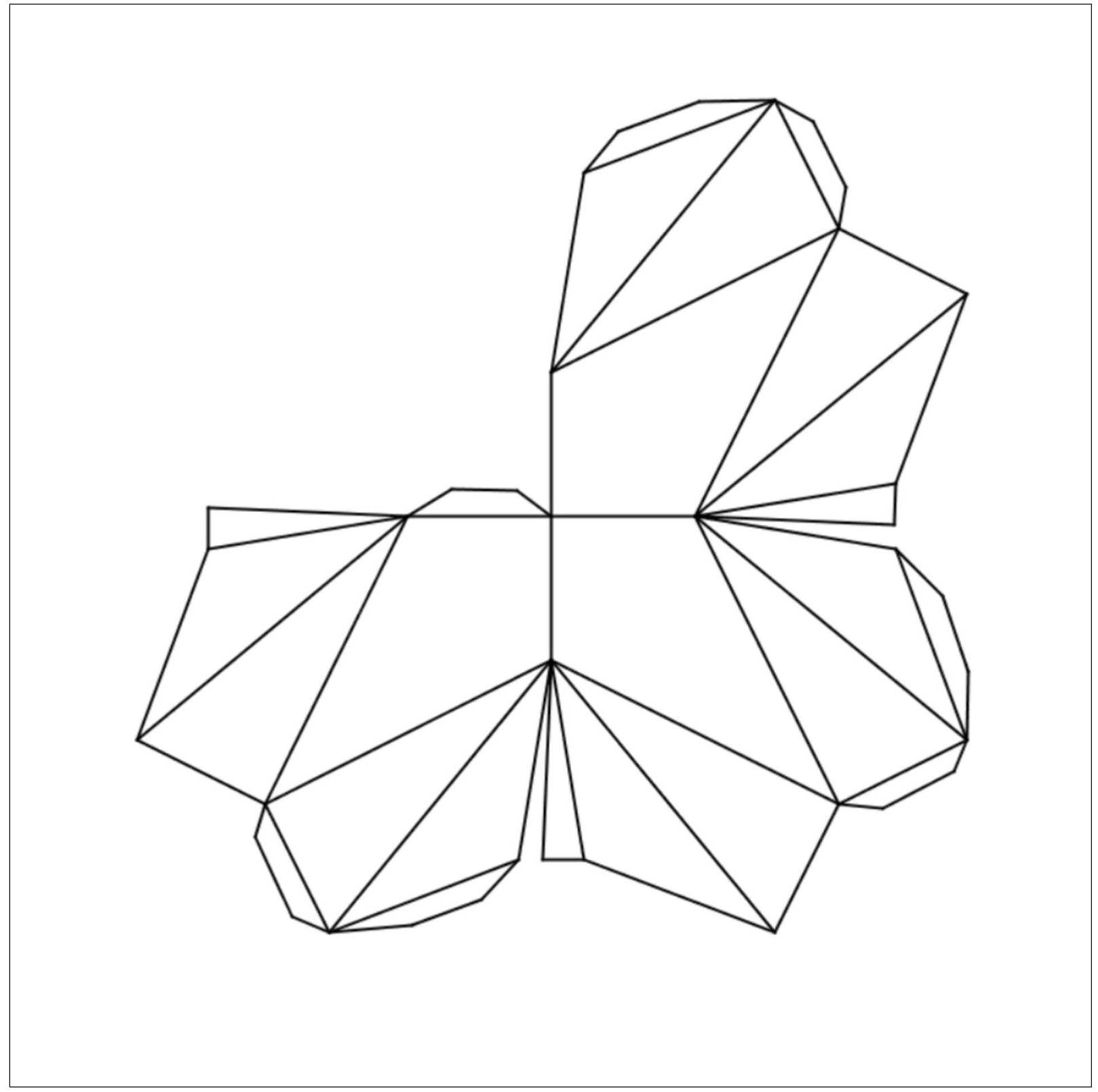

Fonte: Elaborada pelo autor. 
Figura 61 - Terça Parte do Cal eidociclo Cubo Invertível

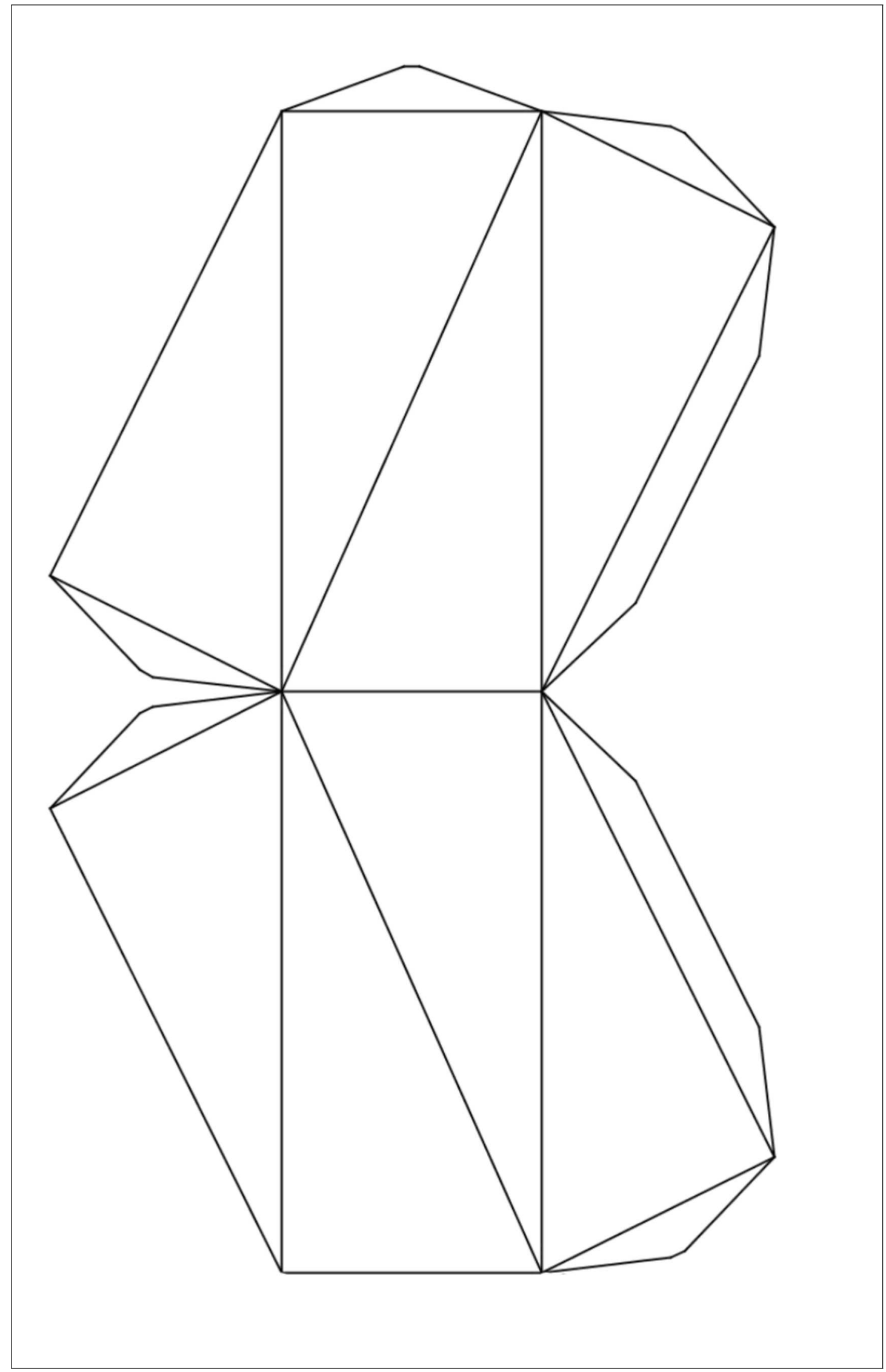

Fonte: Elaborada pelo autor. 
Figura 62 - Terça Parte do Raio do Cubo Invertível

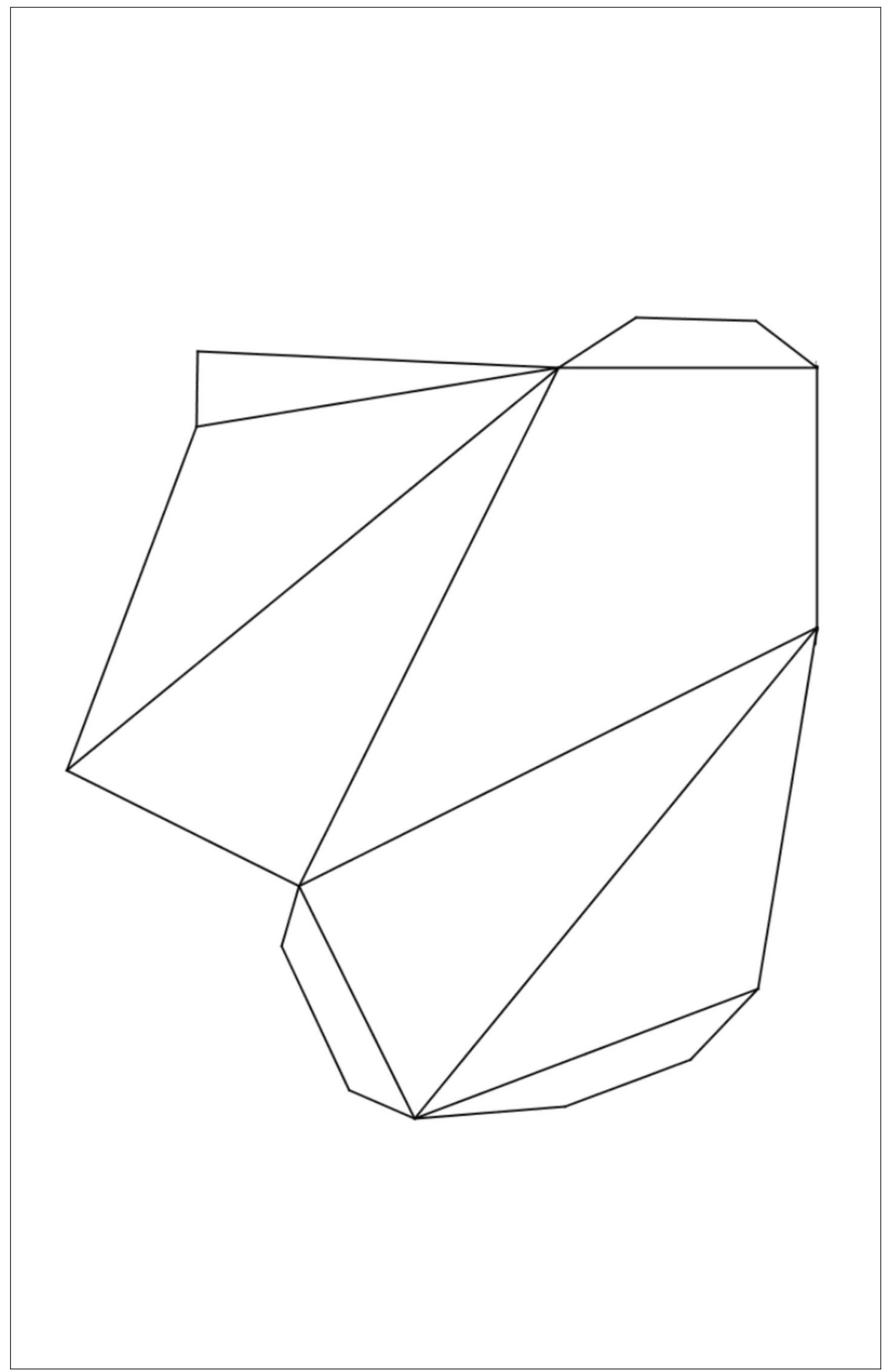

Fonte: El aborada pelo autor. 
Figura 63 - Cal eidociclo Milagre de Shinsei - Metade do Molde

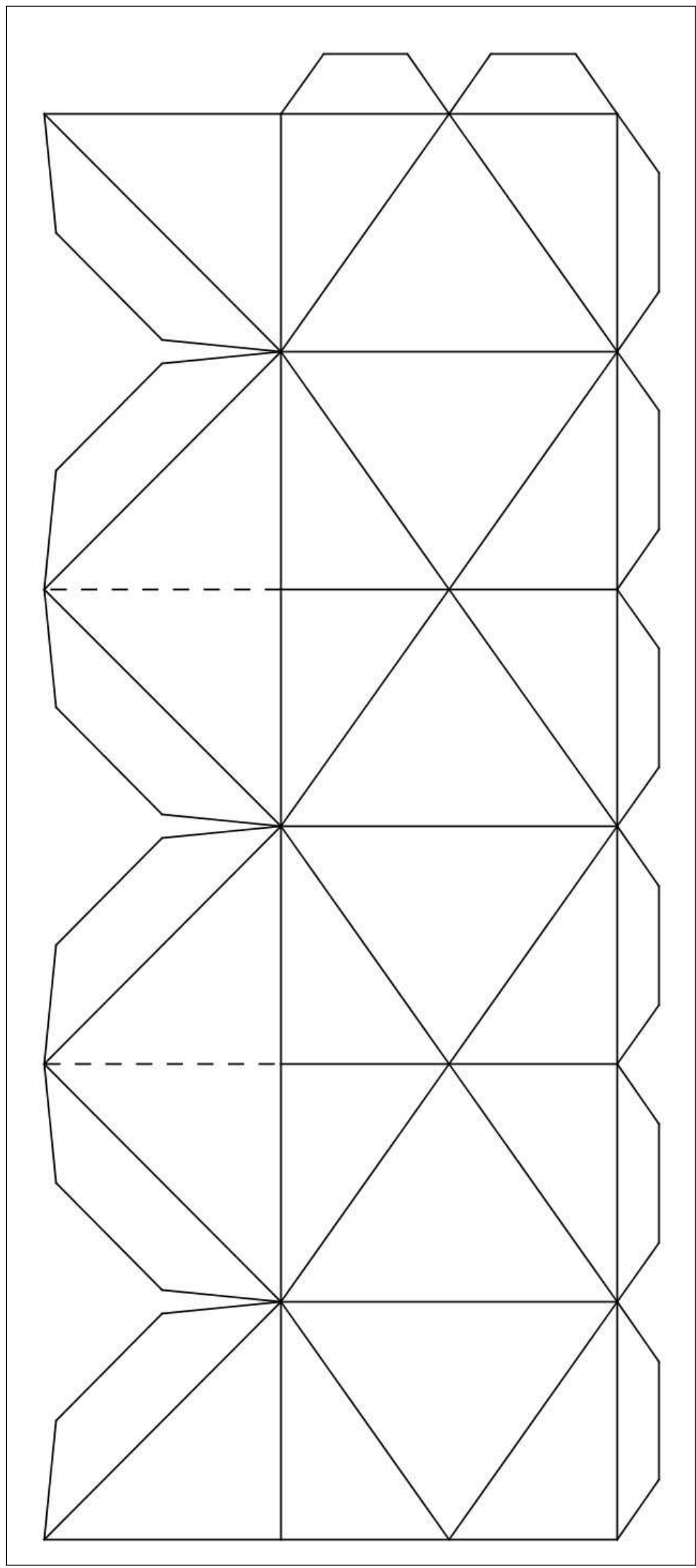

Fonte: Elaborada pelo autor. 
Figura 64 - Cal eidociclo Milagre de Shinsei - Molde com dois tetraedros

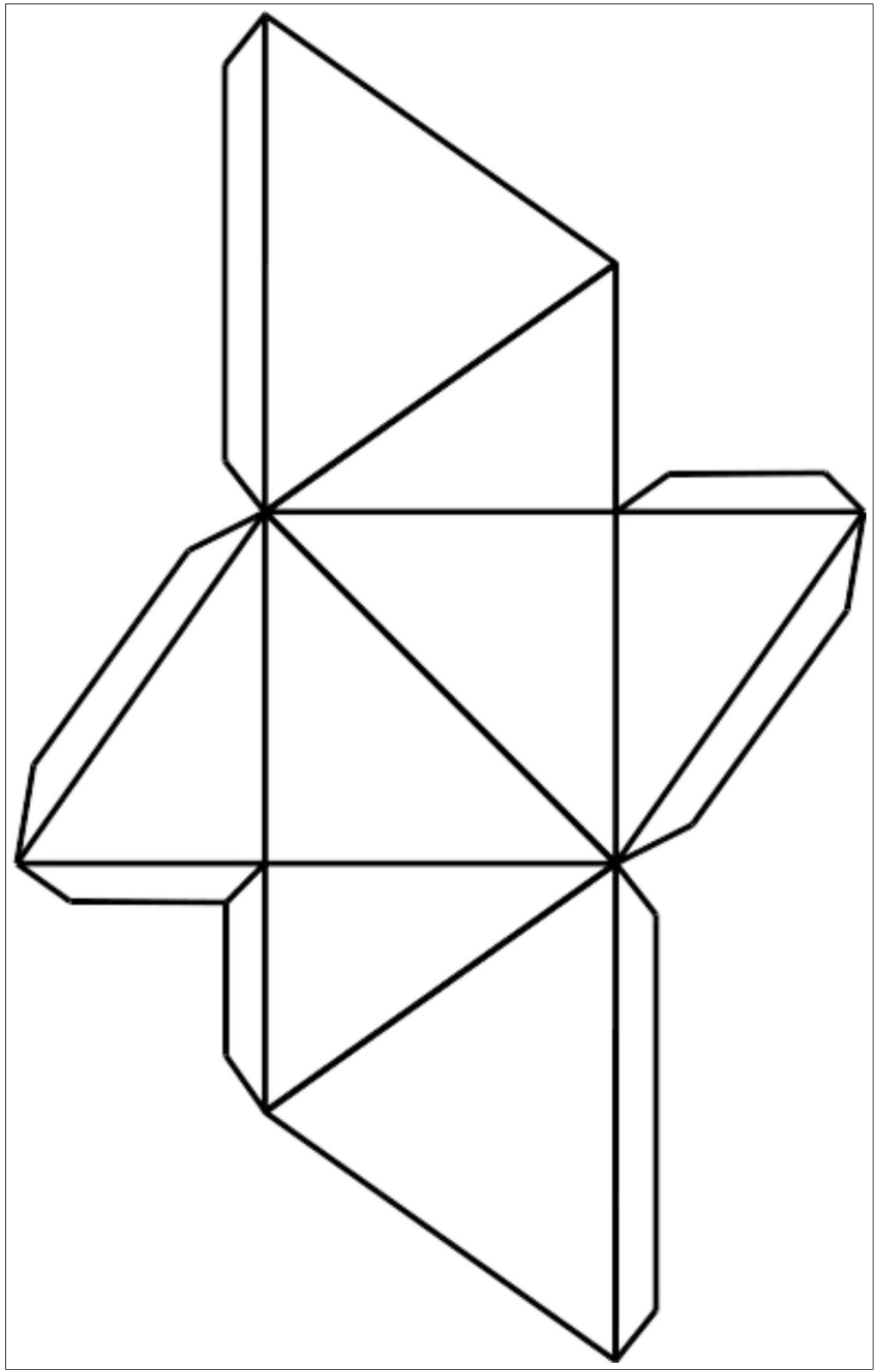

Fonte: Elaborada pelo autor. 

Figura 66 - Cal eidociclo de 8 Tetraedros Regulares

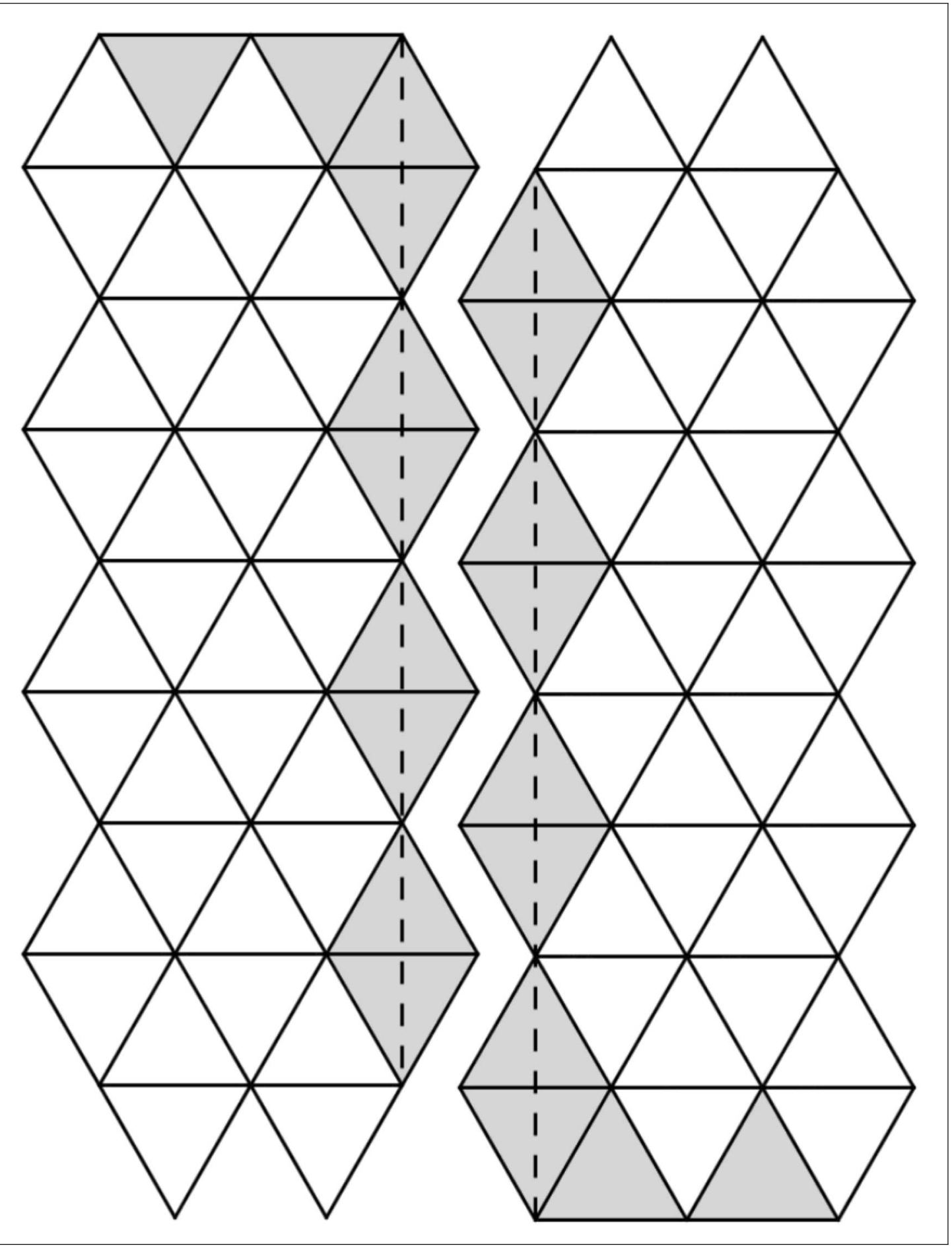

Fonte: Elaborada pelo autor. 
Figura 67 - Metade do Cal eidociclo de 8 Tetraedros Regulares - Parte 1

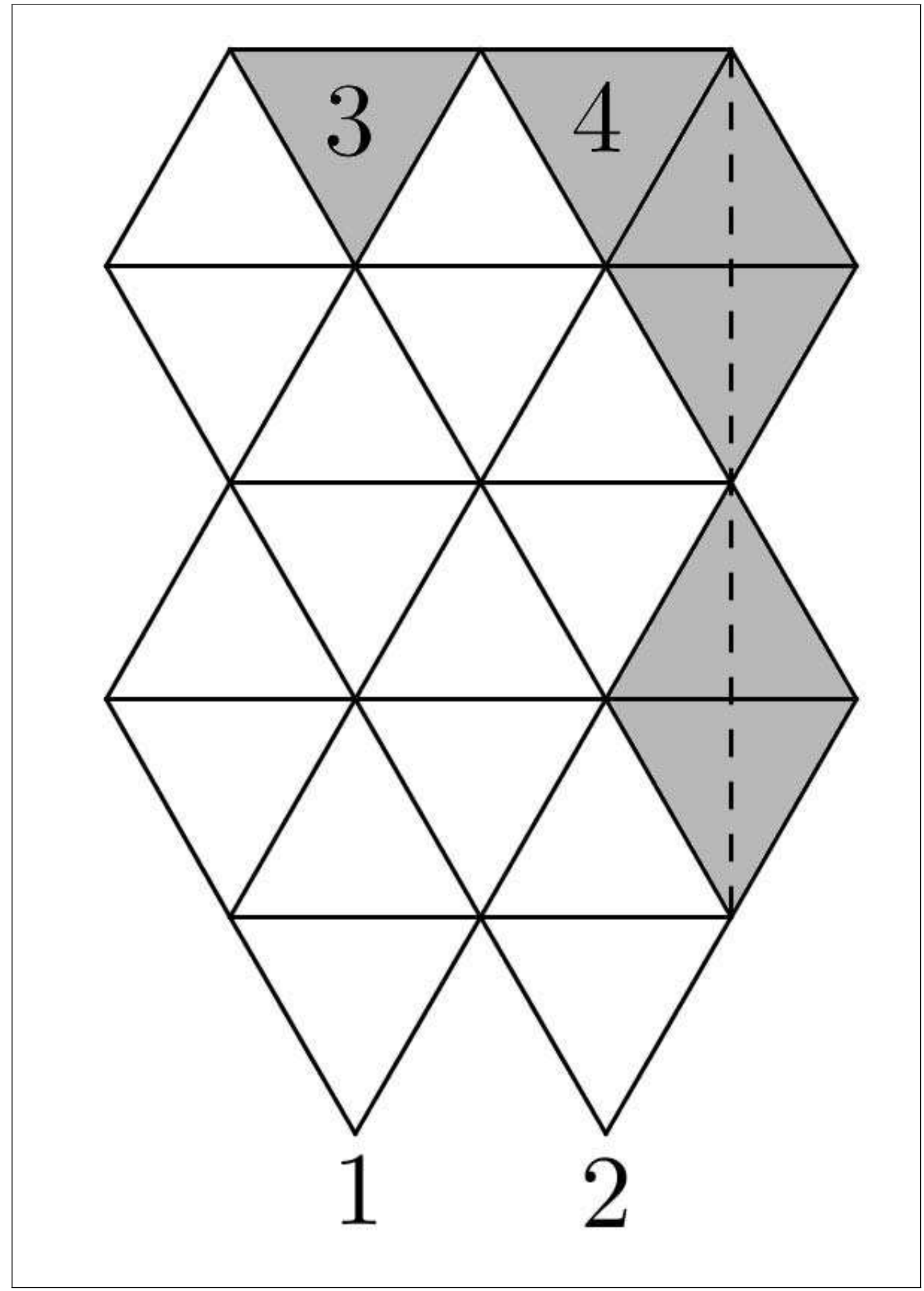

Fonte: Elaborada pelo autor. 
Figura 68 - Metade do Cal eidociclo de 8 Tetraedros Regulares - Parte 2

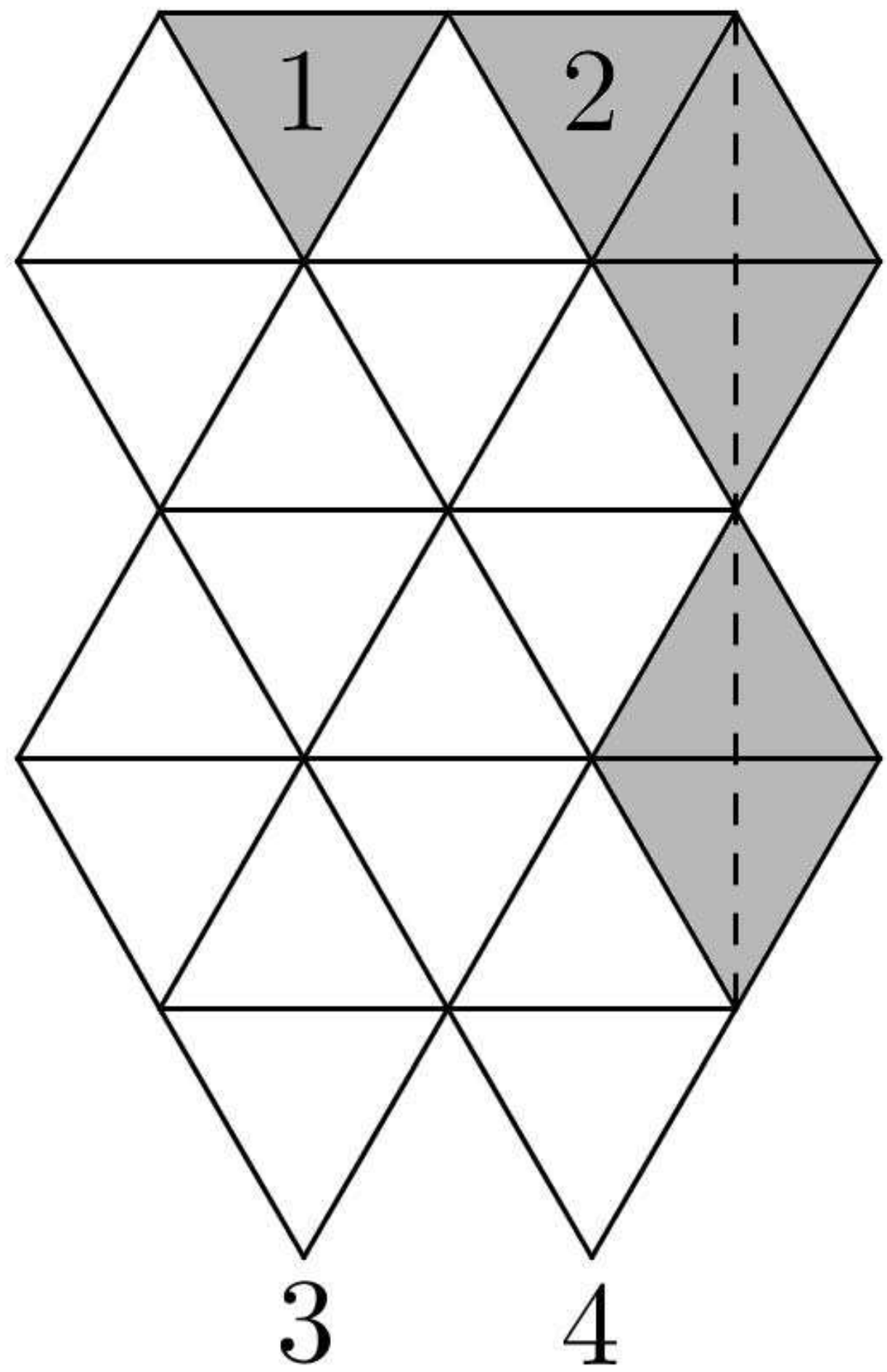

Fonte: Elaborada pelo autor. 
Figura 69 - Cal eidociclo Fechado de 8 Tetraedros

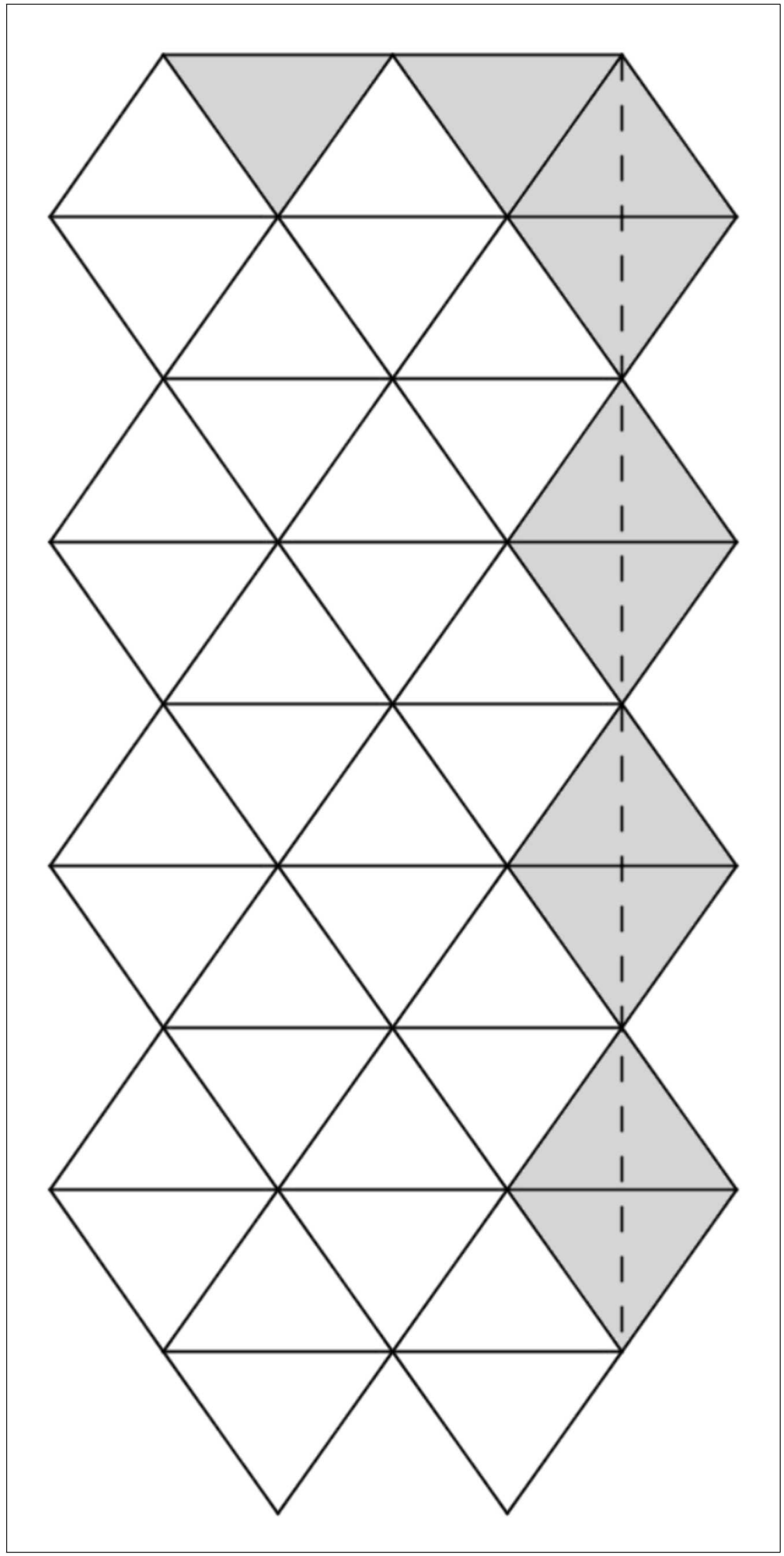

Fonte: Elaborada pelo autor. 
Figura 70 - Cal eidociclo Fechado de 10 Tetraedros

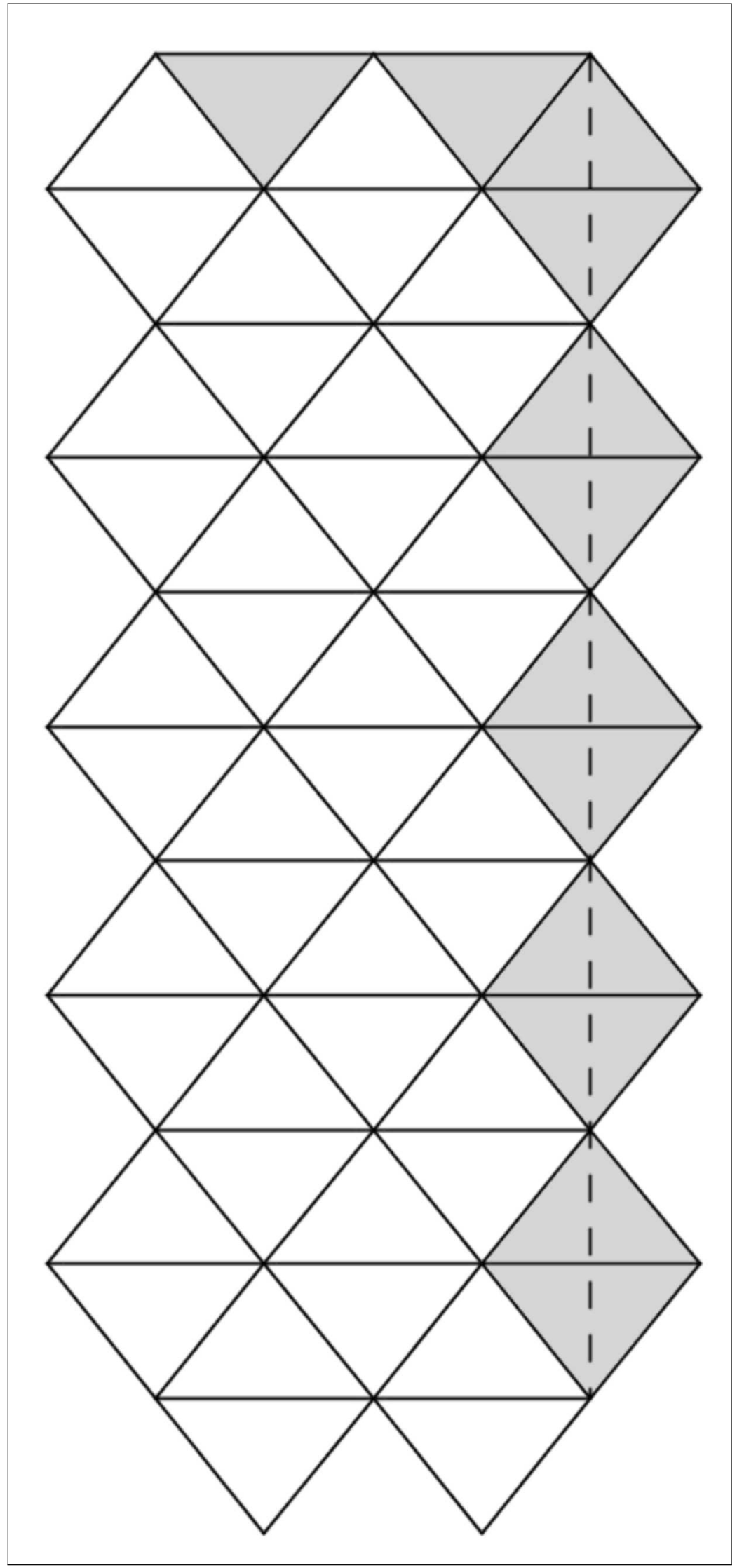

Fonte: Elaborada pelo autor. 


\section{APÊNDICE}

\section{B}

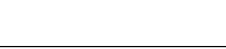

\section{SÓLIDOS LOUCOS}

Sólidos loucos são figuras geométricas espaciais com as seguintes características:

· compostos de sólidos menores;

· os componentes estão ligados por arestas;

os componentes podem ser movimentados formando outros sólidos.

Os sólidos loucos podem ser construídos facilmente com papel. No meio digital, é conhecido como crazy paper ... onde o nome final varia. Os mais comuns são cylinder e cube.

Esses sólidos podem ser utilizados para atividades com al unos desde $6^{\circ}$ ano do Ensino Fundamental para trabal har com figuras tridimensionais até o final do Ensino Médio para relacionar volume e área de superfície. Não é obrigatório encai xar sua construção com al gum conteúdo específico, pois al guns al unos não tiveram a oportuni dade de ver al go diferente nos anos que seriam mais indicados e por isso trazem o lúdico e nova perspectiva do conhecimento matemático a qual quer momento da vida escolar ou depois dela

Oficinas podem ser desenvolvidas em programas de interação da escola com a comunidade como, por exemplo, o programa Escol a da Família, no estado de São Paulo.

Seguem moldes e imagens de al guns dos sól idos loucos encontrados no meio digital.

\section{B.1 Cilindro Alto}

Este cilindro é subdividido em oito sólidos iguais. Cada sólido estáligado a outros dois e cada ligação ocorre por meio de uma aresta comum. 
Figura 71 - Cilindro alto

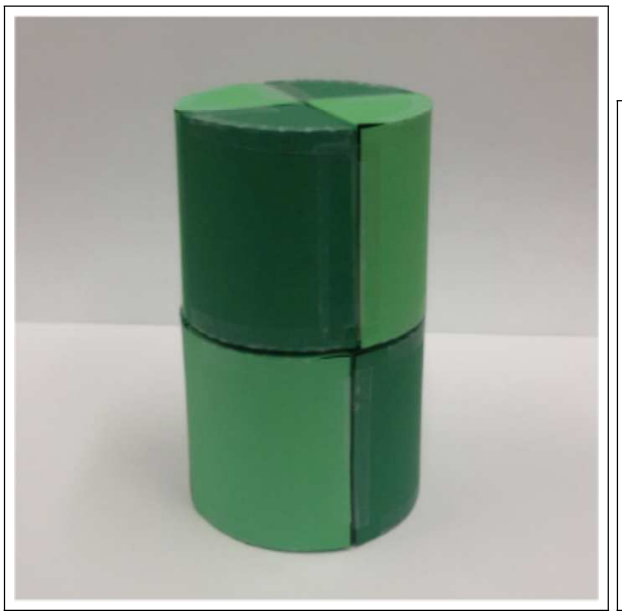

(a) Posição inicial

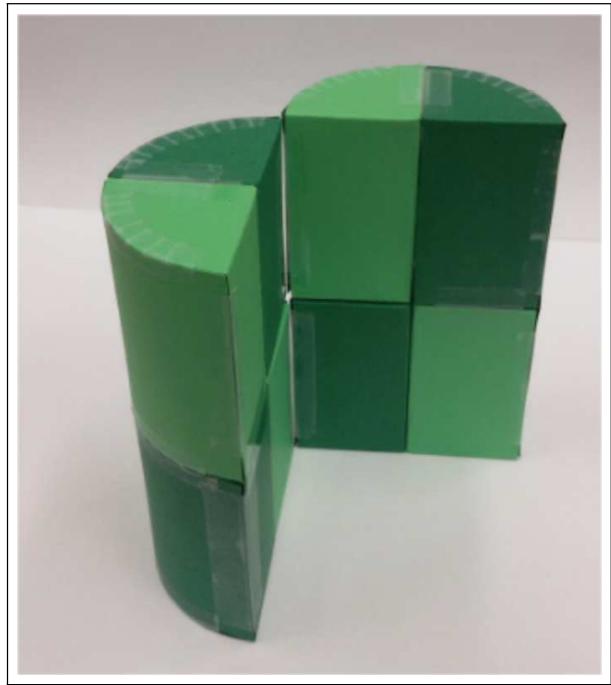

(c) Metades Verticais

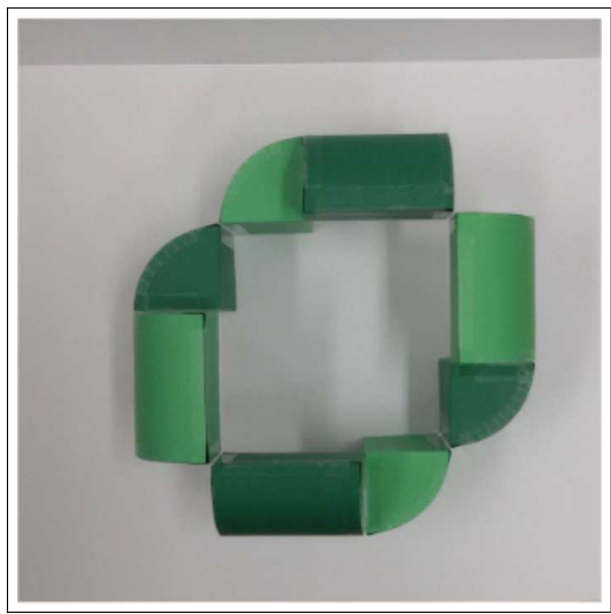

(e) Cubo vazado

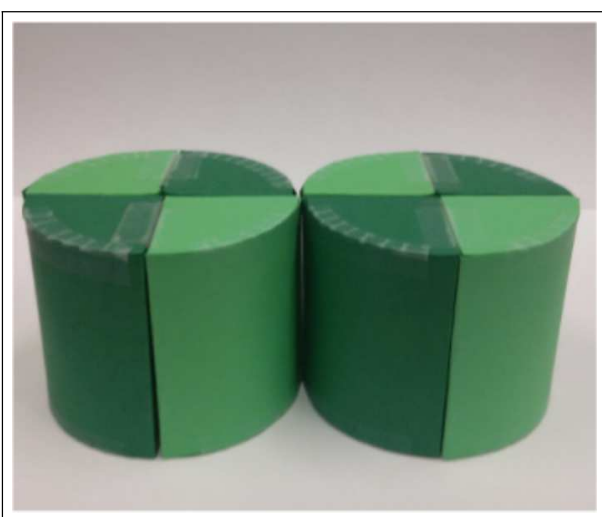

(b) Metades horizontais

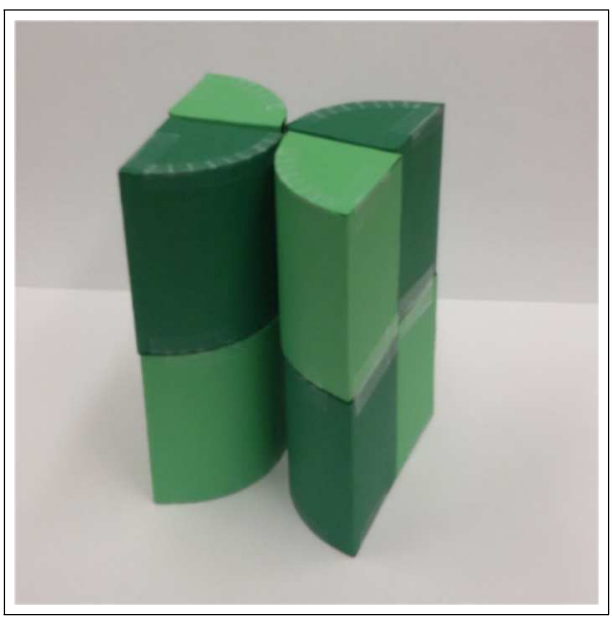

(d) Metades Verticais Opostas

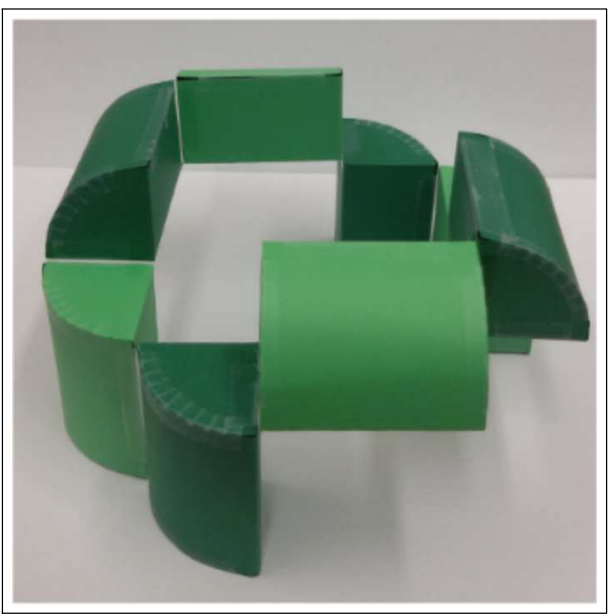

(f) Arestas de ligação

Fonte: Elaborada pelo autor. 
Figura 72 - Molde do cilindro al to

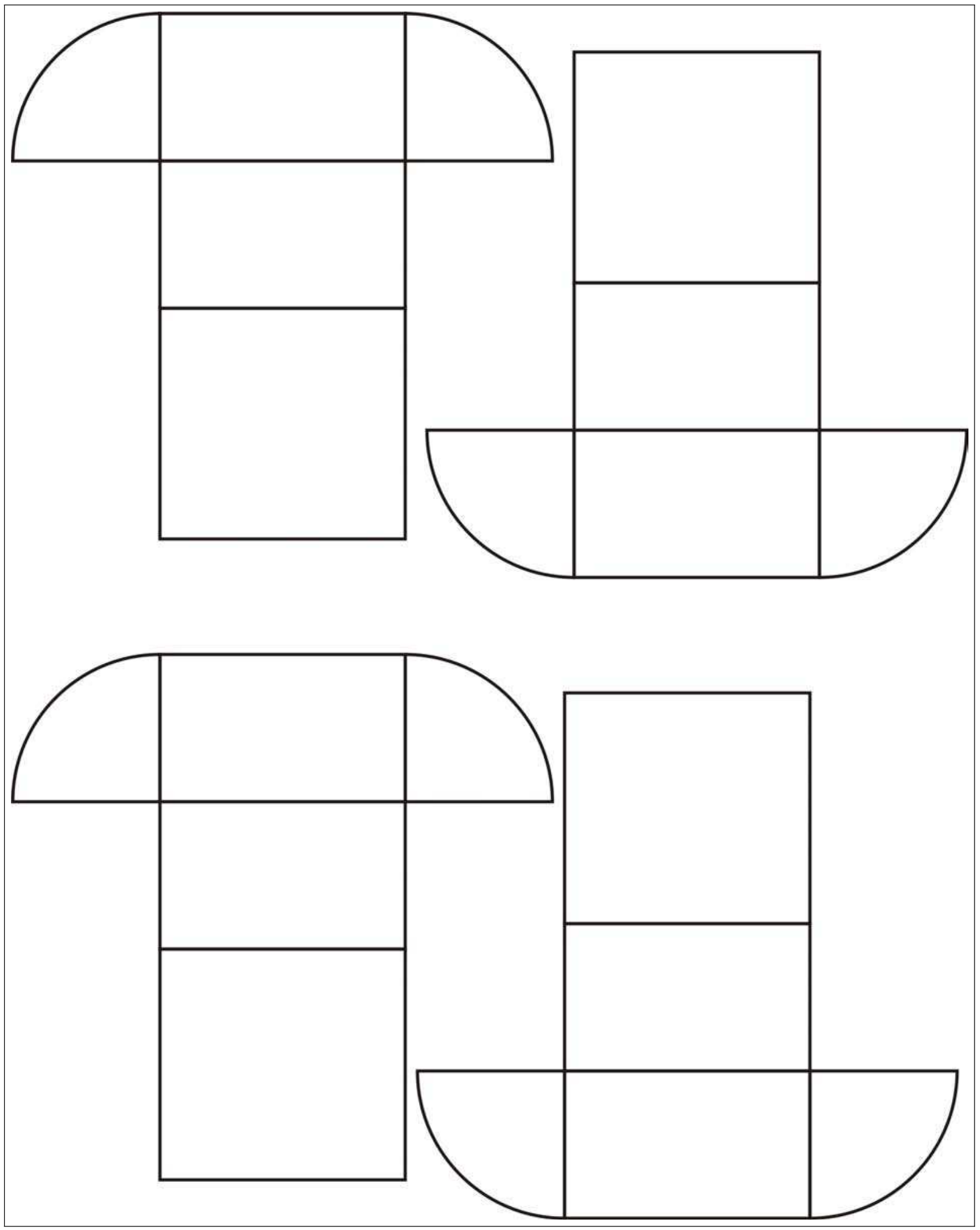

Fonte: Elaborada pelo autor. 


\section{B.2 Cilindro Baixo}

Cilindro subdividido em oito sólidos iguais. Cada sól ido estáligado a outros dois e a ligação entre dois del es é por meio de uma aresta. Este cilindro é mais bai xo que o anterior e não tem sobreposição de partes na posição inicial. 
Figura 73 - Cilindro baixo

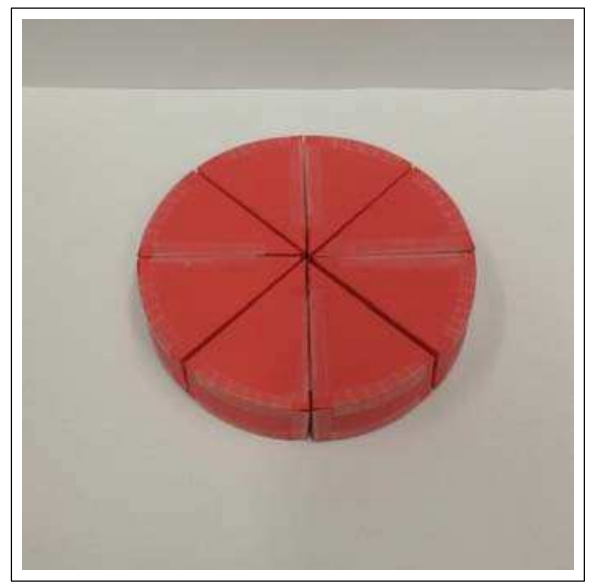

(a) Posição inicial

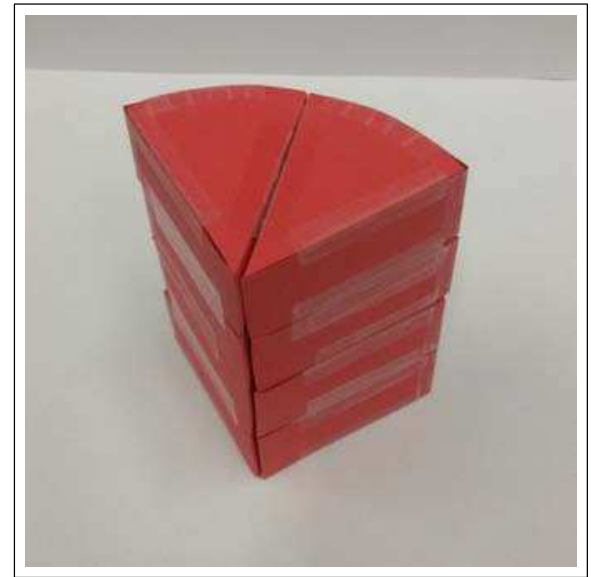

(c) Quartos sobrepostos

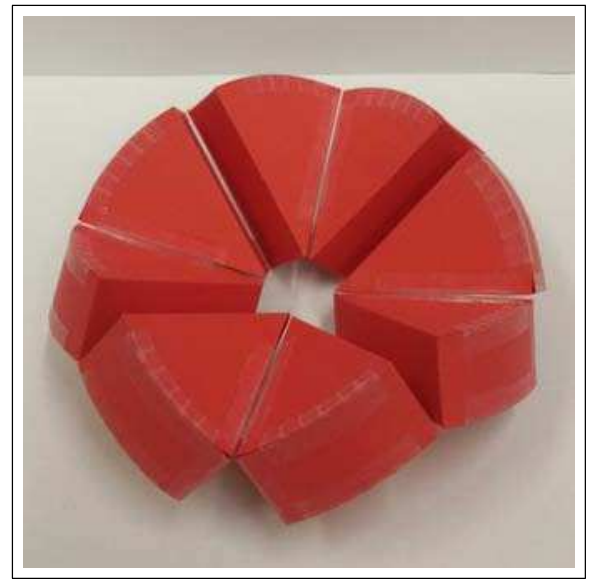

(e) Arestas de ligação 1

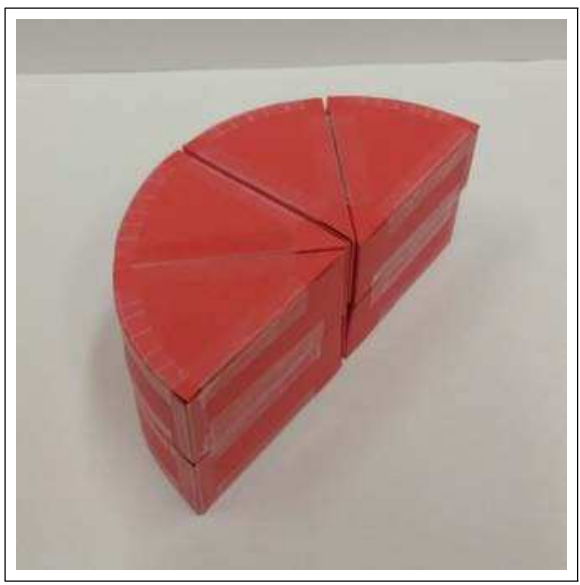

(b) Metades sobrepostas

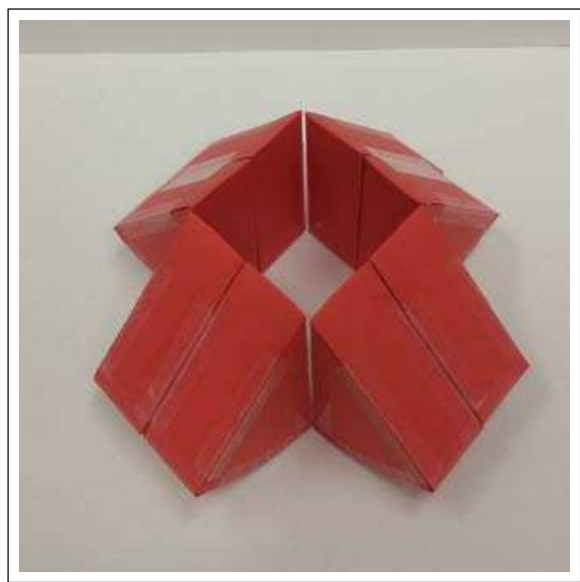

(d) Oitavos

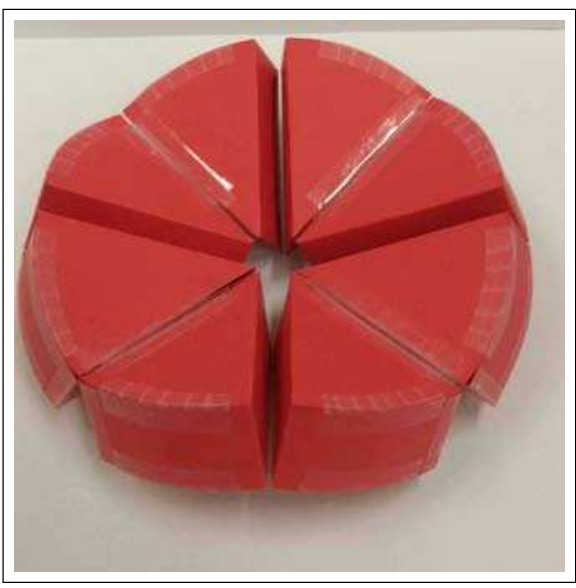

(f) Arestas de ligação 2

Fonte: Elaborada pelo autor. 
Figura 74 - Modelo do cilindro baixo

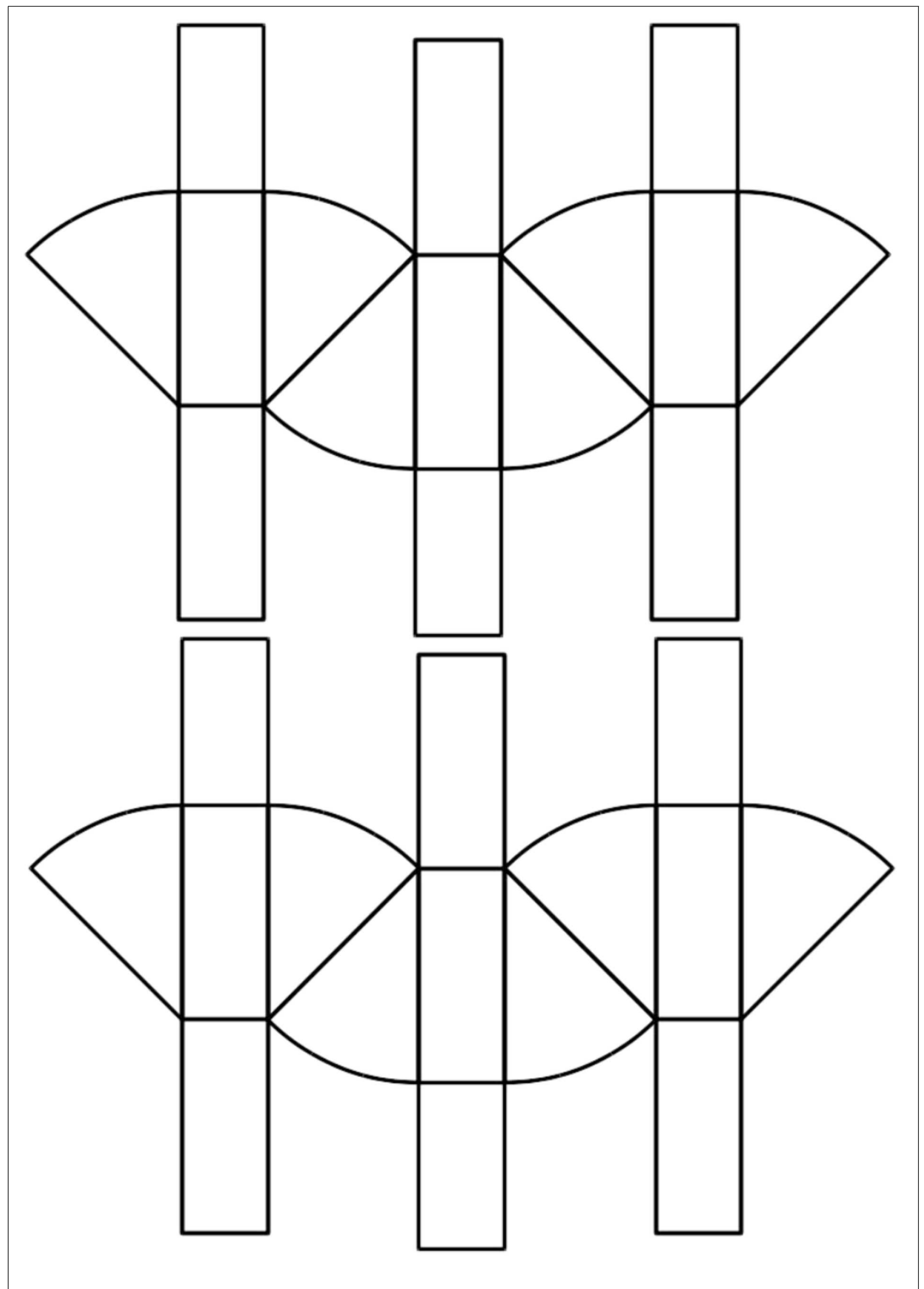

Fonte: Elaborada pelo autor. 


\section{B.3 HyperQBS}

HyperQBS é um cubo dividido em 12 tetraedros com base em metade da face do cubo e vértice da pirâmide no centro do cubo. Cada tetraedro estáligado a outros dois por uma aresta comum.

Veja al gumas imagens de possibilidades de formas com o hyperQBS e em seguida dois moldes. 
Figura 75 - HyperQBS

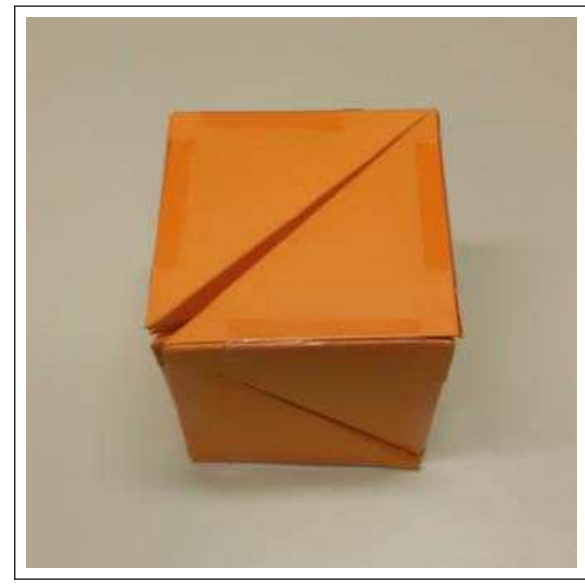

(a) Cubo

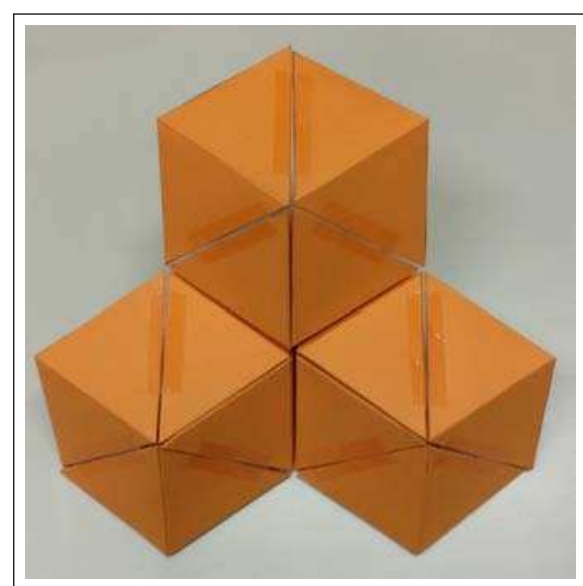

(c) Trio de losangos

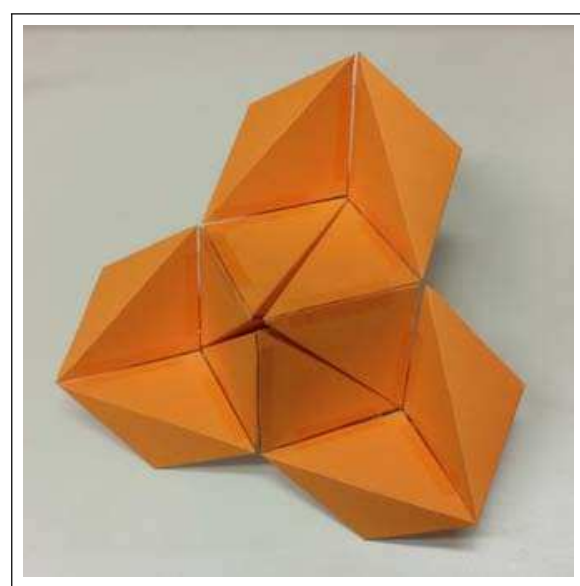

(e) Cubo em canto - perfil

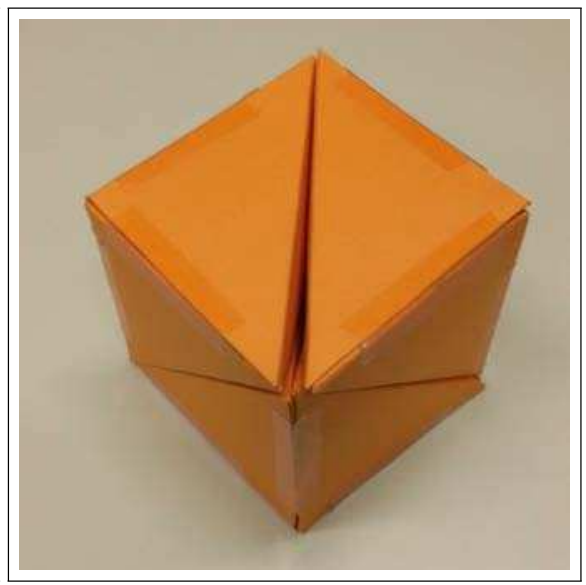

(b) Cubo - perfil

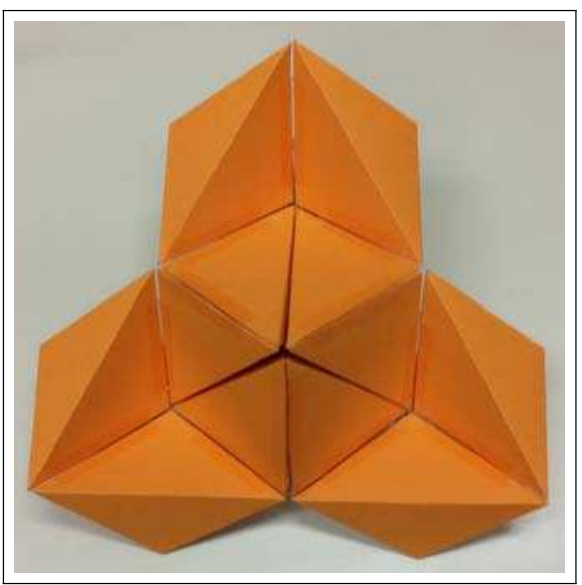

(d) Cubo em canto

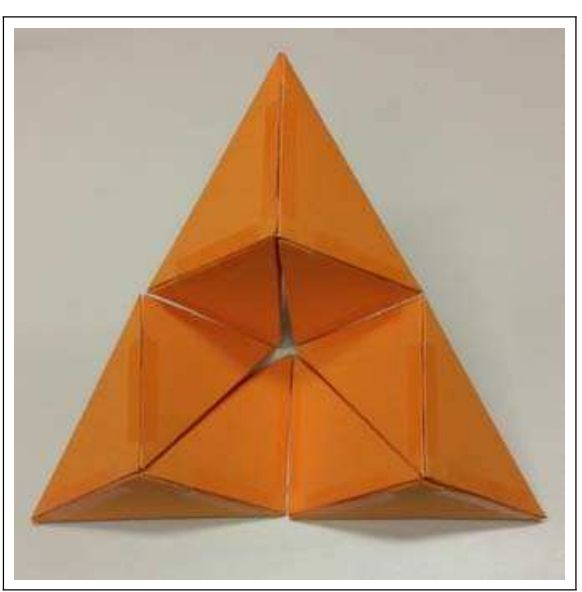

(f) Pirâmide com corte cúbido 


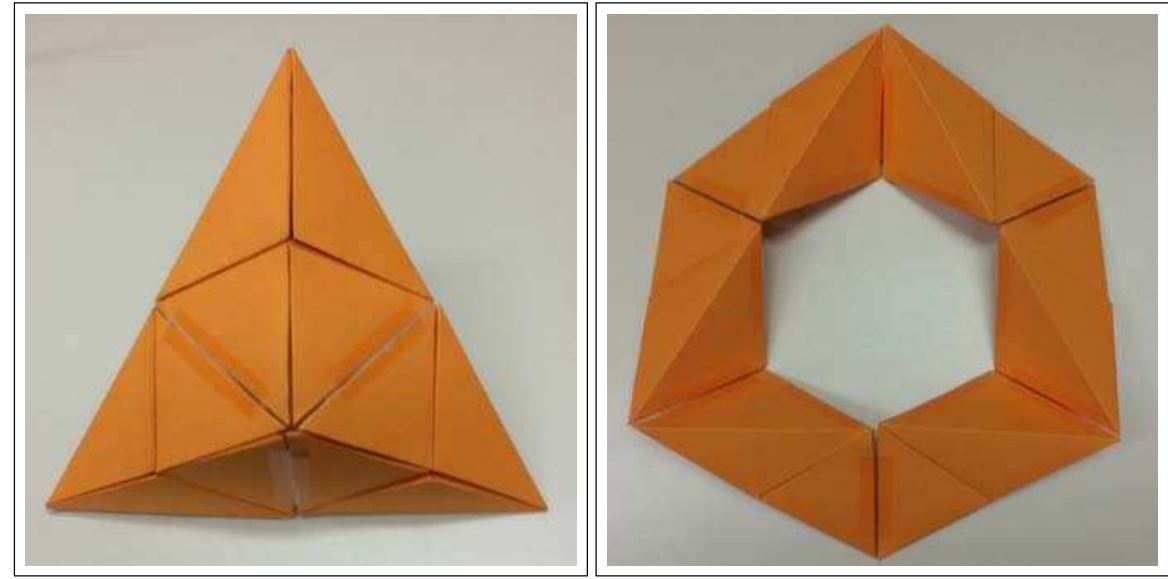

(g) Pirâmide

(h) Contorno Hexagonal

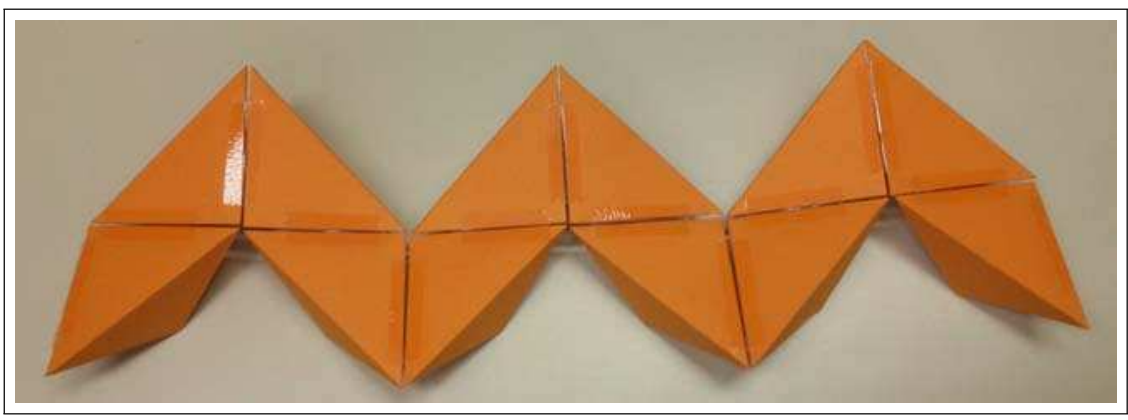

(i) Arestas de ligação

Fonte: Elaborada pelo autor. 
Figura 76 - Molde pequeno do HyperQBS

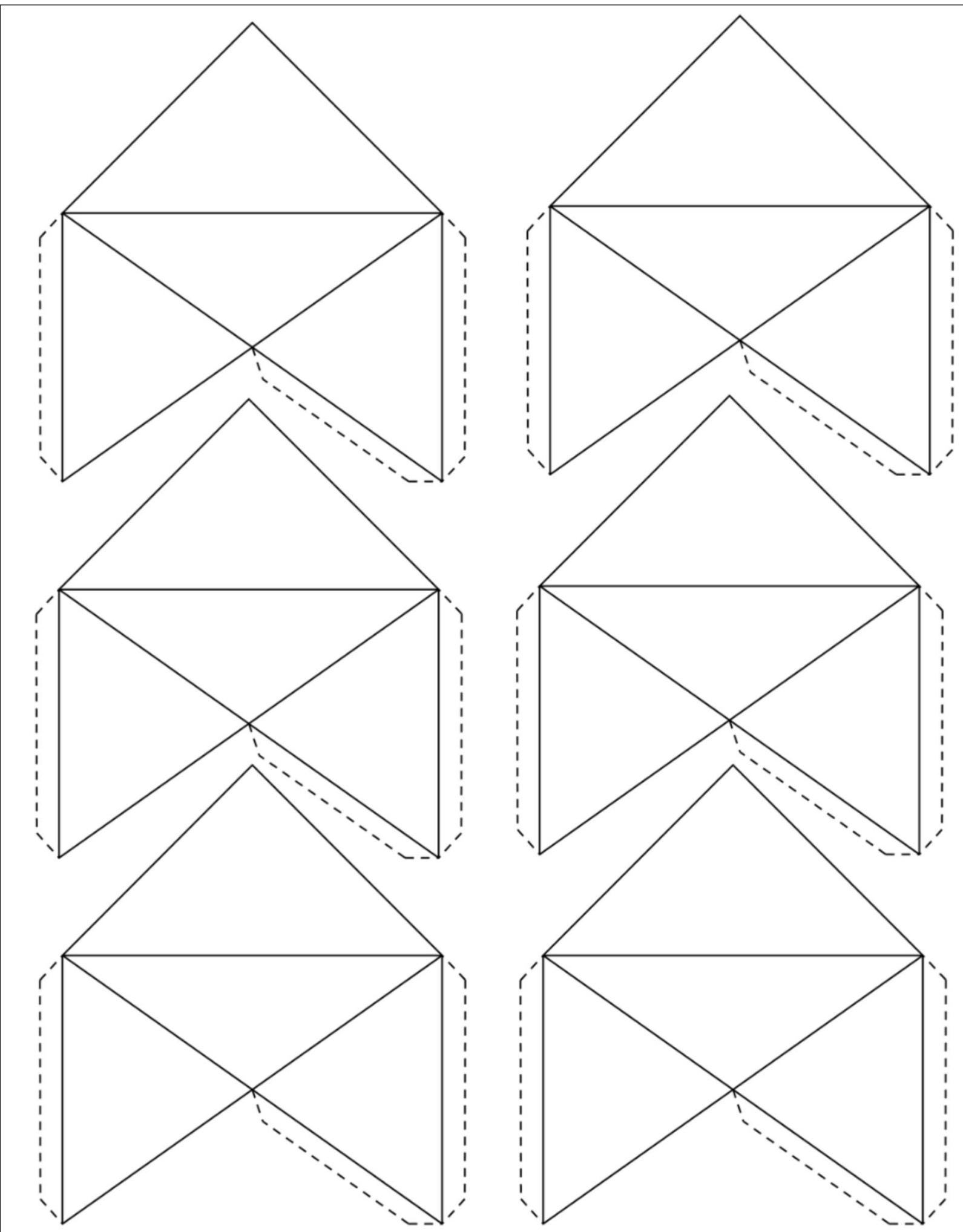


Figura 77 - Molde grande do HyperQBS

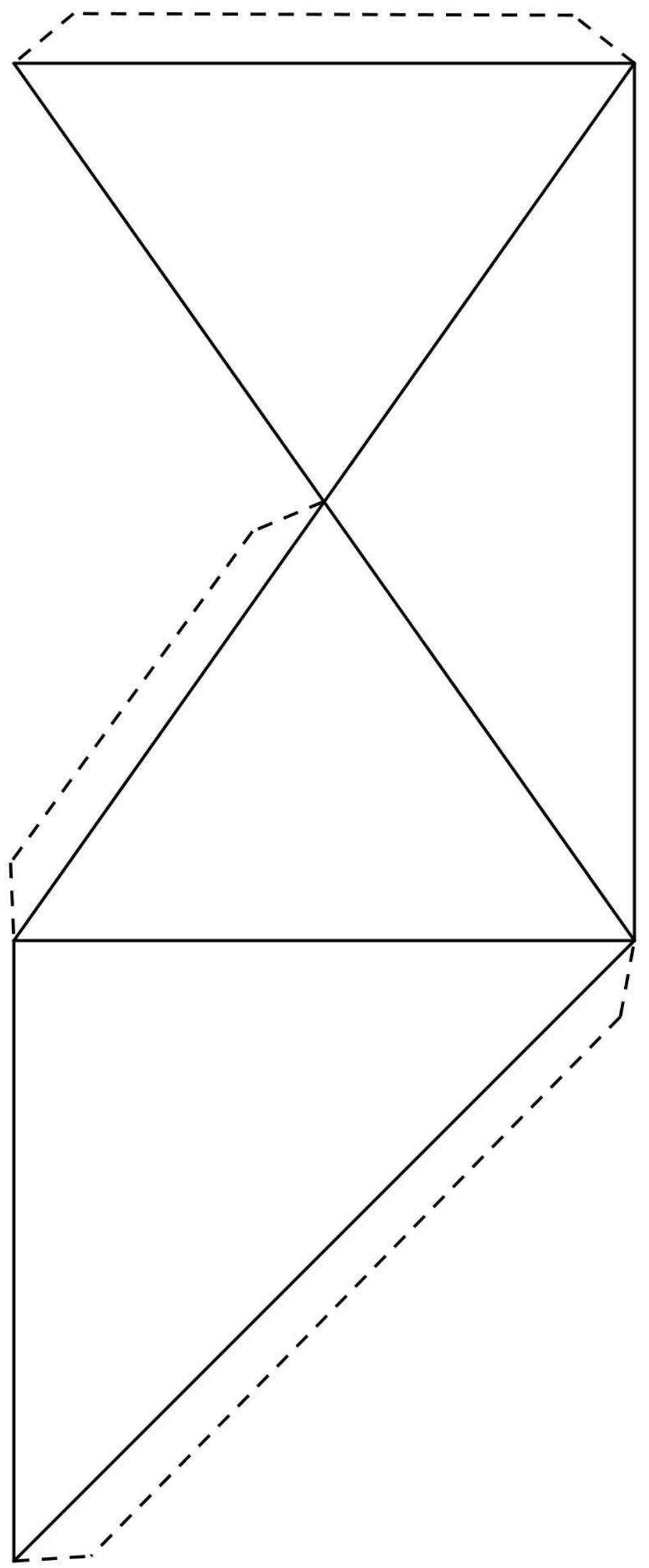

Fonte: Elaborada pelo autor. 